Utah State University

DigitalCommons@USU

\title{
Manipulating Parameters of Reinforcement to Reduce Problem Behavior without Extinction
}

Soraya Shanun Kunnavatana

Utah State University

Follow this and additional works at: https://digitalcommons.usu.edu/etd

Part of the Special Education and Teaching Commons

\section{Recommended Citation}

Kunnavatana, Soraya Shanun, "Manipulating Parameters of Reinforcement to Reduce Problem Behavior without Extinction" (2014). All Graduate Theses and Dissertations. 2298.

https://digitalcommons.usu.edu/etd/2298

This Dissertation is brought to you for free and open access by the Graduate Studies at DigitalCommons@USU. It has been accepted for inclusion in All Graduate Theses and Dissertations by an authorized administrator of DigitalCommons@USU. For more information, please contact digitalcommons@usu.edu.

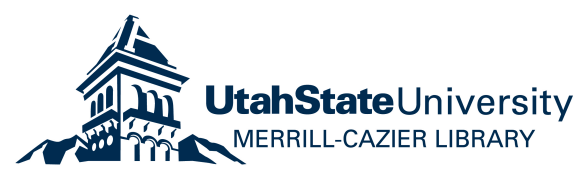




\title{
MANIPULATING PARAMETERS OF REINFORCEMENT TO REDUCE PROBLEM BEHAVIOR WITHOUT EXTINCTION
}

\author{
by \\ Soraya Shanun Kunnavatana \\ A dissertation submitted in partial fulfillment \\ of the requirements for the degree \\ of
}

DOCTOR OF PHILOSOPHY

in

Disability Disciplines

Approved:

Sarah E. Bloom

Major Professor

Andrew L. Samaha

Committee Member

Courtenay Barrett

Committee Member
Timothy A. Slocum

Major Professor

Thomas S. Higbee

Committee Member

Mark R. McLellan

Vice President for Research and

Dean of the School of Graduate Studies

UTAH STATE UNIVERSITY

Logan, Utah 
Copyright (C) Soraya S. Kunnavatana 2014

All Rights Reserved 
ABSTRACT

\author{
Manipulating Parameters of Reinforcement to Reduce \\ Problem Behavior without Extinction
}

by

Soraya Shanun Kunnavatana, Doctor of Philosophy

Utah State University, 2014

Major Professors: Drs. Sarah E. Bloom and Timothy A. Slocum

Department: Special Education and Rehabilitation

Research has demonstrated that function-based interventions are most effective for addressing problem behavior. However, many function-based interventions, such as differential reinforcement of alternative behavior (DRA), rely on extinction procedures. Extinction is not feasible in all cases and can be counter-therapeutic if implemented without optimal treatment integrity. Researchers have successfully implemented DRA without extinction when various parameters of reinforcement (rate, quality, magnitude, immediacy) have been manipulated to favor alternative behavior; that is, participants engaged in higher rates of alternative behavior when reinforcement was delivered contingent on both alternative and problem behavior, but the alternative response produced better reinforcement in terms of rate, quality, magnitude, or immediacy. Parameter sensitivity, however, has been found to be idiosyncratic and therefore warrants individual assessment. Previous researchers have assessed individual sensitivities to parameters of reinforcement in the context of problem behavior; however, this resulted in 
problem behavior occurring during assessment, which could be problematic given severe problem behavior. The purpose of this study was to use arbitrary responses to assess individual sensitivities to quality, magnitude, and immediacy of reinforcement maintaining problem behavior and use the results to implement an intervention for problem behavior without extinction.

The results indicate that arbitrary responses may be used to identify individual sensitivities to parameters of reinforcement that maintains problem behavior.

Additionally, interventions were more effective when parameters for which participants were most sensitive were manipulated than when parameters for which participants were least sensitive were manipulated. 
PUBLIC ABSTRACT

\section{Manipulating Parameters of Reinforcement to Reduce \\ Problem Behavior without Extinction}

\section{Soraya Shanun Kunnavatana}

Research has demonstrated that function-based interventions are most effective for addressing problem behavior. However, many function-based interventions, such as differential reinforcement of alternative behavior (DRA), rely on extinction procedures. Extinction is not feasible in all cases and can be counter-therapeutic if implemented without optimal treatment integrity. Researchers have successfully implemented DRA without extinction when various parameters of reinforcement (rate, quality, magnitude, immediacy) have been manipulated to favor alternative behavior; however, parameter sensitivity is idiosyncratic and warrants individual assessment. Previous researchers have assessed individual sensitivities to parameters of reinforcement in the context of problem behavior; however, this resulted in problem behavior occurring during assessment, which could be problematic given severe problem behavior. The purpose of this study was to use arbitrary responses to assess individual sensitivities to quality, magnitude, and immediacy of reinforcement that maintains problem behavior and use the results to implement an intervention for problem behavior without extinction.

We conducted individual parameter sensitivity assessments with two individuals with developmental/intellectual disabilities who engaged in problem behavior maintained by social positive reinforcement in the form of access to tangibles. The results of the 
parameter sensitivity assessments indicated that one individual was sensitive to only quality of reinforcement. The second participant was sensitive to all three parameters and subsequently, we conducted a relative parameter sensitivity assessment to determine which parameter was most influential. The results indicated that she was most sensitive to quality and least sensitive to magnitude of reinforcement. Interventions were then implemented to evaluate the effectiveness of parameter manipulations to decrease problem behavior and increase an alternative response (i.e., requesting for the tangible item). The interventions were more effective when the parameter for which the participants were most sensitive (i.e., quality) were manipulated.

In sum, the results of this study indicate that arbitrary responses may be used to identify individual sensitivities to parameters of reinforcement that maintain problem behavior. Additionally, the results of the parameter sensitivity assessments may be used to develop effective interventions for problem behavior without the use of extinction. 


\section{ACKNOWLEDGMENTS}

There are a number of individuals without whom this dissertation would not have been possible. First and foremost, I would like to thank my advisor, Dr. Sarah Bloom, for her support and guidance over the past four years. Your unwavering dedication and encouragement, even at a distance, have been paramount and I will be eternally grateful to have had the opportunity to work with and learn from you. I would also like to extend my deepest gratitude to Dr. Tim Slocum for taking me under his wing this past year. I am not sure what condition I would be in had it not been for your wise perspective and calm nature. Thank you for always having a moment to talk, providing your expertise when needed, and for having confidence in me. Dr. Andrew Samaha, I am so thankful I had the opportunity to experience a combined lab with you. Without a doubt, your expertise and research interests have played a very important role in expanding not only my research interests, but also how I go about answering various questions. It has truly been a pleasure working with you. Many thanks to Dr. Tom Higbee and Dr. Courtenay Barrett for your support in pursuing this project and your collaboration in fine-tuning the methodology. I will forever be grateful for having such a supportive and knowledgeable dissertation committee.

A special thank you to my lab mates for always being willing to help, and for knowing when to provide moral support and/or humor when it is needed most. Casey Clay, thank you so much for all your help in conducting sessions, being my sounding board, and always agreeing to a sanity break with me. To my friends, near and far, thank 
you for always standing by me and understanding when I was absent and/or

distracted. I am very honored to have such amazing people in my life.

Finally, to my family, thank you for always believing in me and supporting me, even when it seemed like I was headed in a million different directions. It has been a long journey with many detours, but we have finally reached the end. I could not have done it without you being with me every step of the way.

Soraya Shanun Kunnavatana 
ABSTRACT. iii

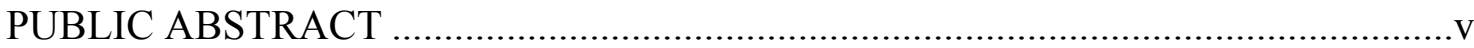

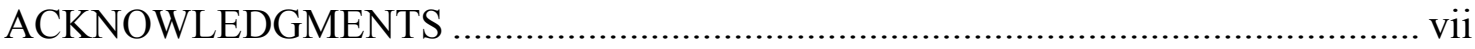

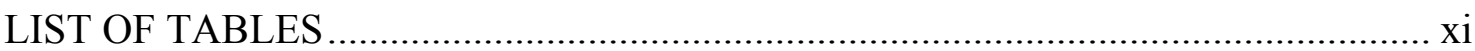

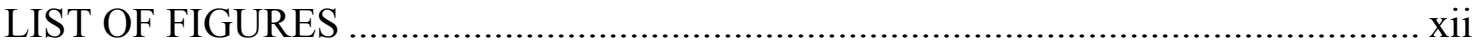

\section{CHAPTER}

I. LITERATURE REVIEW …........................................................

Function-Based Interventions ...............................................................1

Differential-Reinforcement of Alternative Behavior............................11

Concurrent-Schedules of Reinforcement ...........................................23

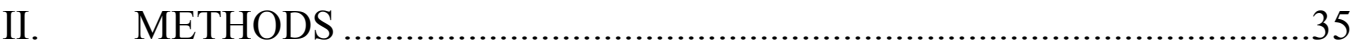

Participants and Setting...................................................................35

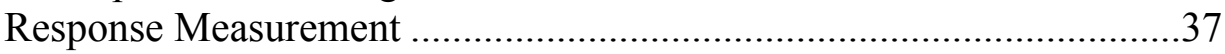

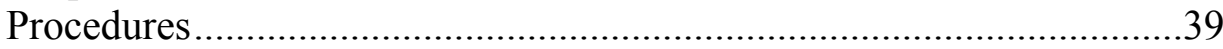

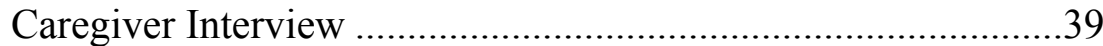

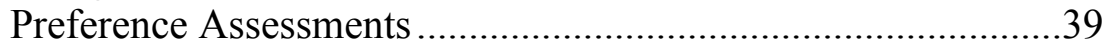

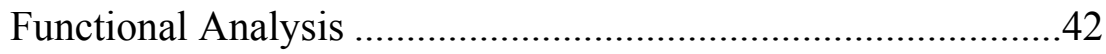

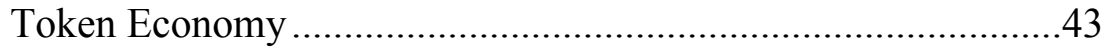

Parameter Sensitivity Assessments......................................45

Relative Parameter Sensitivity Assessment .............................49

Intervention: DRA without Extinction....................................51

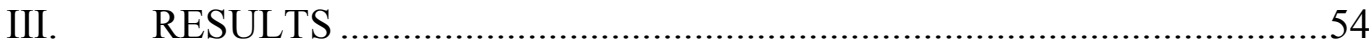

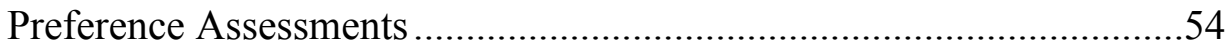

Functional Analyses..................................................................54

Parameter Sensitivity Assessments ...............................................55

Relative Parameter Sensitivity Assessment .....................................58

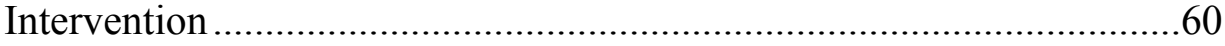




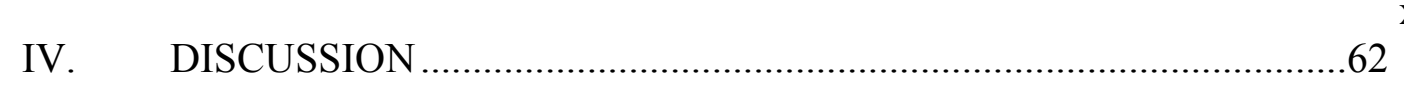

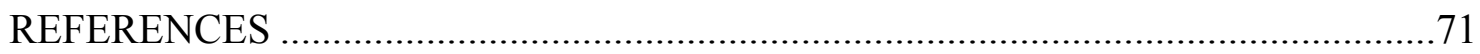

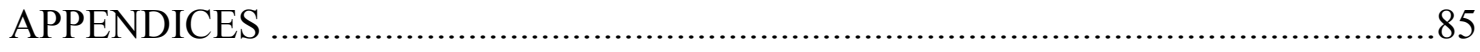

Appendix A: Tables .....................................................................86

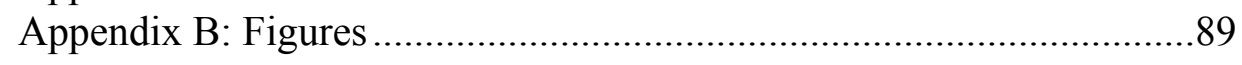

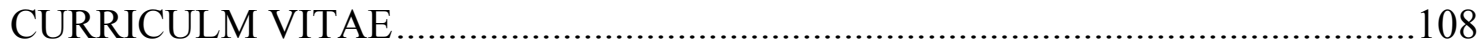




\section{LIST OF TABLES}

Table $\quad$ Page

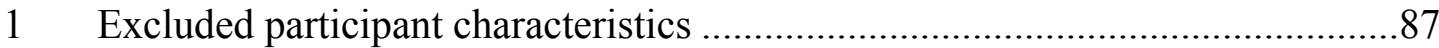

2 Summary of parameter sensitivity assessment values .......................................8

3 Summary of relative parameter sensitivity assessment values ............................88 


\section{LIST OF FIGURES}

Figure $\quad$ Page

$1 \quad$ Preference assessment data for excluded participants.............................90

$2 \quad$ Functional analyses for excluded participants......................................91

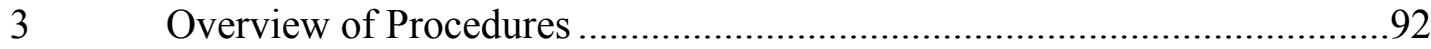

$4 \quad$ Tangible preference assessment results .............................................. 93

$5 \quad$ Attention preference assessment results ..............................................94

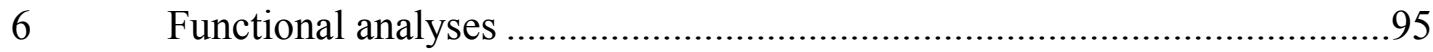

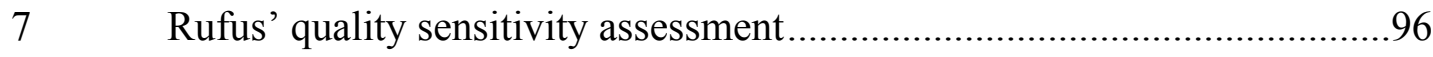

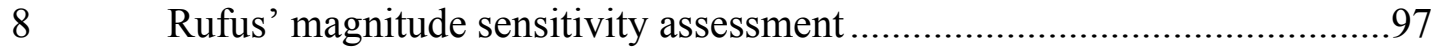

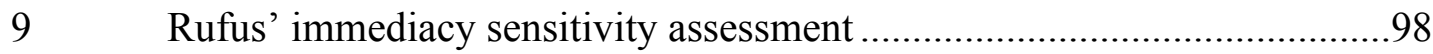

10 Rufus' immediacy versus quality tracking test .....................................

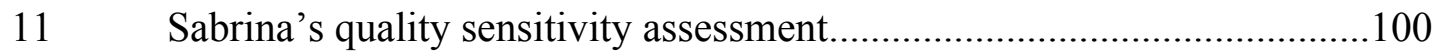

12 Sabrina's magnitude sensitivity assessment ...................................... 101

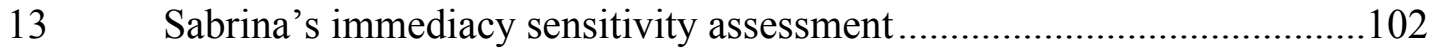

14 Sabrina's comparison for magnitude versus immediacy........................103

15 Sabrina's comparison for immediacy versus quality ..............................104

16 Sabrina's comparison for magnitude versus quality .............................105

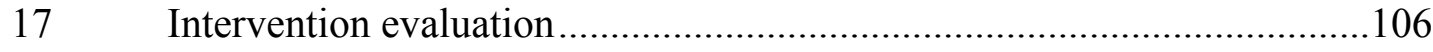

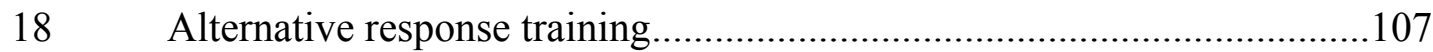




\section{CHAPTER I}

\section{LITERATURE REVIEW}

\section{Function-Based Interventions}

Problem behavior (e.g., aggression, property destruction, self-injurious behavior), can impede an individual's development of appropriate skills, access to community resources, and overall quality of life. Thus, reducing problem behavior can increase educational and social opportunities that may facilitate an individual's appropriate skill development. Problem behavior has been a focus of applied behavior analysis since the 1960s and the underlying assumption that behavior serves a function and is largely maintained by environmental variables (Arndorfer \& Miltenberger, 1993) has been well established. However, it is only within the last thirty years that interventions to address problem behavior have been developed to directly address the functions that maintain problem behavior.

Prior to the 1980 s, problem behavior was typically treated without taking into consideration the contingencies that maintained the behavior. Treatment selection for individuals with developmental disabilities relied on a least-to-most approach; that is, less intrusive treatments were tried first and, if unsuccessful, more intrusive treatments, such as punishment, were implemented (Mace, 1994). For example, Dorsey, Iwata, Ong, and McSween (1980) evaluated the effects of a reinforcement procedure (attention delivered contingent on the absence of target behavior), social punishment (saying, "No," contingent on target behavior), and aversive stimulation (water misted directly in participant's face contingent on target behavior) for addressing self-injurious behavior. 
Neither the reinforcement procedure nor the social punishment procedure alone effectively reduced two participants' self-injury. However, when aversive stimulation was included, self-injury decreased. It was hypothesized that the possible ineffectiveness of some procedures might be indicative of a lack of understanding of the variables that either produce or maintain self-injury (Carr, 1977); that is, although reinforcement procedures were implemented, the stimuli were arbitrarily selected and did not necessarily relate to the variables that maintained the target behavior. Thus, in many cases, the reinforcement procedures did not successfully override the environmental conditions that maintained problem behavior (Mace, 1994), leading interventionists to rely heavily on punishment procedures instead of reinforcement-based procedures (Herzinger \& Campbell, 2007).

Beginning in the mid-1970s, researchers and clinicians expressed concern about the overreliance on default procedures that consisted of the application of contingent aversive stimuli (i.e., punishment) and/or arbitrary positive reinforcement (Iwata, 1988; Mace, 1994). Although powerful reinforcers and punishers were effective in many cases, behavior analysts became increasingly interested in the motivating variables that controlled problem behavior, such as self-injury, and how interventions could be tailored to address specific sources of motivation in individual cases (Carr, 1977). This led to the development of new technologies to identify the precise variables that maintained problem behavior, which would allow treatments to not only break the responsereinforcer relationship that maintained problem behavior, but to also establish a new response-reinforcer relationship to replace problem behavior. The development of functional assessment methods, such as the functional analysis (Iwata, Dorsey, Slifer, 
Bauman, \& Richman, 1992/1994), greatly altered the field by shifting the approach to problem behavior away from punishment (Axelrod, 1987) and toward function-based reinforcement procedures. This shift not only increased treatment precision and efficacy, but also increased the ethicality of behavior analysis by taking into consideration the client's individual characteristics in developing an intervention and reducing the use of aversive procedures (Hanley, 2012).

\section{Identifying Function through Functional Assessments}

The goal of a functional assessment is to identify the environmental events, or variables, that influence problem behavior (Horner \& Carr, 1997). For example, a student may engage in problem behavior in the form of property destruction (e.g., throwing items across a room) that is maintained by negative reinforcement in the form of escape from an aversive stimulus; that is, when instructed to complete a set of math problems, the student throws his work materials because he sometimes (or often) receives a break from the assignment as a result (e.g., he is instructed to go pick up the thrown items and thus receives a temporary break from the math problems). This causal relationship between the environmental variables and the occurrence of a behavior is often referred to as the function of the behavior (Hanley, Iwata, \& McCord, 2003).

There are three general approaches to functional assessments, all of which have specific strengths and weaknesses: indirect, descriptive, and experimental (O’Neill, Horner, Albin, Storey, \& Sprague, 1990).

Indirect assessment. Indirect assessment methods, such as interviews and questionnaires, seek to obtain information from those that work closely with the student, 
including teachers, paraprofessionals, and parents (Lennox \& Miltenberger, 1989). The interviewee is asked to describe the behavior, so that an operational definition can be developed. The interviewee is asked to describe events leading up to the occurrence of problem behavior or the circumstances in which the behavior does not occur, as well as what typically happens after the behavior occurs. Although this method is relatively easy, research indicates that it is, overall, not a reliable assessment procedure. Murdock, O’Neil, and Cunningham (2005) note that by nature, indirect assessments are susceptible to interviewees' forgetfulness, bias, and other distortions. For example, the Questions About Behavioral Function (QABF; Matson \& Vollmer, 1995), is subjective and relies on interviewees accurately recalling past events and being able to identify important features of behavioral sequences. Tarbox et al. (2009) reported $43 \%$ correspondence between the results of a QABF and a traditional functional analysis (described below). Thus, indirect assessments may lead to inconsistent results when determining the function of behavior. At best, they identify only a potential correlation between environmental events and the behavior of interest (Tarbox et al., 2009).

Descriptive assessment. Descriptive assessments obtain information via direct observation and measurement of the problem behavior, as well as the antecedent events (i.e., events preceding the occurrence of the behavior) and the consequent events (i.e., events following the occurrence of the behavior), as they naturally occur (Bijou, Peterson, \& Ault, 1968). "ABC" recording methods are often used to collect data on the sequence of events observed; that is, descriptive data are collected on the (A) antecedent events preceding the occurrence of behavior, the (B) behavior that occurs, and the $(\mathrm{C})$ consequences that are delivered after the occurrence of behavior. Although this method 
provides a temporal account of behavior and the environmental variables, it can be effortful and potentially distract from other individuals (e.g., other students in a classroom setting), as it requires the observer to attend closely to the individual that engages in problem behavior and their environment, so that antecedent events are not missed. Additionally, if the behavior occurs with low frequency, extensive observations may be required to obtain enough data to draw conclusions (Tarbox et al. 2009). Also, descriptive assessments can only provide information on correlations between environmental events and the behavior.

The fact that descriptive assessments are correlational is problematic because certain environmental events may commonly precede or follow the occurrence of behavior and yet not be functionally (i.e., causally) related to it. For example, in a classroom setting, academic demands may commonly precede problem behavior because academic demands are frequent in classrooms. Although for some individuals demands may be an antecedent to problem behavior, for others it may just be a high frequency event that is not functionally related to the problem behavior. Similarly, problem behavior is often followed by attention because problem behavior is difficult or inappropriate to ignore in a classroom; however, this does not necessarily indicate that attention reinforces or maintains the problem behavior. Thus, descriptive assessments can be unreliable when trying to identify the function of problem behavior.

Experimental analyses. Finally, experimental, or functional, analyses entail direct observation of behavior and the direct manipulation of some environmental variable. Functional analysis procedures, such as those first proposed by Iwata et al. $(1982 / 1994)$, generally involve several 5- to 15 -min sessions in which various test 
conditions (i.e., attention, tangible, escape, alone/ignore) are sequentially presented along with a control condition (i.e. play) typically using a multi-element design. The functional analysis is typically conducted in a controlled, clinical setting, allowing independent variables (e.g., amount of attention being delivered, number of demands being placed, access to preferred activities/items) to be isolated and directly manipulated to identify those that occasion and maintain the behavior of interest. For example, when testing for an attention function, attention is withheld unless the individual engages in the target problem behavior. When testing for an escape function (i.e., the individual engages in problem behavior to escape an aversive event, such as demands or work), demands are made continuously unless the individual engages in the target problem behavior. At that time, a brief break is provided. Data are collected on some dimension of problem behavior (e.g. rate) during each type of condition and analyzed to determine which of the conditions produce an elevated level of problem behavior relative to the control condition.

This methodology has been used to identify the function of problem behavior for a wide variety of populations, including adults and children, with and without disabilities, and has been successfully conducted in a variety of settings, including hospitals, schools, and private homes (Hanley et al., 2003). Additionally, a wide range of behavior topographies have been assessed, including self-injurious behavior (e.g., Smith, Iwata, Vollmer, \& Zarcone, 1993), aggression (e.g., Thompson, Fisher, Piazza, \& Kuhn, 1998), and property destruction (e.g., Fisher, Lindlauer, Alterson, \& Thompson, 1998).

Although the Iwata et al. (1982/1994) procedures are commonly referred to as the gold standard of functional analyses (Mace, 1994), a number of modifications have been 
developed to allow for functional analyses to be conducted in a variety of settings under various conditions (Iwata \& Dozier, 2008). For example, when there is limited assessment time, a clinician may conduct a brief functional analysis, for which sessions are abbreviated (Northup et al., 1991). When there is limited environmental control, a clinician may choose to conduct a trial-based functional analysis, in which the assessment is embedded into ongoing activities (Bloom, Iwata, Fritz, Roscoe, \& Carreau, 2011).

Additionally, research suggests that interventions based on functional analyses are more effective than interventions based on other types of functional assessments (Campbell, 2003; Didden, Korzilius, van Oorsouw, \& Sturmey, 2006; Herzinger \& Campbell, 2007). For example, Didden et al. conducted a meta-analysis on effectiveness of behavioral treatments based on functional analyses and descriptive assessments. This entailed calculating percentage of nonoverlapping data (PND) and percentage of zero data (PZD) between baseline and treatment phases for 80 studies. Higher scores indicate greater treatment effectiveness. Their results indicated that interventions based on functional analysis results produced higher PND and PZD scores than interventions based on descriptive assessments (i.e., mean PND and PZD scores of 75\% and 35\%, respectively, for descriptive assessments versus $83 \%$ and $48 \%$, respectively, for functional analyses). Thus, basing treatment on the results of functional analyses may not only lead to more effective treatments being prescribed but also may decrease time between starting assessment and implementing a treatment because of more reliable results. 
Function-Based Treatments

In light of the hundreds of assessments that have been conducted on a wide range of behavior topographies, the general finding is that behavior function is idiosyncratic to the individual; that is, no topography is exclusively associated with a single maintaining variable and each individual's behavior must be separately assessed. For example, Iwata et al. (1994) found that of 152 cases of self-injurious behavior, 58 were maintained by social-negative reinforcement, 40 were maintained by social-positive reinforcement, 39 were maintained by automatic (sensory) reinforcement, 8 were maintained by more than one variable, and 7 could not be determined. This wide distribution of function emphasizes the need for individualized assessments, especially when dealing with severe or dangerous behavior, so that individualized function-based interventions can be developed and implemented.

Interventions are most reliable and effective when developed based on hypotheses about the maintaining variables for problem behavior (e.g., Arndorfer \& Miltenberger, 1993; Repp, Felce, \& Barton, 1988); that is, the intervention procedures should be matched to the function of the behavior. When the function of problem behavior and treatment are matched, three reinforcement-based approaches have been shown to be effective: noncontingent reinforcement, extinction, and differential reinforcement.

Noncontingent reinforcement. Noncontingent reinforcement (NCR) can be used to decrease an individual's motivation to engage in a behavior; that is, because reinforcement is freely available, there is no need to engage in behavior to access it. Piazza, Moes, and Fisher (1996) accomplished this when developing an intervention for individuals that engaged in automatically maintained pica. Prior to intervention, a 
preference assessment was conducted to determine whether stimuli that produced similar oral stimulation as pica were preferred over other types of stimuli. Stimuli that matched the oral stimulation of pica not only were selected more often, but also lower levels of pica were observed while the individual interacted with those items. The subsequent interventions consisted of continuous access to the matched stimuli, which constituted NCR. For all three participants, a decrease in pica was observed.

Extinction. Extinction procedures, which consist of withholding the reinforcer that maintains problem behavior following the occurrence of problem behavior, has been identified as an important component for interventions based on functional analyses because it breaks the response-reinforcer relationship for problem behavior (Vollmer \& Smith, 1996). For example, Richman, Wacker, Asmus, \& Casey (1998) conducted a brief functional analysis for disruptive behavior, and the data indicated that it was maintained by social negative reinforcement in the form of escape from demands. The intervention consisted of escape-extinction, meaning that if the participant did not independently begin completing a task after being given an instruction, hand-over-hand guidance was provided so that she could not escape the demand. Disruptive behavior was reduced to near-zero levels.

Differential reinforcement. Extinction is commonly, but not always, implemented in conjunction with differential reinforcement procedures, such that reinforcement is delivered contingent on some other behavior and reinforcement no longer follows problem behavior (Vollmer \& Iwata, 1992). One benefit of using differential reinforcement is that it does not require individuals to be removed from their environment, as in the case of time-out procedures, and it does not rely on the delivery of 
aversive stimulation, as in the case of positive punishment procedures (Vollmer \& Iwata, 1992). A rich body of research has demonstrated the effectiveness of differential reinforcement with a wide range of diagnoses, topographies, and functions of problem behavior (Lennox, Miltenberger, Spengler, \& Erfanian, 1988). For example, Buckley and Newchok (2006) addressed problem behavior of a 7-year-old that was maintained by social negative reinforcement in the form of escape from music by delivering breaks from music contingent on him not engaging in problem behavior for a specified amount of time (differential reinforcement of other behavior; DRO) and placing problem behavior on extinction. In another study, Fyffe, Kahng, Fittro, and Russell (2004) sought to reduce a 9-year old boy with a traumatic brain injury's inappropriate sexual touching of other people. The results of the functional analysis indicated that problem behavior was maintained by social positive reinforcement in the form of attention. The prescribed treatment consisted of teaching the individual to appropriately request attention by reinforcing an alternative communicative response and withholding reinforcement contingent on inappropriate touching (functional communication training; FCT). The intervention decreased inappropriate sexual touching and increased appropriate requests for attention.

\section{Support for Use of Function-Based Interventions}

In the past 30 years, the assessment of function and prescription of function-based treatments for problem behavior has come to be considered best practice (Arndorfer \& Miltenberger, 1993) not only because it reliably leads to behavior reductions, but also long-term behavior change (e.g., Travis \& Sturmey, 2010). Numerous studies have 
evaluated the effectiveness of function-based interventions for various behavior topographies and functions. For example, when evaluating the effectiveness of interventions for self-injury, Iwata et al. (1994) found that extinction effects were highly selective across behavioral function and were predictable based on the results of functional analyses; that is, extinction procedures were effective only if they matched the function of the behavior. Thus, the accurate identification of function provides a critical foundation from which effective, function-based interventions can be developed for problem behavior (Arndorfer \& Miltenberger, 1993; Repp et al., 1988).

\section{Differential-Reinforcement of Alternative Behavior}

As described above, differential reinforcement is one commonly used approach for addressing problem behavior. Although there are formal variations of differential reinforcement (e.g., differential reinforcement of other behaviors, differential reinforcement of low rates of behavior), differential reinforcement of alternative behavior (DRA) is one of the most commonly prescribed interventions to address problem behavior (Petscher, Rey, \& Bailey, 2009). The greatest strength of DRA procedures is that it directly teaches individuals an appropriate way of contacting the reinforcement previously obtained contingent on problem behavior. This is commonly accomplished by reinforcing behaviors that are socially appropriate and withholding reinforcement following problem behavior (Vollmer \& Iwata, 1992).

In a recent review of the literature, Petscher et al. (2009) found 116 peer-reviewed articles from 1977 to 2007 that implemented DRA procedures to address problem behavior for a total of 336 individuals. Although DRA has been used to address problem 
behavior of adults (e.g., Goh, Iwata, \& Kahng, 1999; Wilder, Matsuda, O’Connor, \& Baham, 2001), over $80 \%$ of the participants in the studies reviewed were children, and the majority of those were diagnosed with autism or another developmental disability. Petscher et al. suggest these findings might indicate an overall preference for DRA in comparison to other procedures that may lead to extinction-induced side effects (e.g., extinction alone, differential reinforcement of other behaviors), because it teaches an appropriate way to access reinforcement. This might particularly be the case with individuals with developmental disabilities because of the language deficits often associated with these populations (e.g., Ferster, 1961). Additionally, some research suggests that DRA might more effectively address problem behavior than other differential reinforcement procedures. For example, LeGray, Dufrene, Sterling-Turner, Olmi, and Bellone (2010) compared the effectiveness of DRA and DRO (reinforcement delivered contingent on the absence of problem behavior for a predetermined interval of time) and found that both interventions were effective; however, DRA produced greater behavior reductions. Similarly, Roberts, Mace, and Daggett (1995) compared a DRA procedure (delivering a break contingent on compliance) with DRO. They found that DRA was more effective at reducing SIB maintained by social negative reinforcement in the form of escape, and that it improved task completion.

\section{DRA Procedures}

Traditionally, DRA procedures consist of delivering reinforcement contingent on alternative behaviors and discontinuing reinforcement contingent on problem behavior (i.e., extinction). The form of reinforcement is matched to the function of problem 
behavior; that is, if aggression has been maintained by social positive reinforcement in the form of attention, a DRA procedure would consist of delivering attention contingent on the individual engaging in an appropriate behavior (e.g., saying, "Excuse me," playing independently, etc.) and ignoring instances of problem behavior.

DRA has successfully addressed various behavior topographies and function, which further supports that behavior is idiosyncratic to the individual; that is, no topography is exclusively associated with a single maintaining variable and each individual's behavior must be separately assessed (Iwata et al., 1994).

Procedures for behaviors maintained by social reinforcement. DRA has successfully been implemented to address behaviors maintained by social reinforcement. For example, Travis and Sturmey (2010) used DRA to address the delusional speech of a 26-year-old man. A functional analysis was conducted and identified the function as attention. The DRA procedure consisted of delivering attention contingent on the man making appropriate statements and ignoring delusional statements. The procedure reduced delusional speech, as well as increased the frequency of appropriate statements. With consistent implementation, the behavior change was maintained 4 years after the intervention was introduced.

DRA has also been used to address behaviors maintained by social negative reinforcement. For example, Kahng, Boscoe, and Byrne (2003) used DRA to address a 4-year-old girl's food refusal. Initially, DRA was implemented using positive reinforcement; that is, contingent on food acceptance, praise was delivered. However, this procedure was ineffective. DRA was then implemented using a combination of positive reinforcement and negative reinforcement: tokens were delivered contingent on 
food acceptance and the tokens could be exchanged for the end of mealtime. The latter treatment effectively reduced food refusal and increased food acceptance, demonstrating the importance of matching reinforcement that previously maintained problem behavior when implementing DRA.

DRA procedures have also been used to treat behaviors that are maintained by both social positive and social negative reinforcement. For example, Wright-Gallo, Higbee, Reagon, and Davey (2006) assessed and treated disruptive behavior in a classroom setting for two students. Functional analyses indicated that the behaviors were maintained by social negative reinforcement in the form of escape from demands and social positive reinforcement in the form of attention for both participants. The students were taught to either request attention or a break from tasks by delivering either attention or a break contingent on these alternative responses and implementing extinction procedures. DRA procedures were effective for both students.

DRA for behaviors maintained by automatic reinforcement. Although there is far less support for using traditional DRA procedures to address problem behavior maintained by automatic reinforcement, it has been demonstrated effective in some cases. For example, Favell, McGimsey, and Schell (1982) used DRA to treat two individuals that engaged in eye poking and pica. Although a functional analysis was not conducted to confirm the hypothesis that eye poking and pica were maintained by automatic reinforcement, problem behavior decreased when materials were made available, by which the individuals could engage in alternative behaviors that produced similar stimulation. For example, when provided with edibles, pica was reduced. Similarly, 
when toys were available and the individual could manipulate them such that visual stimulation occurred, eye poking decreased.

Although by definition it is not necessary for individuals to interact with others to obtain reinforcement that serves an automatic function, functional communication training (FCT; described in detail below) has been used to address problem behavior maintained by automatic reinforcement. Falcomata, Roane, Feeney, and Stephenson (2010) evaluated the elopement behavior of a 5-year-old boy with autism and determined that it was maintained by automatic reinforcement in the form of access to stereotypic door play. FCT was used to teach the boy to request access to the door by touching a red card. Not only did elopement decrease and the red card response increase, but also they were able to thin the schedule of reinforcement from a fixed ratio of one response (FR1) to a fixed interval of $10 \mathrm{~min}$ in a naturalistic setting.

Procedural variations. Differential reinforcement of incompatible behavior (DRI) and FCT are two variations of DRA that have been specified for treating problem behavior.

DRI. Whereas DRA involves reinforcing a topographically dissimilar alternative behavior and withholding reinforcement following problem behavior, DRI specifies that the alternative behavior is physically incompatible with the problem behavior (Young \& Wincze, 1974). For example, Pitman (2007) treated a woman who engaged in various problem behaviors that involved inappropriate ambulation, including crawling on her hands and knees, squatting while moving, and dragging her legs and knees across surfaces when moving from one area to another. A functional analysis indicated that her behavior was maintained by social positive reinforcement in the form of attention. A 
DRI treatment was subsequently implemented, which consisted of staff members providing attention contingent on the woman walking upright (a response that is physically incompatible with the problem behavior); problem behavior decreased and upright walking increased.

Although some authors differentiate between DRA and DRI, it is unclear whether the distinction is necessary or even useful because it is based on topography rather than function. Vollmer and Iwata (1992) note that when behavioral function is taken into account when developing a DRA intervention, any alternative behavior selected, whether physically incompatible with problem behavior or not, is made functionally incompatible with problem behavior because one produces reinforcement and one does not. Thus, Vollmer and Iwata argue, determining whether the alternative behavior is physically incompatible with problem behavior is moot because both do not simultaneously produce reinforcement.

FCT. A second variation of DRA is FCT, in which individuals are specifically taught to engage in a functionally equivalent alternative behavior in the form of a communicative response (Carr \& Durand, 1985). The majority of published studies that used DRA procedures to address problem behavior could be considered FCT because specific communicative responses were taught that produced the same reinforcer that previously maintained problem behavior (Petscher et al., 2009). For example, Carr and Durand, in one of the first studies on FCT, taught children to engage in communicative responses to elicit adult attention. These communicative responses were then reinforced with attention and problem behavior was no longer reinforced with attention. The 
authors reported that problem behavior decreased and appropriate communication increased.

The overarching benefit of FCT is that it teaches an individual an appropriate alternative communicative response to obtain reinforcement and replace problematic behaviors. Teaching a communicative response strengthens important skills that allow an individual to appropriately participate in their environment (Carr \& Durand, 1985). Additionally, a wide range of communicative response topographies can be used, including vocalizations, manual signs, picture or word cards, gestures, and micro switches (Brown et al., 2000), allowing treatments to be tailored to the strengths and limitations of each individual. This is critical because response effort can be an important variable when developing effect FCT interventions (Richman, Wacker, \& Winborn, 2001); that is, an individual may continue to engage in problem behavior if the alternative response is too effortful (e.g., having to walk across the room to access a picture card). If responses are widely understandable, there is a greater likelihood of naïve individuals will reinforce the alternative response because there is no need to be formally trained to implement intervention. For example, Durand and Carr (1992) compared the long-term effects of FCT and time-out with 12 children that engaged in attention maintained problem behavior. Although both effectively decreased problem behavior, the effects of FCT were better maintained than the effects of time-out (i.e., problem behavior reemerged during the time-out condition but not the FCT condition) when naïve therapists interacted with the children. The authors hypothesized that this was the result of the children continuing to contact reinforcement contingent on the 
programmed FCT responses despite the naïve therapists never being provided with information regarding the different intervention plans.

\section{DRA with Other Procedures}

Although DRA alone has been demonstrated to be an effective treatment, it is sometimes combined with other procedures. For example, DRA has been combined with NCR (i.e., the reinforcer that previously maintained problem behavior is delivered noncontingently, in addition to when the individual engages in the alternative behavior). The support for using DRA and NCR is somewhat mixed as NCR may affect the acquisition of the alternative behavior targeted by DRA. For example, Goh, Iwata, and DeLeon (2000) evaluated the combination of DRA and NCR with two individuals that engaged in self-injurious behavior maintained by social positive reinforcement in the form of access to tangibles or attention. Self-injury decreased; however, the alternative behavior (i.e., requests for access to tangibles or attention) increased only modestly. When the NCR schedule was thinned, self-injury remained low and requesting increased. Goh et al. noted that dense schedules of NCR might alter the establishing operation for the alternative behavior and thus might interfere with the acquisition of the alternative behavior. In contrast, Marcus and Vollmer (1996) saw a rapid decrease in problem behavior and an increase in alternative behavior when DRA and NCR were implemented to address the self-injurious behavior (maintained by access to tangibles) of a 5-year-old girl with Down's syndrome. For a second participant, a 4-year-old male that engaged in aggression to access preferred toys, Marcus and Vollmer implemented NCR first and then superimposed DRA. NCR was effective and the alternative response was acquired 
when the DRA procedure was superimposed. Thus, although there are cases of NCR precluding the acquisition of the alternative response, there are also cases for which it did not. Nonetheless, both Goh et al. (2000) and Marcus and Vollmer have suggested that NCR schedules be lean so that the establishing operation for the alternative response can be captured.

DRA has also been combined with various punishment procedures. For example, Kahng, Tarbox, and Wilke (2001) implemented a combined intervention to address a 5year-old male's aggression and food avoidance that had led to him being admitted to an inpatient unit. The treatment consisted of delivering preferred toys when the boy accepted food without engaging in aggression (DRA) and restricted the toys contingent on aggression or avoidance of food (i.e., response cost). The results indicate the intervention increased food acceptance and a decrease in aggression and food avoidance.

Similarly, FCT has also been combined with punishment procedures. In a review of 21 cases, Hagopian, Fisher, Sullivan, Acquisto, and LeBlanc (1998) found support for incorporating punishment into FCT: although FCT reduced problem behavior for the majority of cases (22 out of 25 cases), when it was paired with punishment, the intervention was effective every time (17 cases). The authors suggested that these results might be reflective of the effects of reinforcement and punishment being mutually enhanced when implemented together. In another study, Hanley, Piazza, Fisher, and Maglieri (2005) compared the effects of FCT and FCT with punishment in the form of brief restraints (hands down) and a visual screen. FCT with punishment was more effective for both participants and, interestingly, both participants demonstrated preference for FCT conditions that included punishment. Hanley et al. hypothesized that 
this preference might be related to the effectiveness of the individuals' overall behavior in the conditions. During the FCT condition, both participants continued to engage in problem behavior during extinction and thus only a small percentage of their overall responses (problem behavior plus alternative behavior) were reinforced. In contrast, in the condition that featured FCT with punishment, problem behavior was reduced more quickly and therefore a larger portion of the participants' behavior resulted in reinforcement.

Although the studies described above demonstrated the efficacy of DRA or FCT in combination with other interventions, it is important to note that few of these studies evaluated when DRA or FCT were implemented alone; thus, it is unknown whether the additional treatment components were necessary. This is an important consideration because multi-component interventions can be difficult to implement with integrity, potentially decreasing the overall efficacy of the intervention.

\section{Limitations of DRA}

Although extensive research demonstrates that DRA can be effective, most cases assume optimal treatment integrity. Moreover, research suggests that DRA is most effective when problem behavior is placed on extinction (e.g., Kelley, Lerman, \& Van Camp, 2002; Shirley, Iwata, Kahng, Mazaleski, \& Lerman, 1997). Thus, optimal treatment integrity for DRA procedures requires reinforcement to be delivered every time an individual engages in an alternative response and always withheld following problem behavior. However, in natural settings, this may be difficult to achieve. It may be impossible to withhold attention to behavior that is dangerous and it might can be 
difficult to train staff to implement DRA because of caregivers' long history of reinforcing problem behavior (St. Peter Pipkin, Vollmer, \& Sloman, 2010). Additionally, it may be counter-therapeutic to prescribe extinction if it cannot be implemented with perfect treatment integrity because it may strengthen problem behavior; that is, if problem behavior is reinforced intermittently, it may become more persistent.

St. Peter Pipkin et al. (2010) identify two types of treatment integrity errors in DRA procedures: errors of omission and errors of commission. An error of omission is a failure to deliver reinforcement when it is scheduled. For example, a teacher may become distracted by another student and forget to reinforce hand raising in the target student. An error of commission is the delivery of reinforcement contingent on problem behavior. For example, a parent may not be able to ignore instances of aggression when it is directed at an infant sibling. Together, these types of errors may affect the overall effectiveness of the intervention. Problem behavior may not only continue or become more persistent due to a variable schedule, but the intervention could potentially be discontinued and the parents/caregivers may be less willing to continue with behavioral approaches to problem behavior. Alternatively, more intrusive procedures, such as punishment, might be introduced because the reinforcement-based intervention appears to be ineffective.

Research has evaluated the impact of these two types of treatment integrity errors on the effectiveness of DRA procedures. For example, Vollmer, Borrero, Lalli, and Daniel (1999) examined the effects of treatment integrity errors on the effectiveness of DRA. Their analysis consisted of combined errors of omission and commission, ranging from perfect integrity (i.e., reinforcement is always delivered contingent on alternative 
behavior and never following problem behavior) to perfect integrity failure (i.e., reinforcement is never delivered contingent on alternative behavior and always following problem behavior). When the interventions were implemented with optimal integrity, the alternative behavior replaced problem behavior for three individuals. Interestingly, when errors of omission or commission were introduced, the alternative behavior was maintained so long as the schedule of reinforcement favored alternative behavior. All three participants continued to engage in the alternative response, despite treatment integrity errors; however, problem behavior increased during conditions with programmed treatment integrity errors. This could be especially problematic when dealing with severe problem behavior, such as self-injury, aggression, or property destruction.

St. Peter Pipkin et al. (2010) also investigated the combination of errors of omission and errors of commission on the effectiveness of DRA. Participants shifted their responding between problem behavior and alternative behavior based on the reinforcement rate available for each response type. If reinforcement was more likely to follow problem behavior, the participants engaged in more problem behavior; if reinforcement was more likely to follow alternative behavior, the participants engage in more alternative behavior. St. Peter Pipkin et al. note that the combination of errors appears to have the same effects on behavior as errors of commission, suggesting that errors of commission may be more responsible for treatment failures than errors of omission.

In sum, the research suggests that an error of omission is unlikely to greatly impact the effectiveness of a DRA treatment; however, errors of commission can degrade 
the effectiveness of a treatment, particularly when the rate of reinforcement no longer favors the alternative behavior. This may be an attainable goal for certain cases, especially when resources are available to provide extensive training and support when beginning to implement DRA with extinction to ensure minimal errors of commission. However, resources may not always be available to provide that level of support and there are some cases in which extinction is not feasible. For example, when problem behavior is dangerous and reinforced by attention, it would be unreasonable (and unsafe) to prescribe an extinction procedure. Additionally, if extinction is not possible and problem behavior occurs at high rates, it may be difficult to manipulate rate of reinforcement to that it favors alternative behavior. Thus, alternative approaches to DRA without extinction must be considered so that behavior analysts can prescribe effective treatments that can reasonably be implemented.

\section{Concurrent-Schedules of Reinforcement}

DRA can be conceptualized as a concurrent-operants arrangement (e.g., Athens \& Vollmer, 2010), in which two independent schedules of reinforcement are in effect simultaneously for two different responses (Ferster \& Skinner, 1957). In traditional DRA procedures, the alternative response is initially reinforced on a continuous schedule and problem behavior is on extinction. However, this is only one of many different concurrent schedule arrangements. Other concurrent schedules of reinforcement can be arranged so that the alternative behavior is differentially favored over problem behavior. The matching law has been widely used to describe patterns of responding produced when an organism is presented with concurrent schedules of reinforcement, and, 
generally, it has been found that the relative rate of a response will approximate the relative rate of reinforcement available for that response (Herrnstein, 1961). The matching law accounts for the broad effectiveness of DRA and the findings are robust with respect to modest violations of treatment integrity. However, as with extinction, it may not always be feasible to implement a thinner schedule of reinforcement for problem behavior to shift response allocation to the alternative response. For example, if problem behavior occurs at high rates and has an extensive learning history, it may be difficult to increase an alternative response such that rate of reinforcement favors the alternative behavior, particularly if problem behavior cannot be placed on extinction.

Fortunately, rate of reinforcement is not the only parameter of reinforcement that, when manipulated, can affect how individuals allocate their responding. Research has also evaluated he effects of magnitude, immediacy, and quality manipulations. For example, Borrero, Vollmer, Borrero, and Bourret (2005) analyzed functional analysis and descriptive assessment data of three individuals with developmental disabilities that engaged in both problem behavior and functionally equivalent alternative behavior. They analyzed the descriptive data to calculate probability of reinforcement given a response, rate of responding, and rate of reinforcement, as well as other parameters of reinforcement, including magnitude (i.e., mean duration of reinforcement) and immediacy (i.e., mean delay to reinforcement). For two of the participants, responding was allocated more to the response that produced the higher rate of reinforcement (problem behavior for one and alternative behavior for the other). The third participant, however, allocated more responding to the alternative behavior, despite rate and immediacy favoring problem behavior. This last participant is interesting because 
something other than rate influenced response allocation: The only parameter that favored the alternative behavior was magnitude of reinforcement, suggesting that this parameter was influential enough to shift responding away from the alternative that was favored both in terms rate of reinforcement and immediacy. These results suggest that manipulating other parameters of reinforcement may also be effective in treating problem behavior, which potentially increases the possible variations of DRA that can be implemented without the use of extinction.

\section{Parameter Manipulations}

Quality. One parameter of reinforcement that can be manipulated is the quality of reinforcement, typically associated with the relative efficacy of the consequence event (e.g., Athens \& Vollmer, 2010). For example, if an individual engaged in a response more when chocolate was delivered contingently than when pretzels were delivered contingently, we would say that chocolate is a higher quality reinforcer than pretzels. Research has demonstrated that quality influences how some individuals allocate their responding across response options.

Neef, Mace, Shea, and Shade (1992), for example, reported different patterns of responding for three participants when both reinforcement rate and quality were manipulated. Although evaluated with academic tasks and not problem behavior, quality overrode rate of reinforcement for two individuals; that is, they allocated more responding to the response that produced higher quality reinforcement at a lower rate than lower quality reinforcement at a higher rate. The third participant, however, allocated responding according to rate of reinforcement rather than quality. Similarly, 
Mace, Neef, Shade, and Mauro (1996) demonstrated that reinforcer quality overrode the combined effects of rate of reinforcement and difficulty of academic tasks for two students.

Piazza et al. (1997) applied quality manipulations to a DRA without extinction procedure designed to address problem behavior of three children referred for the assessment and treatment of severe problem behavior maintained by both social positive reinforcement (access to tangibles, attention, or both) and social negative reinforcement (escape from tasks). The effects of the DRA intervention were evaluated by systematically altering the quality of 30 -s breaks for alternative behavior (compliance), while problem behavior consistently produced a 30-s break. The quality of breaks was manipulated by adding additional stimuli (i.e., attention, preferred tangible items, or both). For one participant, quality manipulations alone were not effective; extinction was needed to decrease problem behavior and increase alternative behavior. However, manipulating quality reduced problem behavior and increased alternative behavior without the use of extinction for two participants. Hoch, McComas, Thompson, and Paone (2002) obtained similar results when problem behavior and alternative behavior (task completion) produced different quality breaks; that is, breaks were delivered contingent on both problem behavior and alternative behavior, but access to preferred stimuli was included during breaks for alternative behavior. Problem behavior decreased and task completion increased. Additionally, treatment gains were maintained when the schedule of reinforcement was thinned. Although quality manipulations were effective for the majority of participants in these two studies, it was ineffective for one of Piazza and colleagues participants, suggesting that sensitivity to quality may be idiosyncratic. 
One major criticism of studies that have investigated quality of negative reinforcement is how quality is manipulated. Piazza et al. (1997) and Hoch et al. (2002) manipulated quality by adding additional stimuli, such as attention or preferred items, to breaks from tasks. While the addition of stimuli may alter the relative effectiveness of the break, it is conceptually complicated because it combines negative and positive reinforcement. It may be possible to alter quality of negative reinforcement in other ways; however, the current body of literature does not yet provide a method for doing so.

Magnitude. The magnitude, or the size, of a reinforcer has also been shown to influence response allocation. In 2002, Dube and McIlvane evaluated the sensitivity of six individuals with developmental disabilities to rate of reinforcement and magnitude changes using a computer program and arbitrary responses. They found that three of the participants were highly sensitive to magnitude changes, whereas two were only moderately sensitive and one was not, suggesting that, similar to other parameters of reinforcement, sensitivities vary on an individual basis.

McComas, Hartman, and Jimenez (2008) also evaluated magnitude sensitivity using a computer-based program; however, the participants were graduate students without a disability. The reinforcer used was points that could be exchanged for money at the end of the study. The results of the study indicated that when two options are made available and each is associated with a different magnitude value, individuals will allocate their responding to the option that produces the higher magnitude of reinforcement. Interestingly, response allocation did not differ greatly when there were small or larger magnitude differences (i.e., 1 and 2 points versus 1 and 8 points). Additionally, the authors found that responding was more persistent for the response that 
produced a higher magnitude than the response that produced the lower magnitude.

Although this study used arbitrary responses, it is possible that similar results would be obtained with problem behavior and alternative behavior, suggesting that manipulating magnitude to favor the alternative response might promote behavior persistence during disruption (e.g., extinction or treatment integrity failures).

Magnitude sensitivity has also been demonstrated with individuals with disabilities that engage in problem behavior. For example, Sy, Borrero, and Borrero (2010) evaluated the response allocation between problem behavior (aggression, selfinjury, property destruction, and inappropriate vocalizations) and alternative behavior (request for break or tangible items) of an 11-year-old boy with autism. Descriptive data were collected and analyzed to determine the average duration of reinforcement delivered contingent on problem behavior or alternative behavior. This was then compared to the rate of each behavior. They found that the participant had allocated more responding toward alternative behavior, which was associated with larger magnitudes of reinforcement.

Immediacy. Immediacy of reinforcement delivery has been shown to influence response allocation. In a study by Neef, Mace, and Shade (1993), students diagnosed as emotionally disturbed were exposed to various contingencies to determine how they allocated their responses when both rate and immediacy of reinforcement were manipulated. When immediacy was held constant but rates of reinforcement were unequal, the students allocated their responses equally across both options. However, when delays differed along with rate, there was a bias toward the response associated with more immediate reinforcement, regardless of the rate. This pattern of behavior often 
referred to as impulsivity, or the tendency to prefer smaller-sooner reinforcement over larger-later reinforcement (Rachlin, 1974), suggests that immediacy of reinforcement can override other parameters of reinforcement, such as rate, that favor one response over another.

Vollmer et al. (1999) obtained similar results when they implemented a DRA procedure to address two young boys' problem behavior (aggression) that was maintained by positive reinforcement in the form of access to tangibles (food). After FCT responses had been taught to replace problem behavior, response allocation was evaluated when immediacy and magnitude of reinforcement were manipulated: aggression produced immediate access to one edible item; the trained alternative response produced delayed access $(10 \mathrm{~s})$ to three edible items. Both participants engaged in more aggression despite it producing a small magnitude of reinforcement. Again, these results suggest that immediacy is a powerful parameter that can affect how individuals allocate their responding, even when reinforcement is delayed by as little as $10 \mathrm{~s}$.

Horner and Day (1991) evaluated the effects of immediacy of reinforcement on response allocation between problem behavior and alternative behavior when all other parameters were held constant. One participant, a woman diagnosed with autism and severe mental retardation, engaged in severe self-injury and aggression maintained by negative reinforcement in the form of escape. Because of her limited vocal repertoire, she was taught an alternative behavior in the form of exchanging a break card with trainers. When immediacy favored problem behavior over alternative behavior, the participant continued to engage in higher rates of problem behavior; however, her response allocation shifted to alternative behavior when immediacy was manipulated to 
favor alternative behavior. These results highlight the importance of considering sensitivity to immediacy of reinforcement when developing DRA procedures, particularly for situations in which it may be more likely that caregivers attend more rapidly to problem behavior than appropriate, alternative behavior.

\section{Identifying Individual Sensitivities to Parameters}

Numerous studies have found that sensitivity to parameters of reinforcement varies across individuals (Neef \& Lutz, 2001a, 2001b; Neef et al., 1993; Neef, Shade, \& Miller, 1994; Perrin \& Neef, 2012), and therefore not every manipulation will be effective for each individual. Collectively, these results indicate the need for parameter sensitivity to be assessed at an individual level. If sensitivity to various parameters of reinforcement could be assessed in advance, interventions could be prescribed with greater precision and efficacy. Several methods have been proposed for identifying individual sensitivities to parameters of reinforcement.

Neef et al. (1994) evaluated parameter sensitivity for six individuals in the context of arbitrary responses (i.e., math problems) but the results were not applied to a behavioral treatment. The authors developed an automated computer-based assessment that presented pairs of math problems between which individuals chose. Each option was associated with a schedule of reinforcement that could be manipulated across different parameters; that is, if the student answered the problem on the left correctly, they contacted one contingency, and if the student answered the problem on the right correctly, they contacted a different contingency. The goal of the assessment was to identify relative sensitivity across rate, quality, immediacy, and response effort. To 
achieve this, each parameter was pitted against every other parameter. For example, to assess sensitivity to quality, response allocation was recorded when high and low quality reinforcers (HQ and LQ, respectively) were combined with other parameters: high and low rates of reinforcement (HR and LR, respectively; HQ/HR v. LQ/LR; LQ/HR v. $\mathrm{HQ} / \mathrm{LR}$ ); high and low response effort (HE and LE, respectively; HQ/HE v. LQ/LE; LQ/HE v. HQ/LE); and low and high delays (LD and HD, respectively; HQ/LD v. $\mathrm{LQ} / \mathrm{HD}$; LQ/LD v. HQ/HD) to reinforcement. Responding differed across individuals when dimensions were combined and pitted against each other. This procedure has been used and modified in subsequent studies by Neef and colleagues (e.g., Neef \& Lutz, 2001a, 2001b; Neef, Bicard, \& Endo, 2001; Neef, Bicard, Endo, Coury, \& Aman, 2005; Neef, et al., 2005).

Although the procedure used by Neef and colleagues provides relative sensitivities to a range of parameters by directly pitting the parameters against each other, the procedures may be difficult to apply to parameters of reinforcement for problem behavior. It might not only be difficult to capture the motivating operations to assess the efficacy of reinforcers that maintain problem behavior, but also it might be difficult to deliver reinforcement via an automated program when problem behavior is maintained by positive reinforcement, especially in the form of attention. Thus, an alternative procedure might be more appropriate when assessing parameter sensitivity in the context of problem behavior.

Athens and Vollmer (2010) evaluated individual sensitivities to magnitude, quality, and immediacy of reinforcement in the context of problem behavior. After identifying the function of problem behavior (aggression) for seven children, independent 
assessments were conducted to determine whether individuals were sensitive to quality, magnitude, and immediacy manipulations. For the quality sensitivity assessment, reinforcement was available on a concurrent-schedule arrangement; that is, problem behavior and alternative behavior contacted different contingencies. First, reinforcers of equal high quality were delivered contingent on both problem and alternative behavior, providing a baseline pattern of response allocation. Then, alternative behavior was favored by providing high quality reinforcement contingent on alternative behavior and low quality reinforcement contingent on problem behavior. If this condition did not shift responding to alternative behavior, the quality of reinforcement available for alternative behavior was increased to include three different high quality items in comparison to one low quality item for problem behavior. These conditions were then alternated to establish experimental control. Similar assessments were conducted to assess for sensitivity to magnitude and immediacy.

For all three parameters, Athens and Vollmer (2010) were able to shift responding to alternative behavior by having the parameter favor alternative behavior. For example, manipulating magnitude of reinforcement such that problem behavior produced access to tangible items for $10 \mathrm{~s}$ but alternative behavior produced access for 30 s successfully decreased problem behavior. Similarly, providing a brief break immediately contingent on alternative behavior but delaying the break by $60 \mathrm{~s}$ contingent on problem behavior successfully shifted response allocation to alternative behavior and problem behavior decreased.

Athens and Vollmer (2010) additionally sought to evaluate the effects of parameter manipulations on response allocation for two participants when multiple 
parameters were manipulated simultaneously. Schedules of reinforcement were held constant across problem behavior and alternative behavior. Problem behavior produced 5 s with a low quality reinforcer after a 10-s delay; however, alternative behavior produced $30 \mathrm{~s}$ with a high quality reinforcer immediately after the response was emitted. Both participants almost immediately shifted their responding to alternative behavior when multiple parameters favored alternative behavior.

Together, the results of Athens and Vollmer (2010) demonstrated that DRA can be effective without extinction when parameters of reinforcement are used to favor the alternative behavior. Although the effects were slower when individual parameters were manipulated, for all seven cases, response allocation shifted away from problem behavior and toward alternative behavior without the use of extinction. For the cases in which only one parameter was manipulated, it is possible that more rapid treatment effects would have occurred had a different parameter been manipulated for that individual because parameter sensitivity is idiosyncratic and the individuals may have been more sensitive to other parameters not evaluated. It may be effortful to simultaneously manipulate three dimensions of reinforcement in a natural setting and similar outcomes may have been achieved by manipulating a single parameter to which the individual is highly sensitive. Thus, identifying individual sensitivities might be beneficial for developing individualized interventions and increasing the effectiveness of DRA interventions without extinction.

Athens and Vollmer (2010) propose an assessment procedure that can easily be conducted in the context of problem behavior, whereas it would be difficult to do so using the procedure proposed by Neef et al. (1994). However, the procedures employed 
by Athens and Vollmer require the participants to engage in problem behavior, which could be problematic depending on the severity of the behavior. One benefit of using arbitrary responses to identify sensitivities to parameters of reinforcement, as in Neef et al., is that it does not require an individual to engage in problem behavior. Although not evaluated in the context of problem behavior, basic researchers have previously demonstrated that participant responses to hypothetical tests to determine sensitivity to immediacy of reinforcement is indicative of how the individuals will allocate responding in real choice situations (Odum, 2011). Thus, it may be possible to assess sensitivity to different parameters in the context of arbitrary responses, rather than problem behavior, but to then apply the results to a DRA without extinction procedure. This approach may increase the effectiveness of treatments by taking into consideration individual sensitivities to parameters of reinforcement while avoiding the issues of problem behavior during assessment. Additionally, this approach may decrease potential treatment integrity errors by developing an intervention that does not include extinction.

Thus, the purpose of this study is to answer the following questions:

1. Can we use arbitrary responses (not problem behavior) to identify individual sensitivities to magnitude, quality, and delay of reinforcement for children that engage in problem behavior?

2. Will a DRA procedure in which problem behavior is not placed on extinction be effective when the alternative behavior is differentially favored using the parameter of reinforcement for which the subject is most sensitive? 
CHAPTER II

METHODS

\section{Participants and Setting}

A total of six individuals were recruited for this study and screened for participation. Individuals were eligible to participate in this study if they engaged in problem behavior maintained by social positive reinforcement (i.e., attention or tangible functions) or multiply maintained by social positive reinforcement and social negative reinforcement (i.e., escape function) as determined by a functional analysis (described below). Individuals were excluded from the study if their problem behavior was found to be maintained by automatic reinforcement or exclusively by social negative reinforcement.

\section{Excluded Participants}

We excluded four individuals from the study. All four participated in the tangible and attention preference assessments and a functional analysis was conducted to determine the maintaining variable(s) for their problem behavior. We excluded Pacey and Lucy from the study because results of the functional analyses indicated their behavior was maintained by social negative reinforcement in the form of escape from demands. We excluded Troy after problem behavior was not observed after 12 functional analysis sessions and his staff reported that problem behavior would likely occur only in situations we were not able to replicate during assessment (i.e., restricting and delivering cigarettes). Finally, the functional analysis indicated that Esther had multiply controlled 
problem behavior (i.e., attention, tangible, and escape); however, due to problem behavior observed during the preference assessments when instructions (i.e., "pick one") were delivered, we determined she would benefit most if the escape function was addressed first. Subsequent treatments addressed all three functions and therefore she was no longer eligible for this study. Participant characteristics can be found in Table 1 and data from the preference assessments and functional analyses can be found in Figures 1 and 2, respectively.

\section{Included Participants}

We included Rufus and Sabrina in this study. Rufus was a 31-year-old male diagnosed with cerebral palsy and a visual impairment that consists of no light perception in either eye. He can, however, differentiate between colors, shapes, and large pictures and objects. He was referred for aggression, property destruction, and inappropriate vocalizations. Sabrina was a 24-year-old female diagnosed with mood disorder, autistic disorder, post-traumatic stress disorder, psychotic disorder (not otherwise specified; NOS), personality disorder (NOS), and paranoid and antisocial traits. She was referred for inappropriate vocalizations.

\section{Setting and Materials}

We conducted sessions with Rufus in an empty room at a university-based day program that he attends during the week. We conducted sessions with Sabrina in a university-based clinic equipped with a one-way mirror. Both settings included a table and chairs for the participants and therapists to sit in and relevant materials for the particular condition being conducted (e.g., high preferred items, low preferred items, 
etc.). We used colored cards and colored touch-lights for the arbitrary responses in the parameter sensitivity assessments and relative parameter sensitivity assessments (additional descriptions provided below).

\section{Response Measurement}

Topographies of problem behavior included aggression and property destruction for Rufus, and inappropriate vocalizations for both Rufus and Sabrina. Aggression was defined as hitting, pushing, pinching, biting, kicking, grabbing, or spitting directed at another person. Property destruction was defined as throwing items (not in the direction of a person), hitting/swiping items off of a surface, or hitting any surface with his hand or foot. Inappropriate vocalization was defined for Rufus as screaming/yelling and/or directing profanity toward another person and was defined for Sabrina as yelling, name calling, making false accusations about staff or therapists (e.g., "You're torturing me," "You're abusing me") and/or directing profanity at another person. We collected data on the occurrence of problem behavior throughout the study.

We also collected data on response allocation during the parameter sensitivity assessments and relative parameter assessment. To count as a response, Rufus had to touch one of the colored cards; Sabrina had to touch one of the touch-lights such that the light illuminated. Data collectors scored the response as the parameter value selected (e.g., if the card associated with low magnitude was touched, "low magnitude" was scored).

Finally, during the treatment evaluation, we collected data on a target alternative response. We selected alternative responses for the participants that were easy for the 
participants to acquire. Both participants acquired the alternative responses and independently emitted the responses within four sessions of training. Data for response training can be found in Figure 18. The alternative response for Rufus was defined as handing the primary therapist a communication card that said, "Share with me." The alternative response for Sabrina was to say, "Can I have a turn, please?"

Trained observers collected all data using handheld computers equipped with Observe! software. A second trained observer collected data for $66.4 \%$ of all sessions. For both Rufus and Sabrina, reliability was $100 \%$ for both the tangible and attention preference assessments. For the functional analyses, we collected reliability data for $31.3 \%$ of Rufus' sessions, with mean reliability being $97.5 \%$ (range $93.5 \%$ to $100 \%$ ); we collected reliability for $31.3 \%$ of Sabrina's sessions with mean reliability being $96.3 \%$ (range $90.4 \%$ to $100 \%$ ). We collected reliability data for $45.5 \%$ of Rufus' parameter sensitivity sessions, with mean reliability being $99.6 \%$ (range $98 \%$ to $100 \%$ ). We collected reliability data for $61 \%$ of Sabrina's parameter sensitivity assessments, with mean reliability being $99.1 \%$ (range $94.7 \%$ to $100 \%$ ). We collected reliability data for $50 \%$ of parameter tracking test sessions for Rufus. Mean reliability was $98.9 \%$ (range $98 \%$ to $100 \%$ ). For Sabrina's relative parameter sensitivity assessment, we collected reliability data for $25 \%$ of sessions, with mean reliability being $99.4 \%$ (98-5\% to $100 \%$ ). For the intervention sessions, we collected reliability data for $83.3 \%$ of Rufus' sessions, with mean reliability being $98.2 \%$ (range $93 \%$ to $100 \%$ ); we collected reliability data for $69.2 \%$ of Sabrina's intervention sessions, with mean reliability being $98.8 \%$ (range $96.7 \%$ to $100 \%)$. 


\section{Procedures}

This study consisted of five phases: preference assessments, functional analysis, parameter sensitivity assessments, relative parameter sensitivity assessment, and intervention. An overview of the procedures is depicted in Figure 3.

\section{Caregiver Interview}

Prior to all assessments, we interviewed caregivers using the Functional Assessment Screening Tool (FAST). The purpose of the FAST is to obtain initial information about potential relevant environmental events that might evoke problem behavior to improve the effectiveness of a functional analysis (Iwata, Deleon, \& Roscoe, 2013). Additionally, we used the FAST results to indicate if there was a potential social function (attention, tangible, escape) for problem behavior. We did not exclude any individuals based on information obtained from the FAST. We also asked caregivers to identify preferred items/activities and social interactions to be used in the preference assessments.

\section{Preference Assessments}

We conducted two preference assessments with each participant to determine preferred tangible items and preferred forms of attention. We used the results of the tangible preference assessments to determine what items to use during the different functional analysis conditions (see below) and parameter sensitivity and relative parameter sensitivity assessments if problem behavior was found to be maintained by access to tangible items. We planned to use the results of the attention preference 
assessment in the parameter sensitivity and relative parameter sensitivity assessments if problem behavior was found to be maintained by attention.

Tangible preference assessments. Due to Rufus' visual impairment, he had difficulty scanning across more than a few items. Therefore, we assessed preference for tangible items using a paired stimulus preference assessment (Fisher et al., 1992) in which Rufus made selections between two items at a time. We assessed seven items: an iPad, radio, balls, massager, books, a binder of pictures, and Sesame Street picture cards. The assessment consisted of first providing Rufus 20 to $30 \mathrm{~s}$ of exposure to each item. Then, the therapist presented two items to him simultaneously and he was instructed to "pick one." After a selection, Rufus was given 30 s with the item. The therapist then removed the item and presented another two items. This continued until each item was paired with every other item. We determined preference by calculating the percentage of trials in which the item was selected and ranking the items from highest to lowest percentage.

We assessed preference for tangible items with Sabrina by conducting a multiple stimulus without replacement (MSWO; DeLeon \& Iwata, 1996) preference assessment. We assessed seven items: an iPad, puzzle book, magic 8-ball, radio, massager, digital camera, and a home and garden magazine. The assessment consisted of first providing Sabrina 20 to $30 \mathrm{~s}$ of exposure to each item. Then, the therapist presented all seven items in an array in front of her and she was instructed to "pick one." After a selection, Sabrina was given $30 \mathrm{~s}$ with the item. The therapist then restricted the item and re-presented the remaining items in a different order. This continued until all items had been selected or until 30s elapsed without a selection. This procedure was then repeated two additional 
times. We determined preference by calculating the percentage of trials in which the item was selected by dividing the number of times the item was selected by the number of trials in which the item was available. The results were then ranked from highest to lowest percentage.

Attention preference assessments. We based our attention preference assessment procedures on Clay, Samaha, Bloom, Bogoev, and Boyle (2013). We assessed four forms of attention for each participant: three positive interactions suggested by caregivers and one verbal reprimand that caregivers reported were commonly delivered contingent on problem behavior. For Rufus, we assessed preference between high-fives, a handshake, a pat on the back, and being told, "I don't like when you do that." The forms of attention we assessed for Sabrina included talking about Disney movies, recipes, pets, and being told, "I don't like when you do that." The assessment consisted of trials in which each form of attention was paired with other form of attention. For Rufus, the therapists were seated at a table on either side of him and a selection was defined as touching one of the therapists on the hand. We used this arrangement with Rufus because his disability limits his mobility. For Sabrina, therapists stood at one end of the room with a 6-foot table positioned between them. A therapist instructed Sabrina to stand at the opposite end of the room. A selection was defined as Sabrina walking toward one of the therapists such that she was on one side of the table. Prior to each trial, a different therapist prompted the participant to select each therapist so that they experienced the form of attention. Then, the therapist instructed the participant to, "pick one." The selected therapist then delivered the form of attention for 5-10s. 
Preference was determined by calculating the percentage of trials for which each form of attention was selected and ranking the results from highest to lowest percentage.

We then conducted a tracking test to determine whether participants preferred the form of attention or the therapists delivering attention. This consisted of switching the therapists who delivered the highest and lowest preferred forms of attention; that is, the therapist that was associated with the highest form of attention now delivered the lowest preferred form of attention and the therapist that was associated with the lowest preferred form of attention now delivered the highest preferred form of attention. If the participant continued to prefer the same form of attention, we determined that they tracked the form of attention and not the therapist.

\section{Functional Analysis}

We then conducted a functional analysis (Iwata et al., 1982/1994) to identify the maintaining function(s) of problem behavior. We conducted four conditions: attention, escape, play, and tangible. Sessions were 10-min and conditions were presented in a multi-element design. To aid in discrimination between conditions, different therapists wearing different colored shirts were used for each condition.

During the attention condition, the participant was in the room with the therapist and had access to a moderately preferred item (as indicated in the tangible preference assessment). The therapist informed the participant that $\mathrm{s} /$ he had work to do and diverted her/his attention away from the participant. The therapist delivered brief attention only when the participant engaged in problem behavior. This condition tested for behavior maintained by social-positive reinforcement in the form of attention. 
The escape condition consisted of the therapist placing a continuous series of demands on the participant (e.g., complete various chores, put nuts and bolts together). If the participant complied with a demand, the therapist gave brief praise and then presented another demand. If the participant did not comply, the therapist modeled the task and then provided a second opportunity for the participant to complete the task. The therapist continued to present the demand until the participant complied. The therapist delivered a 30-s break (i.e., demand materials were removed) immediately after the participant engaged in problem behavior. This condition tested for behavior maintained by socialnegative reinforcement in the form of escape from demands.

During the play condition, the participant was in a room with the therapist and had continuous access to their most preferred items (as indicated by the tangible preference assessment). Additionally, the therapist provided attention at least once every $30 \mathrm{~s}$ and no demands were placed on the participant. This served as the control condition.

Finally, during the tangible condition, the participant was in the room and the therapist restricted highly preferred materials but kept them within sight. Contingent on problem behavior, the therapist gave the participant $30 \mathrm{~s}$ of access to the preferred items. This condition tested for behavior maintained by social-positive reinforcement in the form of access to preferred items.

\section{Token Economy}

At different points during the parameter sensitivity assessments and relative parameter sensitivity assessment, we began observing both Rufus and Sabrina engage in problem behavior between sessions and during exposure trials. Because both participants 
had multiply controlled problem behavior (i.e., tangible and escape functions), we hypothesized that attending sessions (Sabrina) and being instructed to "pick one" during sessions (Rufus) was evoking problem behavior maintained by escape. We introduced token economies to address the escape functions by reinforcing attending sessions (Sabrina) and complying with instructions to make selections (Rufus). This type of intervention was selected for two reasons. First, token economies could easily be implemented during the tangible parameter sensitivity assessments. Second, we delivered tokens such that reinforcement would not interfere with response allocation during the parameter sensitivity assessments. Tokens were delivered contingent on Sabrina attending sessions or Rufus making a selection when instructed, regardless of the actual selections made during the assessments. This allowed us to delay when back-up reinforcement was delivered for compliance (Carr, Frazier, \& Roland, 2005), such that we did not adventitiously reinforce participants' response allocation during the parameter sensitivity assessments.

We introduced a token economy with Rufus during the immediacy sensitivity assessment. Rufus did not have previous experience with token economies; thus, brief training was provided. Rufus earned stars contingent on making a selection when instructed to do so. The therapist increased the exchange requirement across sessions until he earned five stars before receiving the backup reinforcer (i.e., an edible reinforcer — ranch flavored chip — that was identified as highly preferred during a pairedstimulus preference assessment). It took six training sessions to establish the token economy. The therapist implemented the token economy for the remainder of the immediacy sensitivity assessment and the tracking test (both described below). 
We introduced a token economy with Sabrina during the relative parameter sensitivity assessment when immediacy was tested against quality. Sabrina had prior experience with token economies; thus, rather than providing training, the therapist described the contingency at the beginning of each appointment. Sabrina earned a happy face for each hour she worked with the therapist, regardless of the selections she made during the assessments. When she had five happy faces (earned across multiple days), the primary therapist took her to the campus food court where Sabrina could choose to purchase one item that cost less than three dollars. Sabrina consistently selected fruit smoothies as her reinforcer. The therapist implemented the token economy for the remainder of the relative parameter sensitivity assessment (immediacy vs. quality and magnitude vs. quality).

\section{Parameter Sensitivity Assessments}

The purpose of the parameter sensitivity assessments was to use arbitrary responses to determine whether each participant was sensitive to quality, magnitude, and immediacy when reinforcers that maintain problem behavior were used. We used arbitrary responses to decrease the likelihood of the participants engaging in problem behavior during the assessment. Both Rufus and Sabrina had problem behavior maintained by social-positive reinforcement in the form of access to tangibles (as well as social negative reinforcement in the form of escape); we assessed their sensitivity to parameters of reinforcement using tangible items. Table 2 contains a summary of the values used for each of the parameter sensitivity assessments. 
Materials. Each participant had a set of switches that served as the initial links during the parameter sensitivity assessments. For Sabrina, the switches were colored touch-lights (2.5-inch diameter plastic light that illuminates when pushed) that we placed on top of 3.5-inch cards that corresponded in color. We used the same colored cards as the switches for Rufus; however the touch-light was removed to make his selections easier. Different colored switches were used for each assessment. The highest preferred (iPad for both Rufus and Sabrina) and lowest preferred (cards for Rufus and magazine for Sabrina) items were used during the parameter sensitivity assessments.

Design. The parameter sensitivity assessments consisted of manipulating the different parameters by giving the participants an opportunity to choose between two consequences by selecting one of the two concurrently available switches that were associated with the different consequences. Each selection resulted in the participant experiencing the relevant consequence associated with that switch. We used an ABABreversal design to demonstrate experimental control. We reversed the contingencies associated with the concurrently available switches across phases to test whether the participant tracking the preferred contingency across phases. For example, if the purple switch was associated with a high quality reinforcer and the green switch associated with a low quality reinforcer in the first phase, during the subsequent phase, the green switch was associated with the high quality reinforcer and the purple switch was associated with the low quality reinforcer.

Each session consisted of 10 trials in which a therapist presented the participant with the two switches and instructed them to "pick one." Contingent on a selection, the therapist delivered the corresponding consequence. Throughout all parameter sensitivity 
assessments there were no programmed consequences for problem behavior and the therapist honored all bids for attention.

Exposure trials. Prior to each phase of the parameter sensitivity assessments, we conducted six exposure trials (three per switch). Each exposure trial consisted of the relevant antecedents for problem behavior (per the functional analysis results; preferred items were restricted) and a prompt to touch one of the switches. The therapist then delivered the relevant consequence associated with that switch (e.g., 15-s access vs. 90-s access). Sessions within a phase sometimes took place across multiple days; therefore, therapists conducted two exposure trials (one for each switch) prior to the first session of the day to ensure that the participant was familiar with the available contingencies.

Quality sensitivity assessment. The purpose of the quality sensitivity assessment was to demonstrate sensitivity to quality of reinforcement. Thus, we made a high quality reinforcer (i.e., highly preferred item) and a low quality reinforcer (i.e., low-preferred item) available. The high quality stimulus was defined as a stimulus selected more than $80 \%$ of trials in the tangible preference assessment (Koehler, Iwata, Roscoe, Rolider, \& O’Steen, 2005). For both Rufus and Sabrina, we used the iPad as the high quality reinforcer. Rufus watched a variety of children's television shows on the iPad and Sabrina played various games and watched movies. The low quality stimulus was defined as a stimulus that was selected between 10 and $30 \%$ of trials during the tangible preference assessment (Koehler et al., 2005). We hypothesized that stimuli that fell within this range would still function as a reinforcer despite being identified as low preferred (Roscoe, Iwata, \& Kahng, 1999). The low quality items for Rufus were the Sesame Street picture cards and for Sabrina it was the home and garden magazine. 
During the quality sensitivity assessment, either the high quality or low quality item was delivered contingent on the switch selected. We kept magnitude and immediacy constant; that is, therapists delivered both items immediately after each selection and participants had $30 \mathrm{~s}$ of access.

Magnitude sensitivity assessment. The purpose of the magnitude sensitivity assessment was to evaluate sensitivity to changes in reinforcer magnitude (i.e., duration of access to reinforcer). We set the values used in the magnitude sensitivity assessment based on values used in Vollmer and Athens (2010). Vollmer and Athens used a 1:6 ratio in setting magnitude values; thus, the low magnitude used in this study was $15 \mathrm{~s}$ access and the high magnitude was 90 -s access. For Rufus, we doubled the high magnitude to $180 \mathrm{~s}$ (a 1:12 ratio) after not observing sensitivity to the high magnitude when it was set at $90 \mathrm{~s}$.

During the magnitude sensitivity assessment, therapists delivered either the high magnitude or low magnitude consequence contingent on the switch selected. We kept quality and immediacy constant; that is, both selections resulted in the therapists delivering the highly preferred item immediately. Only the duration of access varied across selections.

Immediacy sensitivity assessment. The purpose of the immediacy sensitivity assessment was to test for sensitivity to immediacy of reinforcement. The immediate value was a 0 -s delay. We set the delayed value for each participant by calculating their median IRT for problem behavior during the functional analysis and multiplying it by two. This resulted in a delayed value of $10 \mathrm{~s}$ for Rufus and 4 min $40 \mathrm{~s}$ for Sabrina. We 
doubled the delay for Rufus to $20 \mathrm{~s}$ (4 times the median IRT) after we did not observe sensitivity to immediacy.

During the immediacy sensitivity assessment, therapists either delivered reinforcement immediately or delayed contingent on the switch selected. We kept quality and magnitude constant; that is, both selections produced the highly preferred item for $30 \mathrm{~s}$.

Tracking test. Due to Rufus' insensitivity to magnitude and immediacy (described in results section), we conducted a tracking test to assess side and colors bias that might have overridden the effects of manipulating these parameters. Using the same colors used in the immediacy sensitivity assessment, we tested immediacy against quality (a parameter for which Rufus is sensitive). One switch was associated with the low quality item delivered immediately and the other switch was associated with the high quality item delivered after a 20 s delay. We used an ABA-reversal design to demonstrate that he tracked contingencies when a parameter for which he is sensitive is manipulated.

\section{Relative Parameter Sensitivity Assessment}

The purpose of the relative sensitivity assessment was to determine if the participants are more or less sensitive to each parameter of reinforcement when they are sensitive to more than one parameter. We used the same materials as those used in the individual parameter sensitivity assessments and presented them in the same concurrent arrangement. We conducted sessions using an ABAB-reversal design as in the individual parameter sensitivity assessments, reversing the consequences associated with 
the switches across phases. We conducted sessions similarly to the individual parameter sensitivity assessments, including the exposure trials. Each session consisted of 10 trials in which the therapist presented the participant with the two switches and instructed to "pick one" (initial links). Contingent on a selection, the therapist delivered the corresponding consequence (terminal links). There were no programmed consequences for problem behavior and the therapist honored all bids for attention. Table 3 contains a summary of the values used for the relative parameter sensitivity assessment.

We conducted this assessment only for Sabrina because the results of the individual parameter sensitivity assessments indicated she was sensitive to all three parameters. Rufus was only sensitive to quality of reinforcement; therefore, the relative parameter assessment was not conducted because the purpose was to find relative preference to identify the parameter for which participants are most sensitive.

Magnitude versus immediacy. The purpose of this assessment was to determine whether Sabrina was more sensitive to magnitude or immediacy of reinforcement (given the particular values tested). The two consequences we evaluated in this assessment were low-magnitude reinforcement delivered immediately and high-magnitude reinforcement delivered after a delay. We used values for magnitude and immediacy identical to those used in the magnitude immediacy parameter sensitivity assessments. We kept quality consistent across both options; that is, both choices resulted in Sabrina receiving the iPad . Thus, one switch was associated with immediately receiving the iPad for $15 \mathrm{~s}$ and one switch was associated with receiving the iPad for $90 \mathrm{~s}$ after a 4-min and 40-s delay.

Immediacy versus quality. The purpose of this assessment was to determine whether Sabrina was more sensitive to immediacy or quality of reinforcement. The two 
consequences we evaluated in this assessment were low quality reinforcement delivered immediately and high quality reinforcement delivered after a delay. We used the same items and values for immediacy as those used in the quality and immediacy parameter sensitivity assessments. We kept magnitude consistent across both options; that is, both choices resulted in Sabrina having access to the reinforcer for $30 \mathrm{~s}$. One switch was associated with receiving the magazine (low quality) immediately and the other switch was associated with receiving the iPad (high quality) after a 4- min 40-s delay.

Magnitude versus quality. The purpose of this assessment was to determine whether Sabrina was more sensitive to magnitude or quality. In this assessment, we compared high magnitude of a low quality reinforcer to low magnitude of a high quality reinforcer. We used the same items and values for magnitude as to those used in the quality and magnitude parameter sensitivity assessments. We kept immediacy consistent across both options; that is, the therapist delivered both consequences immediately after Sabrina made a selection. One switch was associated with 90 -s access to the magazine and the other switch was associated with 15-s access to the iPad.

\section{Intervention: DRA without Extinction}

In all previous parts of this study, we assessed sensitivity to parameters of reinforcement using arbitrary responses. This portion of the study was intended to determine whether the results of the sensitivity assessments can inform the design of an intervention to reduce problem behavior. The purpose of this phase was to determine whether a DRA without extinction procedure that uses parameters for which the 
participants are most sensitive is more effective than a DRA without extinction procedure that uses parameters for which the participants are less sensitive. If the effectiveness of the intervention varies based on the parameter manipulated, it would provide support for evaluating individual sensitivities to parameters of reinforcement when implementing DRA without extinction. This may increase the overall effectiveness of the intervention and promote long-term behavior change because it would require fewer treatment components (e.g., multiple parameter manipulations).

We found both Rufus and Sabrina to be most sensitive to quality of reinforcement. We found Sabrina to be least sensitive to magnitude of reinforcement. Rufus was insensitive to both magnitude and immediacy of reinforcement; however, there was less variability in data during the magnitude parameter sensitivity assessment, suggesting he may be slightly less sensitive to magnitude. Therefore, we manipulated magnitude as the parameter for which Rufus is least sensitive.

Materials. We again used the high quality and low quality tangible items during the intervention. We also included additional preferred items (i.e., nesting blocks and sight-and-see puzzle) for Rufus to decrease potential satiation with the iPad. Also, a 3.5inch response card lined in bright yellow that said, "Share with me," was available for Rufus to use as an alternative response to problem behavior.

Design. We used a multiple baseline, ABC-design across the two participants to determine the effectiveness of magnitude manipulations and quality manipulations in treating problem behavior. In all phases, we programmed reinforcement for both problem behavior and alternative behavior; however, the parameters of reinforcement varied across phases. Sessions were $10 \mathrm{~min}$. 
Baseline. We used baseline procedure similar to those used in Vollmer and Athens (2010). Problem behavior and alternative behavior both resulted in both high quality and high magnitude reinforcement; that is, the programmed consequence for problem behavior and alternative behavior was 90 -s access to the iPad for both Sabrina and Rufus.

Magnitude manipulation. During the magnitude manipulation, reinforcement favored the alternative behavior; that is, therapists delivered high magnitude of reinforcement (i.e., $90 \mathrm{~s}$ ) contingent on alternative behavior and low magnitude of reinforcement (i.e., $15 \mathrm{~s}$ ) contingent on problem behavior. We kept immediacy of reinforcement constant, such that therapists always delivered reinforcement immediately. We also kept quality of reinforcement consistent for both problem behavior and alternative behavior; however, we used low quality items to assess the effectiveness of the magnitude manipulation because using high quality reinforcers (a parameter both participants were sensitive to) would likely overshadow the effect of magnitude because both behaviors would produce high quality reinforcement. .

Quality manipulation. The quality manipulation consisted of favoring alternative behavior using the parameter the participants were most sensitive. The programmed consequence for alternative behavior was access to a high quality reinforcer. The programmed consequence for problem behavior was access to a low quality reinforcer. We kept magnitude and immediacy consistent; that is, therapists delivered reinforcers immediately and participants had access for $30 \mathrm{~s}$. 


\section{CHAPTER III}

\section{RESULTS}

\section{Preference Assessments}

The results of the tangible preference assessments are depicted in Figure 4. The paired-stimulus preference assessment suggested that Rufus' most preferred items are the iPad and portable radio. We identified the book as moderately preferred and the Sesame Street picture cards as low preferred. The MSWO preference assessment identified the iPad as Sabrina's most preferred item. We identified the portable radio as a moderately preferred item and the magazine was identified as a low-preferred item.

The results of the attention preference assessment are depicted in Figure 5. The results of the attention preference assessment identified pats on the back as Rufus' highest preferred form of attention. His lowest preferred form of attention was the verbal reprimand. During the tracking test, Rufus initially tracked the therapist; however, after additional sessions, he began tracking the form of attention. This suggests that Rufus prefers pats on the back regardless of therapist. Sabrina's highest preferred form of attention was talking about pets. Similarly, her lowest preferred form of attention was the verbal reprimand, which she never selected. During the tracking test, Sabrina immediately tracked the form of attention.

\section{Functional Analyses}

The results of the functional analyses are depicted in Figure 6. For Rufus, elevated levels of problem behavior were observed in the escape and tangible conditions. 
Problem behavior was not observed in the attention or play conditions. These results suggest that Rufus' problem behavior is maintained by social negative reinforcement in the form of escape from demands and social positive reinforcement in the form of access to tangible items. Similar patterns of responding were observed during Sabrina's functional analysis: elevated levels of problem behavior were observed during the escape and tangible conditions; problem behavior was not observed during the attention and play conditions. The results indicate that Sabrina's problem behavior is maintained by social negative reinforcement in the form of escape from demands and social positive reinforcement in the form of access to tangibles.

Sensitivity to parameters of reinforcement was evaluated only for the tangible functions; however, token economies were introduced for both participants to address the escape functions such that they would not interfere with conducting sessions. By delivered reinforcement contingent on making selections (Rufus) or attending sessions (Sabrina), we were able to increase compliance throughout sessions.

\section{Parameter Sensitivity Assessments}

\section{Rufus}

When sensitivity to quality was assessed, Rufus consistently selected the switch associated with the high quality item (Figure 7). Additionally, he tracked the contingencies across the phases, with the exception of one session. In session 7 , he selected the switch associated with the low-quality item more than the switch associated with the high-quality item. His response allocation, however, returned to the option that 
produced the high quality item for the remainder of sessions. These data suggest that Rufus is sensitive to quality as a parameter of reinforcement.

Data were less consistent during the magnitude and immediacy parameter sensitivity assessments. During the magnitude sensitivity assessment (Figure 8), Rufus alternated between the high magnitude and low magnitude throughout the first phase. At session 7, we increased the high magnitude value to $180 \mathrm{~s}$; however, Rufus continued to allocate more responding to the low magnitude option. We did not observe sensitivity to the higher magnitude value and, therefore, returned the high magnitude value to the original value (i.e., $90 \mathrm{~s}$ ) when the next phase was introduced to avoid having unnecessarily long session durations. When we switched the contingencies across phases, Rufus continued to allocate his responding to the pink switch, regardless of the contingency associated with it. The results of this assessment indicate that Rufus is not sensitive to magnitude at these values ( $15 \mathrm{~s}$ vs. $90 \mathrm{~s})$.

The results of Rufus' immediacy sensitivity assessment are depicted in Figure 9. In the first phase of the assessment, Rufus initially alternated between the immediate and delayed options. In session 2 , Rufus requested that the switch on the left (the red card) be moved closer to his dominant hand (right hand). In session 3, the therapist shifted both switches to the right so that both were to the right of his midline but equal distance from his resting, right hand. The therapist presented the switches in this position for the remainder of the immediacy sensitivity assessment. Sessions 3-5, Rufus allocated almost all of his responses to the switch associated with immediate reinforcement (the red card). In the second phase, Rufus continued to select the red card that was now associated with the delayed consequence. The therapist introduced the token economy with Rufus at 
session 11 when we saw an increase in problem behavior between sessions and during exposure trials. The token economy did not affect his response allocation, as he continued to select the switch associated with the delayed consequence more frequently. At session 14, we increased the delay to 20 s. During that session, Rufus allocated more responding to the switch associated with the immediate consequence; however this did not persist. Rufus continued to allocate responding during the second phase to the switch associated with the delayed consequence. In the last two phases of the assessment, Rufus continued to allocate his responses to the switch on the left (the red card), regardless of the contingency associated with it. This suggests that he is insensitive to immediacy as a parameter of reinforcement when these values are used (immediate vs. $20 \mathrm{~s}$ delay).

A tracking test was conducted at this point because this was the second parameter to which we did not observe sensitivity. We wanted to ensure that there were no extraexperimental features that were so powerful that they would override the effects of parameter sensitivity (e.g., side bias, color bias). The results of the tracking test are depicted in Figure 10. During the first phase, Rufus allocated more responding to the switch associated with the high-quality item delivered after a delay. When the therapist switched the contingencies during the second phase, Rufus tracked the contingencies and continued to allocate more responding to the switch associated with the high-quality delayed option. During the final phase, Rufus again tracked the contingencies and selected the option that produced the high-quality delayed option. The results of the tracking test demonstrate that when parameters that Rufus is sensitive to are manipulated, he tracks the contingencies. Additionally, the tracking test confirmed that Rufus was 
more sensitive to quality than immediacy; this confirmed the results of the individual parameter sensitivity assessments.

\section{Sabrina}

The results of Sabrina's quality sensitivity assessment are depicted in Figure 11. Sabrina consistently selected the switch associated with the high-quality item more than the switch associated with the low-quality item. Additionally, she tracked the contingencies across the different phases. These data suggest that Sabrina is sensitive to quality as a parameter of reinforcement.

Similar patterns of responding were observed during the magnitude sensitivity assessment (Figure 12). Sabrina consistently allocated more responding to the option that produced the high-magnitude of reinforcement. Again, she tracked the contingencies across the different phases. These data also suggest that Sabrina is sensitive to magnitude as a parameter of reinforcement.

During the immediacy sensitivity assessment (Figure 13), Sabrina allocated more responding to the option that produced immediate reinforcement. She tracked the contingencies across the different phases. However, higher rates of problem behavior were observed during the third and fourth phase. These data suggest that Sabrina is sensitive to immediacy as a parameter of reinforcement.

\section{Relative Parameter Sensitivity Assessment}

We conducted the relative parameter sensitivity assessment only for Sabrina because she was sensitive to all three parameters of reinforcement. The results of the 
assessment are depicted in Figures 14 through 16. In the first comparison, magnitude was tested against immediacy (Figure 14). Across all phases, Sabrina exclusively selected the switch that was associated with immediate, low-magnitude reinforcement. These data suggest that Sabrina is more sensitive to immediacy than magnitude.

In the second comparison, we tested immediacy against quality (Figure 15). In the first phase, Sabrina allocated more responding to the switch that produced the delayed high-quality reinforcement. There was more variability during the second phase, as Sabrina initially allocated more responding to the option that produced the immediate low-quality reinforcer. At session 10, Sabrina switched to selecting the option that produced delayed high quality reinforcement. The therapist introduced the token economy at the beginning of session 14, after Sabrina began engaging in more problem behavior between sessions and during exposure trials and made statements about choosing the immediate option so that she could go home sooner. After we incorporated the token economy, Sabrina tracked the option that produced the delayed high-quality reinforcement (the third phase). In the final phase, she again allocated more responding to the option that produced delayed high-quality reinforcement, with the exception of session 19. These data suggest that Sabrina is more sensitive to quality than immediacy. In the last comparison, magnitude was tested against quality (Figure 16). In the first three phases, Sabrina consistently selected the switch associated with low-magnitude high-quality reinforcement. In the final phase, she continued to select the switch associated with low-magnitude high-quality reinforcement $60 \%$ of trials. These data suggest that Sabrina is more sensitive to quality over magnitude. 
Together the results of the relative parameter sensitivity assessment suggest that using these specific stimuli (i.e., iPad and magazine), Sabrina is most sensitive to quality, followed by immediacy (in comparison to a 4-min and 40-s delay). Although sensitive, she is least sensitive to magnitude as a parameter of reinforcement at the values tested (i.e., 15-s access vs. 90-s access).

\section{Intervention}

Data for the intervention phase of the study are depicted in Figure 17. When problem behavior and alternative behavior resulted in the same consequences with both magnitude (least sensitivity) and quality (most sensitivity) being manipulated (i.e., resulted in 90-s access to the iPad), we saw increasing trends of problem behavior for both Rufus and Sabrina. During this phase, Rufus engaged an average of 2.1 instances of problem behavior per minute (range of 2.2 to 3.4 ). Sabrina engaged in an average of 0.4 instances of problem behavior per minute (range 0.1 to 0.7 ). We did not observe alternative responses for either Rufus or Sabrina.

During the second phase of the intervention, we manipulated the magnitude of reinforcement to favor the alternative behavior to determine whether manipulating a parameter the participants are least sensitive to in a DRA procedure would be effective. Thus, problem behavior resulted in immediately accessing a low quality item for $15 \mathrm{~s}$ and alternative behavior resulted in immediately accessing a low quality item for $90 \mathrm{~s}$. Initially, Rufus engaged in the alternative behavior at 0.7 responses per minute; however, over subsequent sessions, the rate of alternative behavior decreased to zero. We did not observe any instances of problem behavior. For Sabrina, we initially observed both 
problem behavior and alternative behavior. In session 6, problem behavior and alternative behavior both occurred at 0.1 responses per minute. Rate of alternative behavior increased slightly in session 7; however, it then decreased to zero for the last three sessions of the phase. Problem behavior was not observed during sessions 7-9; however, problem behavior occurred at a rate of 0.2 responses per minute in the final session of the phase. These data suggest that magnitude manipulations that favor alternative behavior were not sufficiently reinforcing to produce and maintain alternative behavior for Rufus and Sabrina.

The final phase of intervention consisted of favoring alternative behavior by manipulating quality (the parameter of greatest sensitivity for both participants). Both Rufus and Sabrina engaged in increasing rates of alternative behavior and we did not observe any instances of problem behavior. Rufus engaged in an average of 0.4 instances of alternative behavior per minute (range 0 to 0.8 ). Sabrina engaged in an average of 1.5 instances of alternative behavior per minute (range 1.3 to 1.6). Thus, for both Rufus and Sabrina, quality manipulations that favored alternative behavior increased rates of alternative behavior.

Collectively, the results of the intervention phase indicate that quality manipulations were more effective than the magnitude manipulations. For both participants, we saw the alternative behavior decrease to zero when magnitude was manipulated; however, we saw increasing trends of alternative behavior with zero instances of problem behavior when quality was manipulated. 


\section{CHAPTER IV}

\section{DISCUSSION}

The results of this study indicate that it may be possible to use arbitrary responses to assess individual sensitivity to different parameters of reinforcement that maintain problem behavior. In addition, when an individual is sensitive to multiple parameters of reinforcement, relative parameter sensitivity can also be determined using arbitrary responses rather than problem behavior. The results of the intervention for both participants validate the results of the parameter sensitivity assessment for Rufus and the relative parameter sensitivity assessment for Sabrina. Moreover, a parameter sensitivity assessment using arbitrary responses may be used to develop effective treatments for problem behavior in which extinction may not be feasible or possible. These results must be taken cautiously, however, until the procedures are implemented with additional participants, including those with problem behavior maintained by attention.

This study extends previous research in a number of ways. First, this study extends the work of Athens and Vollmer (2010) and Neef et al. (1994) by using arbitrary responses and reinforcers that maintain problem behavior to assess sensitivity to parameters of reinforcement for the purpose of developing a treatment for problem behavior. We were not only able to conduct an assessment using arbitrary responses to predict parameter sensitivity when applied to functionally alternative responses for problem behavior, but the results also allowed us to predict which parameter manipulation would likely be ineffective when applied to a treatment for problem behavior. Additionally, our procedures allowed us to minimize the occurrence of 
problem behavior during assessment and potentially increase efficiency of the intervention. This extension may be particularly important for those participants that engage in high severity problem behavior that puts the participant and/or others in danger.

Second, our use of arbitrary responses also made it possible to expose participants to contingencies prior to conducting the sensitivity assessments, something not previously done. In using problem behavior to assess sensitivity to parameters of reinforcement, it is unclear whether the participants in Athens and Vollmer (2010) were exposed to the contingencies as intended because pre-exposures were not possible. This is particularly important for the immediacy parameter sensitivity assessment. Participants may have experienced the delay in reinforcement delivery as extinction rather than as a delayed consequence, potentially resulting in extinction-induced side effects (e.g., high rates of responding). Thus, ensuring that participants are exposed to the different relevant contingencies prior to assessment could more accurately identify sensitivity to immediacy.

Third, we sought to identify one parameter that each participant was most sensitive to so that an intervention could be developed using only one parameter manipulation rather than multiple parameter manipulations as other researchers have done. The results of Rufus' parameter sensitivity assessments indicate that not all individuals will be sensitive to all parameters of reinforcement, particularly when the reinforcer being assessed maintains problem behavior. Thus, it should not be assumed that all individuals will be sensitive to all parameters of reinforcement. We successfully identified the most, or only, influential parameter for both participants and subsequently 
implemented effective treatments. By reducing the number of treatment components to the most important parameter for each participant, it may be possible to increase overall treatment integrity and long-term effectiveness of the intervention. This approach may allow practitioners or other behavior change agents (e.g., parents, teachers) to concentrate their efforts and reduce treatment integrity errors (e.g., not implementing extinction correctly) that could be detrimental to the effectiveness of the intervention. However, there may be cases in which the parameter for which an individual is most sensitive cannot easily be manipulated (e.g., delaying reinforcement for problem behavior). Future researchers may want to investigate the extent to which less sensitive parameters can be manipulated to be effective; that is, can multiple less sensitive parameters be combined in a manipulation to outweigh a parameter for which an individual is very sensitive?

It is possible that had we tested additional magnitude and immediacy values, we may have been able to detect sensitivity for Rufus. For example, basic researchers have assessed sensitivity to immediacy of reinforcement (i.e., impulsivity) by testing a variety of values and determining at exactly what value subjects become indifferent (e.g., Madden \& Johnson, 2010). Procedures such as these could be useful in determining exact values necessary to completely shift response allocation from one option to another; however, doing so would likely to be time consuming and therefore, not feasible for clinicians and practitioners. Additionally, using extreme values for parameters may result in the response being put on extinction; that is, if the delay value is long enough, it can functionally be equivalent to extinction. Although we tested only certain values, it is likely that we can make certain extrapolations beyond the tested values. For example, if 
a participant is sensitive to magnitude when 15-s access and 90-s access are compared, it is likely that they would also be sensitive to larger access durations (e.g., 120-s access) when it is compared 15-s access. We extended previous research by attempting to select values for magnitude and immediacy that were meaningful for the participants instead of using completely arbitrary values. For immediacy values, we extended previous research by selecting values based on individual participant behavior (i.e., IRT). Therefore, we would expect that the delays tested would have been sufficient and any sensitivity to immediacy should have been detected. Similarly, we attempted to choose values for the magnitude assessment that would be detectable and meaningful to the participants but also feasible for implementation. An alternative could be to determine what is feasible for the behavior change agents to implement. Additional research should investigate various methods for efficiently selecting values to be evaluated in the parameter sensitivity assessments.

One potential limitation of this study is that although problem behavior was relatively infrequent for both participants during the parameter sensitivity assessments, all occurrences were ignored while the switch touches were reinforced. During the intervention phase of the study, we re-established baseline rates of problem behavior; however, it is possible that the arrangement used during the parameter sensitivity assessments inadvertently contributed to the rapid reduction of problem behavior during the intervention phase of the study. One potential explanation is problem behavior contacted extinction during the parameter assessments, thus weakening the behavior. Or, it is possible that we established a strong reinforcement history for alternative behavior in general. Additional participants are needed to determine whether such rapid reductions 
are common after being exposed to the parameter sensitivity assessments or if these two participants are unique. If such reductions are common, future research may be useful on whether similar effects are observed when parameter assessments are conducted in a briefer format.

A second limitation is the low rates of problem behavior observed during the intervention parameter manipulations. The purpose of the intervention phase was to evaluate a DRA without extinction procedure using the parameters for which each participant was most and least sensitive. However, Rufus did not engage in problem behavior during the magnitude manipulation phase or the quality manipulation phase; Sabrina also did not engage in problem behavior during the quality manipulation phase. Thus, they did not contact the programmed contingencies for problem behavior in those conditions. Therefore, although procedurally we implemented DRA without extinction, we cannot be certain that reinforcing both problem behavior and alternative behavior but favoring the alternative behavior would be effective in reducing problem behavior. However, it is important to note that manipulating the parameter that the participants were most sensitive to was effective in producing higher rates of alternative behavior for both participants. Thus, we can conclude that manipulating parameters for which participants are most sensitive may be effective in increasing alternative behavior; however, we cannot make strong conclusions about the parameter manipulation effects on problem behavior without additional participants.

Both participants had behavior maintained by social positive reinforcement in the form of access to tangibles as well as social negative reinforcement in the form of escape. It was necessary to address the escape function during the parameter sensitivity 
assessments because participants' attempts to escape from the sessions could have otherwise interfered with the results. The inclusion of token economies sufficiently addressed the escape function for both participants, allowing us to obtain results on parameter sensitivity for tangible items. Of course, the token economy was in place for all conditions once it was introduced; therefore, it cannot directly account for differential results across conditions. However, the extent to which the token economy interacted with the experimental contingencies is unclear. Although we identified the parameters that both participants were most sensitive to and implemented an effective intervention, it is possible that without treating both functions, the parameter manipulations would not be as effective; that is, practitioners are cautioned against treating only one function of problem behavior through parameter manipulations. Additional research is needed on how multiple functions for problem behavior might influence sensitivity to parameters of reinforcement and subsequently influence the effectiveness of an intervention.

Finally, social negative reinforcement was excluded from this investigation because research thus far has not directly manipulated quality in parameter manipulations. For example, Peterson, Frieder, Smith, Quigley, and Van Norman (2009) manipulated quality of demand by providing a break from the demand with high quality (or highly preferred) items. This manipulation more accurately is a way to enrich the break rather than a way to alter the quality of the break. Rather, quality of negative reinforcement varies based on the aversiveness of the demand being escaped (e.g., Knighton, Bloom, \& Clark, 2014). Thus, additional research is needed on quality manipulations for behaviors maintained by social negative reinforcement so that 
procedures, such as those investigated here, can be applied to and evaluated with problem behavior with various functions.

It is important to emphasize that the current investigation only included two adult participants. The results of the study suggest that the methods used are promising for determining parameter sensitivity for the purpose of designing a treatment for problem behavior; however, they must be replicated with additional participants before strong conclusions can be drawn about both internal and external validity. The participants that took part in this study were both adults, with behavior maintained by social positive and social negative reinforcement. The target behaviors for which they were referred were relatively low severity and therefore may be feasible to place on extinction if those implementing the intervention could do so consistently. It is possible that individuals with more severe topographies of problem behavior would engage in more problem behavior during the parameter sensitivity assessments. This could be problematic if problem behavior interferes with the assessment being conducted. The assessments, however, were designed to always have an option available that provides a favorable outcome, decreasing the need to engage in problem behavior once the selection response (i.e., touching the switch) has been acquired. Nonetheless, additional research should be done to expand the populations for which this assessment procedure has been evaluated.

The use of parameter manipulations to implement a DRA without extinction procedures is still relatively new and additional research is needed to determine the most efficient and effective procedures to determine how best to manipulate parameters. Finetuning these procedures may provide practitioners with additional options for addressing problem behavior when extinction is not a feasible treatment component. Additionally, 
continued research in this area may provide practitioners with more flexibility in designing interventions that can be implemented with high treatment integrity and subsequently result in long-term behavior change.

In addition to the areas for potential research mentioned above, the most crucial first step in developing this line of research is to further evaluate the reliability of the parameter sensitivity assessments with different populations. Specifically, it is most important to first evaluate these procedures with participants that have problem behavior with different functions. First, more research is needed with participants that have behavior maintained by a single social positive function to demonstrate clearly the effectiveness of the procedures in identifying parameter sensitivity that can be applied to an intervention. Once sufficient data has been obtained indicating the utility of the parameter sensitivity assessments with individuals that have behavior maintained by social positive reinforcement, studies should be conducted to determine whether the procedures are effective in evaluating parameter sensitivity for behaviors maintained by social negative reinforcement. Finally, additional research will be needed on evaluating parameter sensitivity for multiply maintained behaviors. In the current study, we used token economies to address escape functions while assessing parameter sensitivity for tangible reinforcers; however, it may be necessary to evaluate parameter sensitivity for both functions to develop a comprehensive intervention. If these steps have not included a variety of participants (e.g., age, diagnosis), additional research should be conducted to determine which individuals benefit from these types of assessments.

As research continues to establish the reliability of the parameter sensitivity assessments for different functions, researchers may begin to refine the procedures so that 
they are feasible and realistic for practitioners to conduct. The participants for this study were seen two to three times per week for up to 2 hours per visit and data were collected over the span of 6 months. Although sessions were occasionally cancelled for holidays or participant illness and experimental rigor was needed for the purpose of this study, it was lengthy and would not be feasible to implement clinically. Thus, if the procedures are found to be reliable in identifying sensitivity to parameters of reinforcement such that an effective treatment can be implemented, then additional work is needed to make the procedures more efficient. It may be possible to conduct briefer assessments without decreasing the reliability of the assessments, and doing so, may increase the likelihood that practitioners will utilize the procedures.

Finally, one of the primary goals of using individual parameter sensitivity to develop treatments is to potentially increase treatment integrity by eliminating the need for extinction procedures. Thus, future research should assess caregiver treatment integrity and social validity of treatments that use parameter manipulations. If treatment integrity decreases over time or data indicate that social validity is not high, additional research should investigate how to improve these measures. Ultimately, the validity of these procedures will be seen in the degree to which it can be used to develop effective interventions and the extent to which those interventions can be implemented with integrity to produce long-term behavior change. 


\section{REFERENCES}

Arndorfer, R. E., \& Miltenberger, R. G. (1993). Functional assessment and treatment of challenging behavior: A review with implications for early childhood. Topics in Early Childhood Special Education, 13, 82-105. doi:

$10.177 / 027112149301300109$

Athens, E. S., \& Vollmer, T. R. (2010). An investigation of differential reinforcement of alternative behavior without extinction. Journal of Applied Behavior Analysis, 43, 569-589. doi: 10.1901/jaba.2010.43-569

Axelrod, S. (1987). Functional and structural analyses of behavior: approaches leading to reduced use of punishment procedures? Research in Developmental Disabilities, 8, 165-178. doi: 10.1016/0891-4222(87)90001-1

Bijou, S. W., Peterson, R. F., \& Ault, A. H. (1968). A method to integrate descriptive and experimental field studies at the level of data and empirical concepts. Journal of Applied Behavior Analysis, 1, 175-191. doi: 10.1901/jaba.1968.1-175

Bloom, S. E., Iwata, B. A., Fritz, J. N., Roscoe, E. M., \& Carreau, A. B. (2011). Classroom application of trial-based functional analysis. Journal of Applied Behavior Analysis,44, 19-31. doi: 10.1901/jaba.2011.44-19

Borrero, C. S. W., Vollmer, T. R., Borrero, J. C., \& Bourret, J. (2005). A method for evaluating parameters of reinforcement during parent-child interactions. Research in Developmental Disabilities, 26, 577-592. doi: 10.1016/j.ridd.2004.11.010

Brown, K. A., Wacker, D. P., Derby, K. M., Peck, S. M., Richman, D. M., Sasso, G. M.,...Harding, J. W. (2000). Evaluating the effects of functional communication 
training in the presence and absence of establishing operations. Journal of Applied Behavior Analysis, 33, 53-71. doi: 10.1901/jaba.2000.33-53

Buckley, S. D., \& Newchok, D. K. (2006). Analysis and treatment of problem behavior evoked by music. Journal of Applied Behavior Analysis, 39, 141-144. doi: 10.1901/jaba.2006.39-141

Campbell, J. M. (2003). Efficacy of behavioral interventions for reducing problem behavior in persons with autism: a quantitative synthesis of single-subject research. Research in Developmental Disabilities, 24, 120-138. doi:

$10.1016 / \mathrm{S} 0891-4222(03) 00014-3$

Carr, E. G. (1977). The motivation of self-injurious behavior: A review of some hypotheses. Psychological Bulletin, 84, 800-816. doi: 10.1037/00332909.84.4.800

Carr, E. G., \& Durand, V. M. (1985). Reducing behavior problems through functional communication training. Journal of Applied Behavior Analysis, 18, 111-126. doi: 10.1901/jaba.1985.18-111

Carr, J. E., Frazier, T. J., \& Roland, J. P. (2005). Token economy. In A. M. Gross \& R. S. Drabman (Eds.), Encyclopedia of behavior modification and cognitive behavior therapy - Volume 2: Child clinical applications (pp. 1075-1079). Thousand Oaks, CA: Sage.

Clay, C. J., Samaha, A. L., Bloom, S. E., Bogoev, B. K., \& Boyle, M. A. (2013). Assessing preference for social interactions. Research in Developmental Disabilities, 34, 362-371. doi: 10.1016/j.ridd.2012.07.028 
DeLeon, I. G., \& Iwata, B. A. (1996). Evaluation of a multiple-stimulus presentation format for assessing reinforcer preferences. Journal of Applied Behavior Analysis, 29, 519-533. doi: 10.1901/jaba.1996.29-519

Didden, R., Korzilius, H., van Oorsouw, W., \& Sturmey, P. (2006). Behavioral treatment of challenging behaviors in individuals with mild mental retardation: Metaanalysis of single-subject research. American Journal on Mental Retardation, 111, 290-298. doi: 10.1352/0895-8017(2006)111[290:BTOCBI]2.0CO;2

Dorsey, M. F., Iwata, B. A., Ong, P., \& McSween, T. E. (1980). Treatment of selfinjurious behavior using a water mist: Initial response suppression and generalization. Journal of Applied Behavior Analysis, 13, 343-353. doi: 10.1901/jaba.1980.13-343

Dube, W. V., \& Mcllvane, W. J. (2002). Quantitative assessments of sensitivity to reinforcement contingencies in mental retardation. American Journal on Mental Retardation, 107, 136-145.

Durand, V. M., \& Carr, E. G. (1992). An analysis of maintenance following functional communication training. Journal of Applied Behavior Analysis, 25, 777-794. doi: 10.1901/jaba.1992.25-777

Falcomata, T. S., Roane, H. S., Feeney, B. J., \& Stephenson, K. M. (2010). Assessment and treatment of elopement maintained by access to stereotypy. Journal of Applied Behavior Analysis, 43, 513-517. doi: 10.1901/jaba.2010.43-513

Favell, J. E., McGimsey, J. F., \& Schell, R. M. (1982). Treatment of self-injury by providing alternate sensory activities. Analysis and Intervention in Developmental Disabilities, 2, 83-104. doi: 10.1016/0270-4684(82)90007-6 
Ferster, C. B. (1961). Positive reinforcement and behavioral deficits of autistic children. Child Development, 32, 437-456.

Ferster, C. B., \& Skinner, B. F. (1957). Schedules of reinforcement. New York, NY: Appleton-Century-Crofts.

Fisher, W. W., Lindlauer, S. E., Alterson, C. J., \& Thompson, R. H. (1998). Assessment and treatment of destructive behavior maintained by stereotypic object manipulation. Journal of Applied Behavior Analysis, 31, 513-527. doi: 10.1901/jaba.1998.31-513

Fisher, W., Piazza, C. C., Bowman, L. G., Hagopian, L. P., Owens, J. C., \& Slevin, I. (1992). A comparison of two approaches for identifying reinforcers for persons with severe and profound disabilities. Journal of Applied Behavior Analysis, 25, 491-498. doi: 10.1901/jaba.1992.25-491

Fyffe, C. E., Kahng, S., Fittro, E., \& Russell, D. (2004). Functional analysis and treatment of inappropriate sexual behavior. Journal of Applied Behavior Analysis, 37, 401-404. doi: 10/1901/jaba.2004.37-401

Goh, H., Iwata, B. A., \& DeLeon, I. G. (2000). Competition between noncontingent and contingent reinforcement schedules during response acquisition. Journal of Applied Behavior Analysis, 33, 195-205. doi: 10.1901/jaba.2000.33-195

Goh, H., Iwata, B. A., \& Kahng, S. (1999). Multicomponent assessment and treatment of cigarette pica. Journal of Applied Behavior Analysis, 32, 297-316. doi: $10.1901 /$ jaba.1999.32-297

Hagopian, L. P., Fisher, W. W., Sullivan, M. T., Acquisto, J., \& LeBlanc, L. A. (1998). Effectiveness of functional communication training with and without extinction 
and punishment: a summary of 21 inpatient cases. Journal of Applied Behavior Analysis, 31, 211-235. doi: 10.1901/jaba.1998.31-211

Hanley, G. P. (2012). Assessment of problem behavior: Dispelling myths, implementing obstacles, and developing new lore. Behavior Analysis in Practice, 5, 54-72.

Hanley, G. P., Iwata, B. A., \& McCord, B. E. (2003). Functional analysis of problem behavior: A review. Journal of Applied Behavior Analysis, 36, 147-185. doi: 10.1901/jaba.2003.36-147

Hanley, G. P., Piazza, C. C., Fisher, W. W., \& Maglieri, K. A. (2005). On the effectiveness of and preference for punishment and extinction components of function-based interventions. Journal of Applied Behavior Analysis, 38, 51-65. doi: 10.1901/jaba.2005.38-51

Herrnstein, R. J. (1970). On the law of effect. Journal of the Experimental Analysis of Behavior, 13, 243-266. doi:10.1901/jeab.1970.13-243

Herzinger, C. V., \& Campbell, J. M. (2007). Comparing functional assessment methodologies: A quantitative synthesis. Journal of Autism and Developmental Disorders, 37, 1430-1445. doi: 10.1007/s10803-006-0219-6

Hoch, H., McComas, J. J., Thompson, A. L., \& Paone, D. (2002). Concurrent reinforcement schedules: behavior change and maintenance without extinction. Journal of Applied Behavior Analysis, 35, 155-169. doi: 10.1901/jaba.2002.35155

Horner, R. H., \& Day, H. M. (1991). The effects of response efficiency on functionally equivalent competing behaviors. Journal of Applied Behavior Analysis, 24, 719732. doi: 10.1901/jaba.1991.24-719 
Horner, R. H., \& Carr, E. G. (1997). Behavioral support for students with severe disabilities: Functional assessment and comprehensive intervention. Journal of Special Education, 31 , 84-104. doi: 10.1177/002246699703100108

Iwata, B. A. (1988). The development and adoption of controversial default technologies. The Behavior Analyst, 11, 149-157.

Iwata, B. A., DeLeon, I. G., \& Roscoe, E. M. (2013). Reliability and validity of the functional analysis screening tool. Journal of Applied Behavior Analysis, 46, 271284. doi: $10.1002 /$ jaba.31

Iwata, B. A., Dorsey, K. F., Slifer, K. J., Bauman, K. J., \& Richman, G. S. (1982/1994). Toward a functional analysis of self-injury. Journal of Applied Behavior Analysis, 27, 197-209. doi: 10.1901/jaba.1994.27-197

Iwata, B. A., \& Dozier, C. L. (2008). Clinical application of functional analysis methodology. Behavior Analysis in Practice, 1, 3-9.

Iwata, B. A., Pace, G. M., Dorsey, M. F., Zarcone, J. R., Vollmer, T. R., Smith, R. G., ...Willis, K. D. (1994). The functions of self-injurious behavior: an experimentalepidemiological analysis. Journal of Applied Behavior Analysis, 27, 215-240. doi: 10.1901/jaba.1994.27-215

Kahng, S., Boscoe, J. H., \& Byrne, S. (2003). The use of an escape contingency and a token economy to increase food acceptance. Journal of Applied Behavior Analysis, 36, 349-353. doi: 10.1901/jaba.2003.36-349

Kahng, S., Tarbox, J., \& Wilke, A. E. (2001). Use of a multicomponent treatment for food refusal. Journal of Applied Behavior Analysis, 34, 93-96. doi: 10.1901/jaba.2001.34-93 
Kelley, M. E., Lerman, D. C., \& Van Camp, C. M. (2002). The effects of competing reinforcement schedules on the acquisition of functional communication. Journal of Applied Behavior Analysis, 35, 59-63. doi: 10.1901/jaba.2002.35-59

Knighton, R., Bloom, S. E., \& Clark, D. (2014). The use of progressive-ratio schedules to assess negative reinforcers. Manuscript in preparation.

Koehler, L. J., Iwata, B. A., Roscoe, E. M., Rolider, N. U., \& O’Steen, L. E. (2005). Effects of stimulus variation on the reinforcing capability of nonpreferred stimuli. Journal of Applied Behavior Analysis, 38, 469-484. doi: 10.1091/jaba.2005.38469

LeGray, M. W., Dufrene, B. A., Sterling-Turner, H., Olmi, D. J., \& Bellone, K. (2010). A comparison of function-based differential reinforcement interventions for children engaging in disruptive classroom behavior. Journal of Behavioral Education, 19, 185-204. doi: 10.1007/s10864-010-9109-2

Lennox, D., \& Miltenberger, R. (1989). Conducting a functional assessment of problem behavior in applied settings. Journal of the Association for Persons with Severe Handicaps, 14, 304-311.

Lennox, D. B., Miltenberger, R. G., Spengler, P., \& Erfanian, N. (1988). Decelerative treatment practices with persons who have mental retardation: A review of five years of the literature. American Journal on Mental Retardation, 92, 492-501.

Mace, F. C. (1994). The significance and future of functional analysis methodology. Journal of Applied Behavior Analysis, 27, 385-392. doi: 10.1901/jaba.1994.27385 
Mace, F. C., Neef, N. A., Shade, D., \& Mauro, B. C. (1996). Effects of problem difficulty and reinforcer quality on time allocated to concurrent arithmetic problems. Journal of Applied Behavior Analysis, 29, 11-24. doi:

10.1901/jaba.1996.29-11

Madden, G. J., \& Johnson, P. S. (2010). A delay-discounting primer. In: G. J Madden, \& W. K. Bickel (Eds.), Impulsivity: The behavioral and neurological science of discounting (pp. 11-37). Washington, DC: American Psychological Association.

Marcus, B. A. \& Vollmer, T. R. (1996). Combining noncontingent reinforcement and differential reinforcement schedules as treatment for aberrant behavior. Journal of Applied Behavior Analysis, 29, 43-51. doi: 10.1901/jaba.1996.29-43

Matson, J. L., \& Vollmer, T. (1995) Questions about behavioral function (QABF). Baton Rouge, LA: Disability Consultants.

McComas, J. J., Hartman, E. C., \& Jimenez, A. (2008). Some effects of magnitude of reinforcement on persistence of responding. The Psychological Record, 58, $517-$ 528.

Murdock, S. G., O’Neil, R. E., \& Cunningham, E. (2005). A comparison of results and acceptability of functional behavioral assessment procedures with a group of middle school students with emotional/behavioral disorders (E/BD). Journal of Behavioral Education, 14, 5-18. doi: 10.1007/s10864-005-0958z

Neef, N. A., Bicard, D. F., \& Endo, S. (2001). Assessment of impulsivity and the development of self-control in students with attention deficit hyperactivity disorder. Journal of Applied Behavior Analysis, 34, 397-408. doi: 10.1901/jaba.2001.34-397 
Neef, N. A., Bicard, D. F., Endo, S., Coury, D. L., \& Aman, M. G. (2005). Evaluation of pharmacological treatment of impulsivity in children with attention deficit hyperactivity disorder. Journal of Applied Behavior Analysis, 38, 135-146. doi: 10.1901/jaba.2005.116-02

Neef, N. A., \& Lutz, M. N. (2001a) A brief computer-based assessment of reinforcer dimensions affecting choice. Journal of Applied Behavior Analysis, 34, 57-60. doi: $10.1901 /$ jaba.2001.34-57

Neef, N. A., \& Lutz, M. N. (2001b). Assessment of variables affecting choice and application to classroom interventions. School Psychology, Quarterly, 16, 239252. doi: $10.1521 /$ scpq.16.3.239.19887

Neef, N. A., Mace, F. C., \& Shade, D. (1993). Impulsivity in students with serious emotional disturbance: The interactive effects of reinforcer rate, delay, and quality. Journal of Applied Behavior Analysis, 26, 37-52. doi: 10.1901/jaba.1993.26-37

Neef, N. A., Mace, F. C., Shea, M. C, \& Shade, D. (1992). Effects of reinforcer rate and reinforcer quality on time allocation: Extensions of matching theory to educational settings. Journal of Applied Behavior Analysis, 25, 691-699. doi: 10.1901/jaba.1992.25-691

Neef, N. A., Marckel, J., Ferreri, S. J., Bicard, D. F., Endo, S., Aman, M. G., ...Armstrong, N. (2005). Behavioral assessment of impulsivity: A comparison of children with and without attention deficit hyperactivity disorder. Journal of Applied Behavior Analysis, 38, 23-37. doi: 10.1901/jaba.2005.38-23 
Neef, N.A., Shade, D., \& Miller, M. S. (1994). Assessing influential dimensions of reinforcers on choice in students with serious emotional disturbance. Journal of Applied Behavior Analysis, 27, 575-583. doi: 10.1901/jaba.1994.27-575

Northup, J., Wacker, D., Sasso, G., Steege, M., Cigrand, K., Cook, J., \& DeRaad, A. (1991). A brief functional analysis of aggressive and alternative behavior in an outclinic setting. Journal of Applied Behavior Analysis, 24, 509-522. doi: 10.1901/jaba.1991.24-509

O’Neill, R. E., Horner, R. H., Albin, R. W., Storey, K., \& Sprague, J. R. (1990). Functional analysis of problem behavior: A practical assessment guide. Sycamore, IL: Sycamore.

Odum, A. L. (2011). Delay discounting: I'm a k, you're a k. Journal of the Experimental Analysis of Behavior, 96, 427-439. doi: 10.1901/jeab.2011.96-423

Perrin, C. J., \& Neef, N. A. (2012). Further analysis of variables that affect self-control with aversive events. Journal of Applied Behavior Analysis, 45, 299-313. doi: 10.1901/jaba.2012.45-299

Peterson, S. M., Frieder, J. E., Smith, S. S., Quigley, S. P., \& Van Norman, R. K. (2009). The effects of varying quality and duration of reinforcement on mands to work, mands for break, and problem behavior. Education and Treatment of Children, 32, 605-630. doi: 10.1353/etc.0.0075

Petscher, E. S., Rey, C., \& Bailey, J. S. (2009). A review of empirical support for differential reinforcement of alternative behavior. Research in Developmental Disabilities, 30, 409-425. doi: 10.1016/j.ridd.2008.08.008 
Piazza, C. C., Moes, D. R., \& Fisher, W. W. (1996). Differential reinforcement of alternative behavior and demand fading in the treatment of escape-maintained destructive behavior. Journal of Applied Behavior Analysis, 29, 569-572. doi: 10.1901/jaba.1996.29-569

Piazza, C. C., Fisher, W. W., Hanley, G. P., Remick, M. L., Contrucci, S. A., \& Aitken, T. L. (1997). The use of positive and negative reinforcement in the treatment of escape-maintained destructive behavior. Journal of Applied Behavior Analysis, 30, 279-298. doi: 10.1901/jaba.1997.30-279

Pitman, M. J. (2007). Functional analysis and treatment of socially stigmatizing ambulation. The Behavior Analyst Today, 8, 284-297

Rachlin, S. (1974). With liberty and psychosis for all. Psychiatric Quarterly, 48, 410420. doi: 10.1007/BF01562163.

Repp, A. C., Felce, D., \& Barton, L. E. (1988). Basing the treatment of stereotypic and self-injurious behaviors on hypotheses of their causes. Journal of Applied Behavior Analysis, 21, 281-289. doi: 10.1901/jaba.1988.21-281

Richman, D. M., Wacker, D. P., Asmus, J. M., \& Casey, S. D. (1998). Functional analysis and extinction of different behavior problems exhibited by the same individual. Journal of Applied Behavior Analysis, 31, 475-478. doi: 10.1901/jaba.1998.31-475

Richman, D. M., Wacker, D. P., \& Winborn, L. (2001). Response efficiency during functional communication training: Effects of effort on response allocation. Journal of Applied Behavior Analysis, 34, 73-76. doi: 10.1901/jaba.2001.34-73 
Roberts, M. L., Mace, F. C., \& Daggett, J. A. (1995) Preliminary comparison of two negative reinforcement schedules to reduce self-injury. Journal of Applied Behavior Analysis, 28, 579-580. doi: 10.1901/jaba.1995.28-579

Roscoe, E. M., Iwata, B. A., \& Kahng, S. (1999). Relative versus absolute reinforcement effects: implications for preference assessments. Journal of Applied Behavior Analysis, 32, 479-493. doi: 10.901/jaba.1999.32-479

Shirley, M. J., Iwata, B. A., Kahng, S., Mazaleski, J. L., \& Lerman, D. C. (1997). Does functional communication training compete with ongoing contingencies of reinforcement? An analysis during response acquisition and maintenance. Journal of Applied Behavior Analysis, 30, 93-104. doi: 10.1901/jaba.1997.30-93

Smith, R. G., Iwata, B. A., Vollmer, T. R., \& Zarcone, J. R. (1993). Experimental analysis and treatment of multiply controlled self-injury. Journal of Applied Behavior Analysis, 26, 183-196. doi: 10.1901/jaba.1993.26-183

St. Peter Pipkin, C., Vollmer, T. R., \& Sloman, K. N. (2010). Effects of treatment integrity failures during differential reinforcement of alternative behavior: A translational model. Journal of Applied Behavior Analysis, 43, 47-70. doi: 10.1901/jaba.2010.43-47

Sy, J. R., Borrero, J. C., \& Borrero, C. S. W. (2010). Characterizing response-reinforcer relations in the natural environment: Exploratory matching analyses. The Psychological Record, 60, 609-626.

Tarbox, J., Wilke, A. E., Najdowski, A. C., Findel-Pyles, R. S., Balasanyan, S., Caveney, A. C.,...Tia, B. (2009) Comparing indirect, descriptive, and experimental functional assessments of challenging behavior in children with autism. Journal 
of Developmental and Physical Disabilities, 21, 493-514. doi: 10.1007/s10882009-9154-8

Thompson, R. H., Fisher, W. W., Piazza, C. C., \& Kuhn, D. E. (1998). The evaluation and treatment of aggression maintained by attention and automatic reinforcement. Journal of Applied Behavior Analysis, 31, 103-116. doi: 10.1901/jaba.1998.31103.

Travis, R., \& Sturmey, P. (2010). Functional analysis and treatment of the delusional statements of a man with multiple disabilities: a four-year follow-up. Journal of Applied Behavior Analysis, 43, 745-749. doi: 10.1901/jaba.2010.43-745

Vollmer, T. R., Borrero, J. C., Lalli J. S., \& Daniel, D. (1999). Evaluating self-control and impulsivity in children with sever behavior disorders. Journal of Applied Behavior Analysis, 32, 451-466. doi: 10.1901/jaba.1999.32-451

Vollmer, T. R., \& Iwata, B. A. (1992). Differential reinforcement as treatment for behavior disorders: Procedural and functional variations. Research in Developmental Disabilities, 13, 393-417. doi: 10.106/0891-4222(92)90013-V

Vollmer, T. R., \& Smith, R. G. (1996). Some current themes in functional analysis research. Research in Developmental Disabilities, 17, 229-249. doi:10.1016/08914222(96)00006-6

Wilder, D. A., Matsuda, A., O’Connor, C., \& Baham, M. (2001). Brief functional analysis and treatment of bizarre vocalizations in an adult with schizophrenia. Journal of Applied Behavior Analysis, 34, 65-68. doi: 10.1901/jaba.2001.34-65. 
Wright-Gallo, G. L., Higbee, T. S., Reagon, K. A., \& Davey, B. J. (2006). Classroombased functional analysis and intervention for students with emotional/behavioral disorders. Education and Treatment of Children, 29, 421-436.

Young, J. A., \& Wincze, J. P. (1974). The effects of the reinforcement of compatible and incompatible alternative behaviors on the self-injurious and related behaviors of a profoundly retarded female adult. Behavior Therapy, 5, 614-623. 
APPENDICES 
Appendix A

Tables 
Table 1

Excluded participant characteristics

\begin{tabular}{|c|c|c|c|}
\hline Name & Age & Diagnosis & $\begin{array}{c}\text { Referred Problem } \\
\text { Behavior }\end{array}$ \\
\hline Pacey & 31 years old & $\begin{array}{l}\text { Mild MR, major } \\
\text { depressive disorder, } \\
\text { impulse control } \\
\text { (NOS) }\end{array}$ & $\begin{array}{l}\text { Inappropriate } \\
\text { vocalizations }\end{array}$ \\
\hline Lucy & 31 years old & $\begin{array}{l}\text { Mild developmental } \\
\text { disability, } \\
\text { oppositional defiant } \\
\text { disorder, } \\
\text { malingering, } \\
\text { attention deficit } \\
\text { hyperactivity } \\
\text { disorder }\end{array}$ & $\begin{array}{l}\text { Inappropriate } \\
\text { vocalizations }\end{array}$ \\
\hline Troy & 26 years old & $\begin{array}{l}\text { Mild MR, } \\
\text { personality disorder } \\
\text { (NOS), mood } \\
\text { disorder (NOS), } \\
\text { oppositional defiant } \\
\text { disorder, attention } \\
\text { deficit hyperactivity } \\
\text { disorder, possible } \\
\text { brain injury }\end{array}$ & $\begin{array}{l}\text { Inappropriate } \\
\text { vocalizations }\end{array}$ \\
\hline Esther & 8 years old & $\begin{array}{l}\text { Attention deficit } \\
\text { hyperactivity } \\
\text { disorder, } \\
\text { oppositional defiant } \\
\text { disorder }\end{array}$ & $\begin{array}{l}\text { Aggression, } \\
\text { flopping, } \\
\text { inappropriate } \\
\text { vocalizations, } \\
\text { elopement }\end{array}$ \\
\hline
\end{tabular}


Table 2

Summary of parameter sensitivity assessment values

\begin{tabular}{|c|c|c|c|c|}
\hline Parameter & Definition & Consequence 1 & Consequence 2 & $\begin{array}{c}\text { Other } \\
\text { Parameters }\end{array}$ \\
\hline Quality & $\begin{array}{l}\text { Preference for } \\
\text { stimulus }\end{array}$ & $\begin{array}{l}\text { High Quality } \\
\text { - iPad }\end{array}$ & $\begin{array}{l}\text { Low Quality } \\
\text { - Rufus: cards } \\
\text { - Sabrina: magazine }\end{array}$ & $\begin{array}{l}\text { Mag: } 30-\text { s access } \\
\text { Imm: } 0 \text {-s delay }\end{array}$ \\
\hline Magnitude & $\begin{array}{l}\text { Duration of } \\
\text { access }\end{array}$ & $\begin{array}{l}\text { High Mag } \\
\text { - 90-s access }\end{array}$ & $\begin{array}{l}\text { High Mag } \\
-15 \text {-s access }\end{array}$ & $\begin{array}{l}\text { Quality: high } \\
\text { Imm: 0-s delay }\end{array}$ \\
\hline Immediacy & $\begin{array}{l}\text { Delay between } \\
\text { behavior and } \\
\text { reinforcer } \\
\text { delivery }\end{array}$ & $\begin{array}{l}\text { Immediate } \\
\text { - 0-s delay }\end{array}$ & $\begin{array}{l}\text { Delay } \\
\text { - Rufus: 10s } \\
\text { - Sabrina: 4min 40s }\end{array}$ & $\begin{array}{l}\text { Quality: high } \\
\text { Mag: 30-s access }\end{array}$ \\
\hline
\end{tabular}

Table 3

Summary of relative parameter sensitivity assessment values

\begin{tabular}{llll}
\hline \multicolumn{1}{c}{ Parameters } & \multicolumn{1}{c}{ Consequence } & \multicolumn{1}{c}{ Consequence } & \multicolumn{1}{c}{ Other } \\
Tested & \multicolumn{1}{c}{ Parameter } \\
\hline Magnitude vs. & Low Mag-Immediate & \multicolumn{1}{c}{ High Mag-Delayed } & Quality: High \\
Immediacy & - 15-s access & - 90-s access & \\
& - Immediate & - 4-min 40-s delay & \\
Quality vs. & Low Quality-Immediate & High Quality-Delayed & Mag: 30-s access \\
Immediacy & - Low quality & - High quality & \\
& - Immediate & - 4-min 40-s delay & \\
Magnitude vs. & Low Mag-High Quality & High Mag-Low Quality & Imm: 0-s delay \\
Quality & - 15-s access & - 90-s access & \\
& - High quality & - Low quality & \\
\hline
\end{tabular}


Appendix B

Figures 

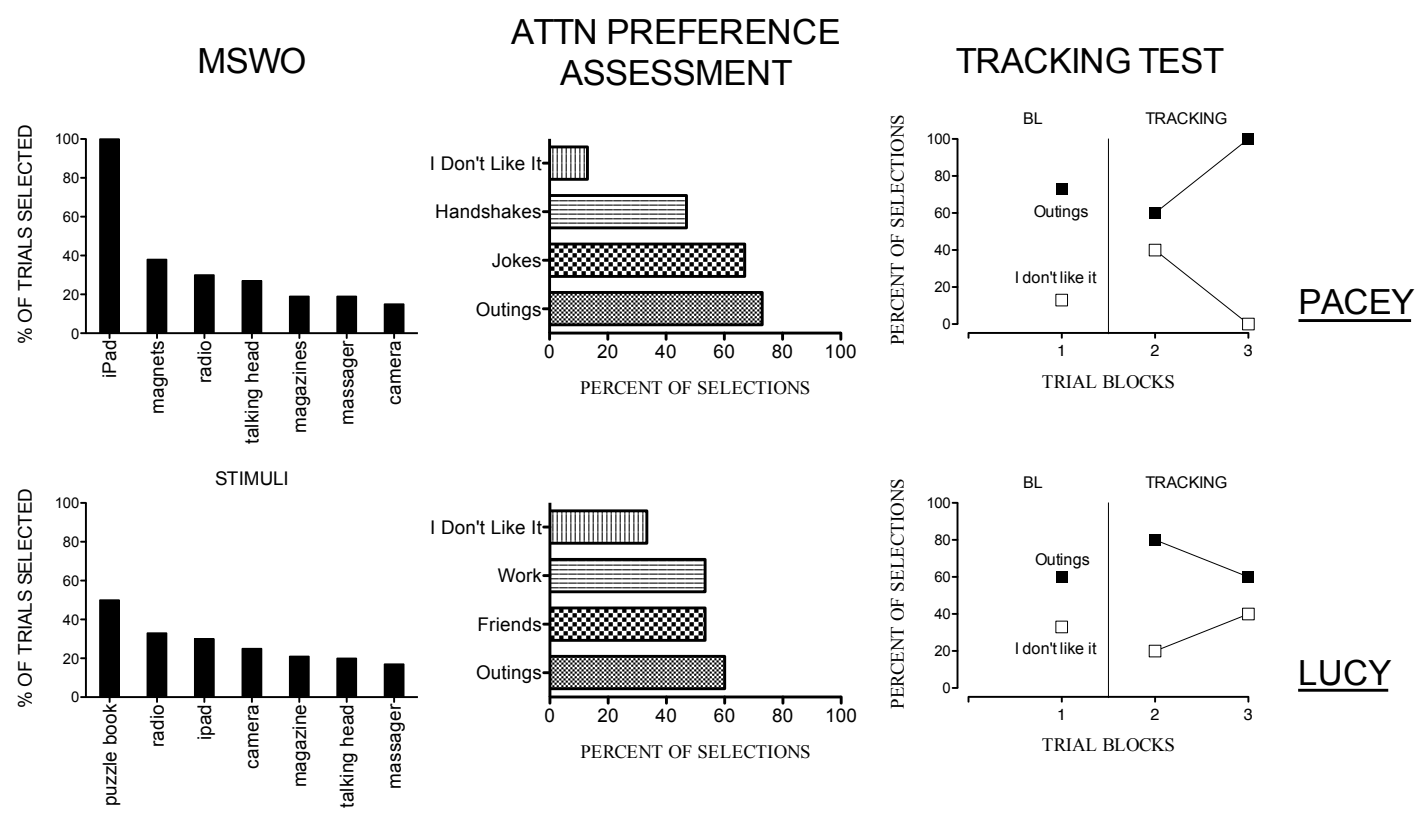

STIMULI
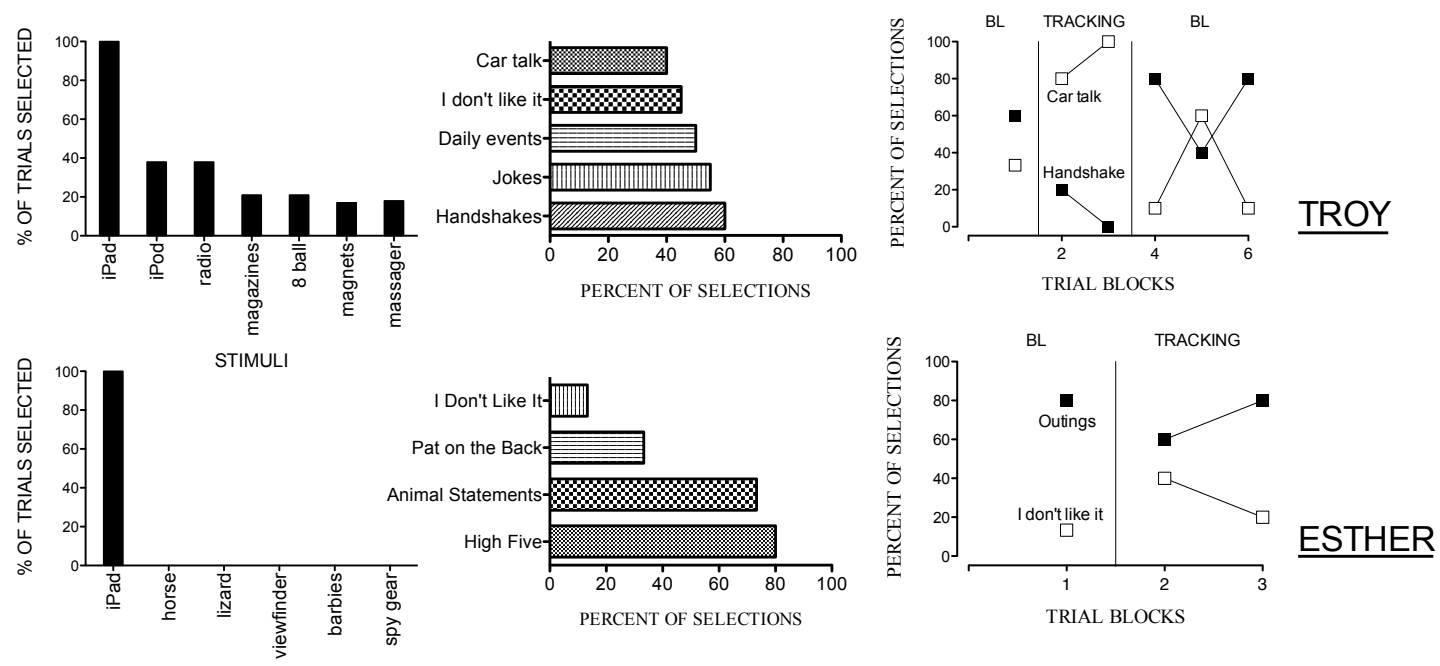

STIMULI

Figure 1. Preference assessment results for Pacey, Lucy, Troy, and Esther. The first panel depicts the results of the MSWO preference assessment. The second and third panels depict the results of the attention preference assessment and the tracking test. 
FUNCTIONAL ANALYSES
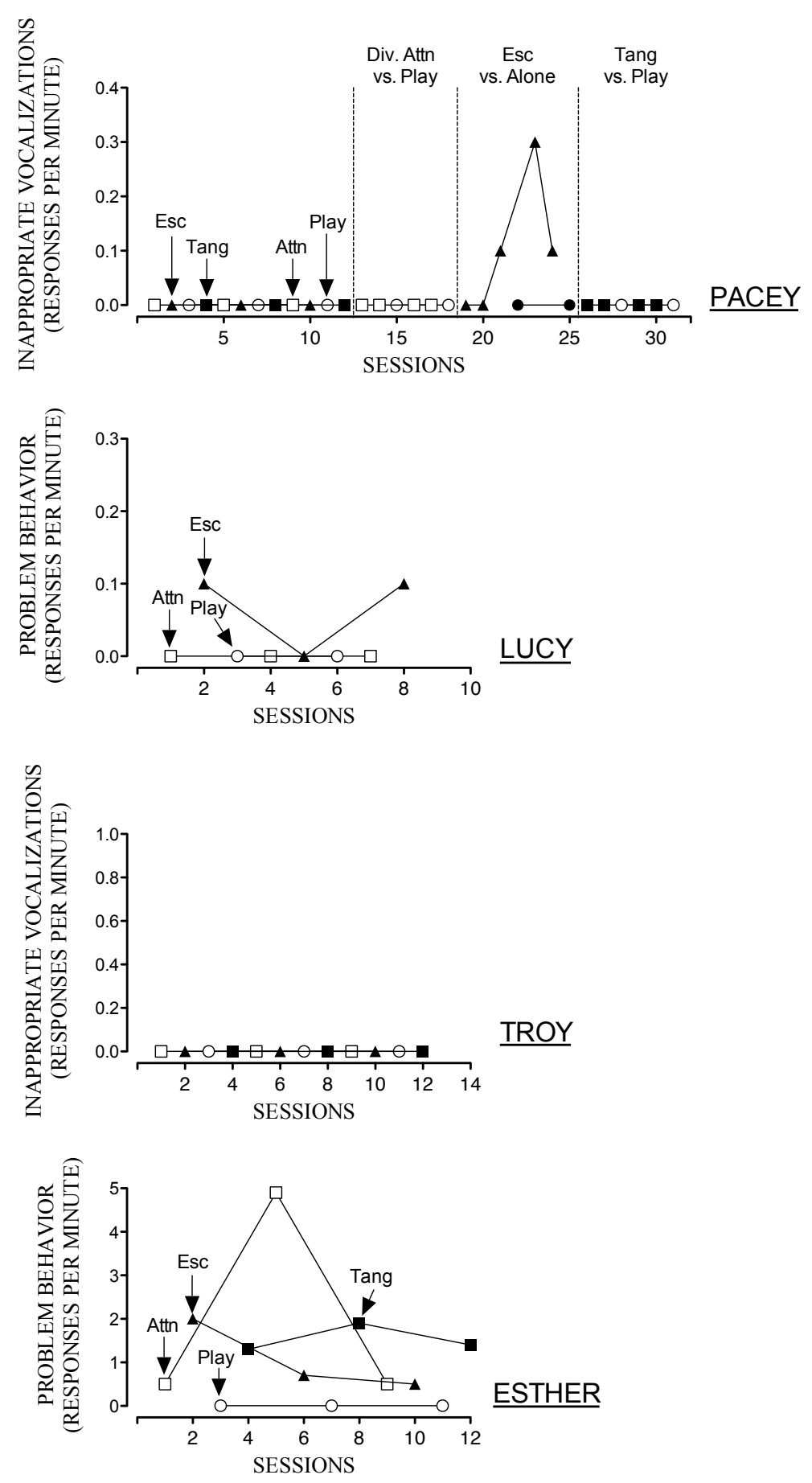

Figure 2. Functional analyses of problem behavior for Pacey, Lucy, Troy, and Esther. Triangles denote responses during the escape condition, closed squares denote tangible condition, open squares denote attention condition, and open circles denote play condition. 


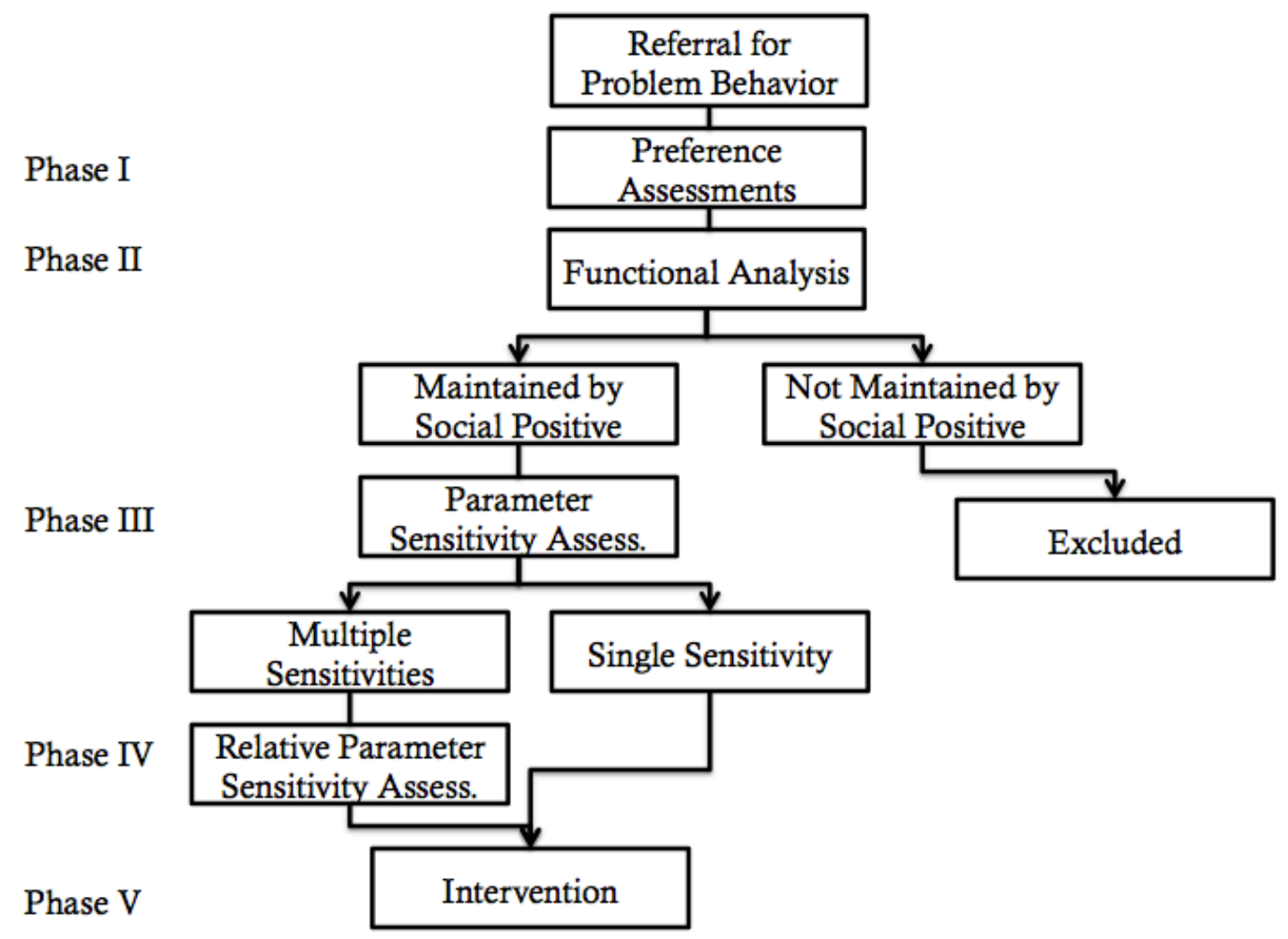

Figure 3. Overview of procedures. 
PAIRED-STIMULUS PREFERENCE ASSESSMENT

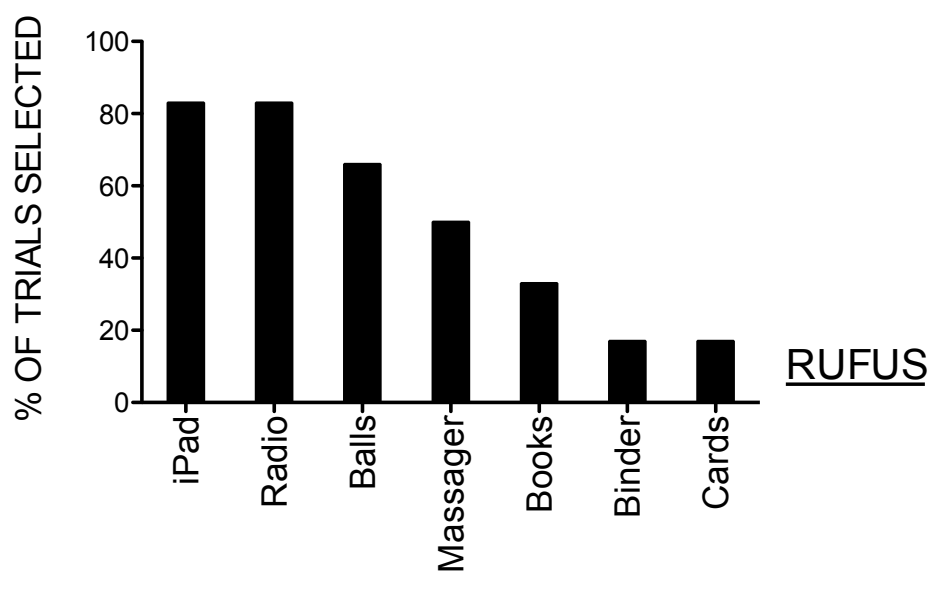

STIMULI

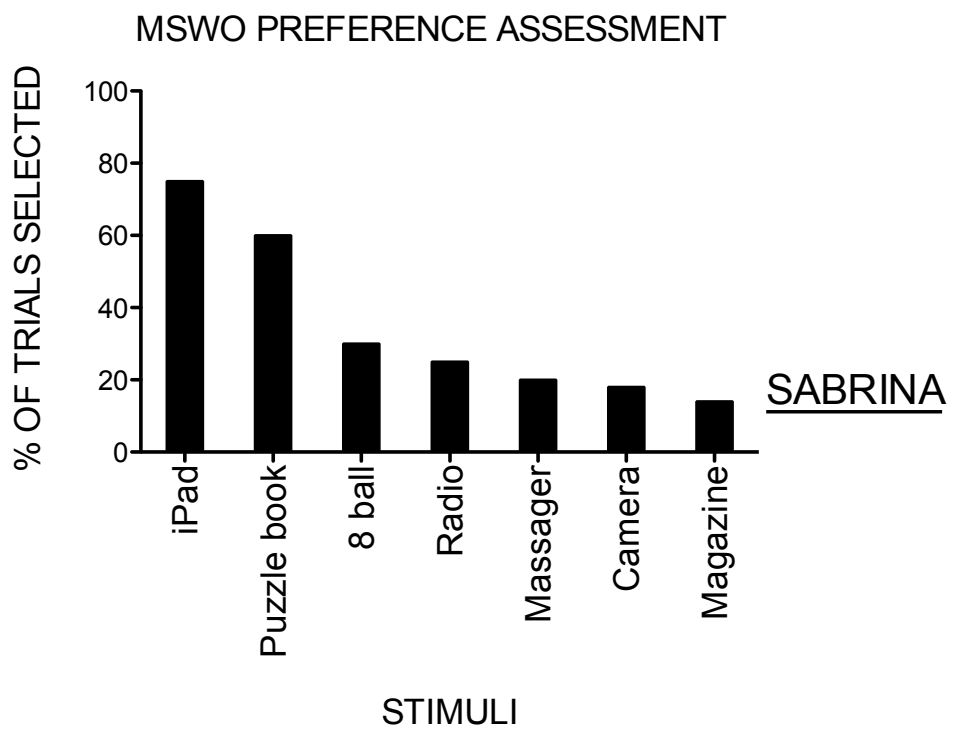

Figure 4. Tangible preference assessment results for Rufus and Sabrina. 


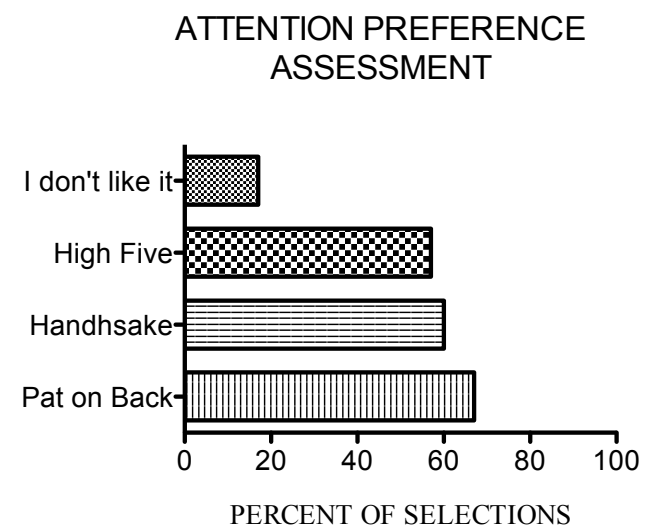

TRACKING TEST
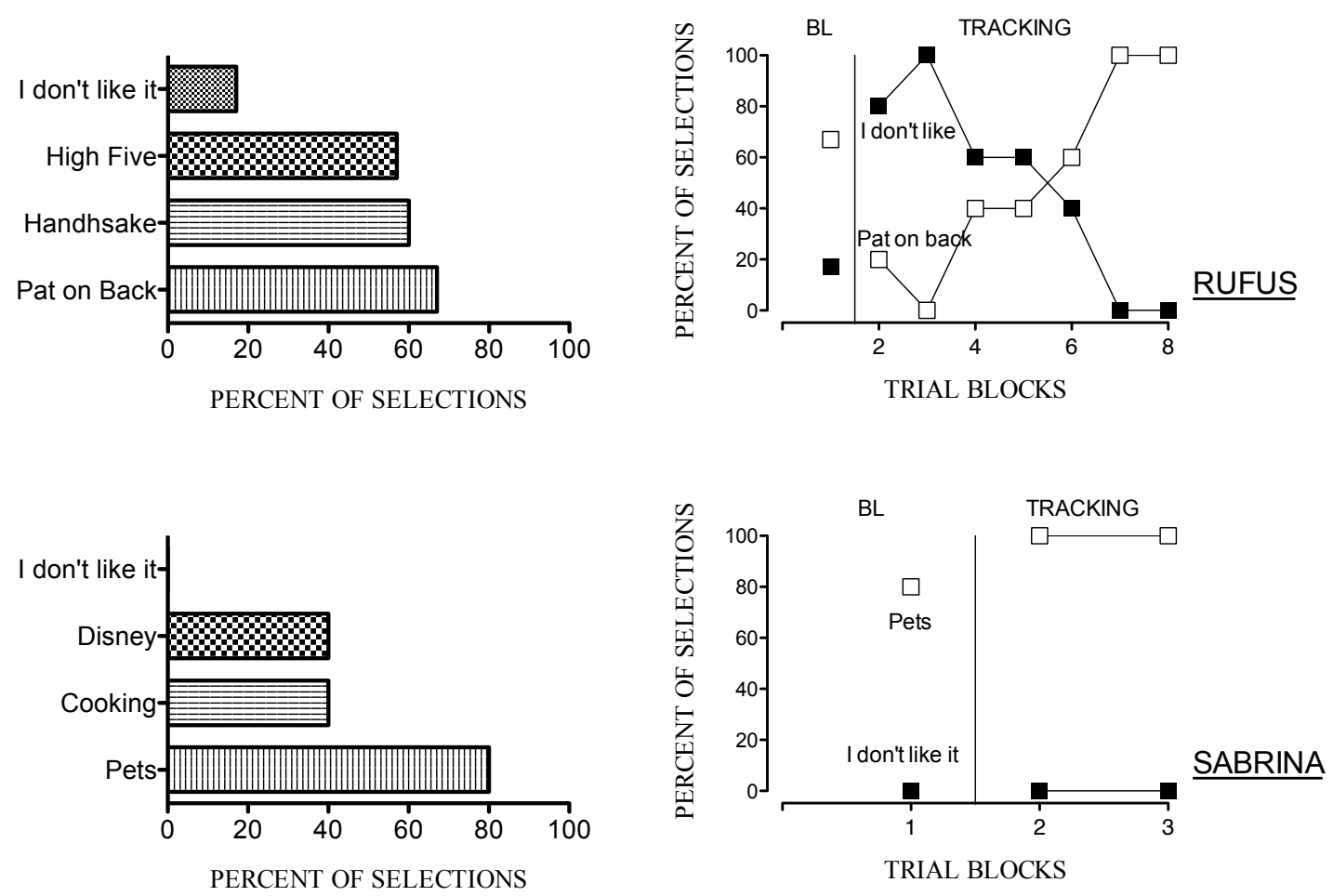

Figure 5. Attention preference assessment results for Rufus and Sabrina. The left panels represent the attention preference assessment where participants selected from pairs of four forms of attention. The right panels depict the tracking test where the therapists for the highest and lowest forms of attention switched to determine whether the participants tracked forms of attention or therapists. 

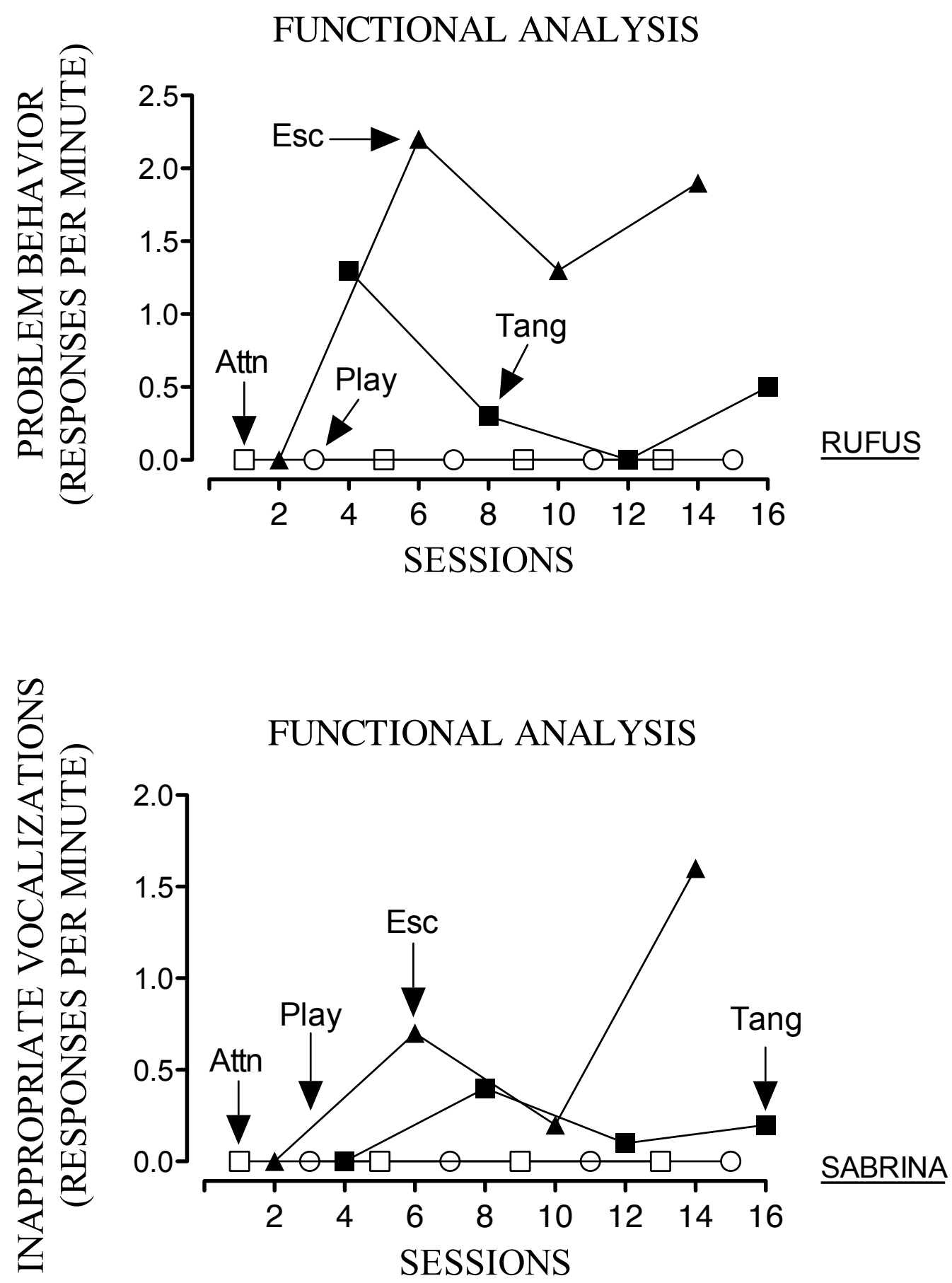

Figure 6. Functional analyses for Rufus and Sabrina. Open squares denote responding during the attention condition; open circles during the play condition; black triangles during the escape condition; and black squares during the tangible condition. 


\section{Quality Sensitivity Assessment}

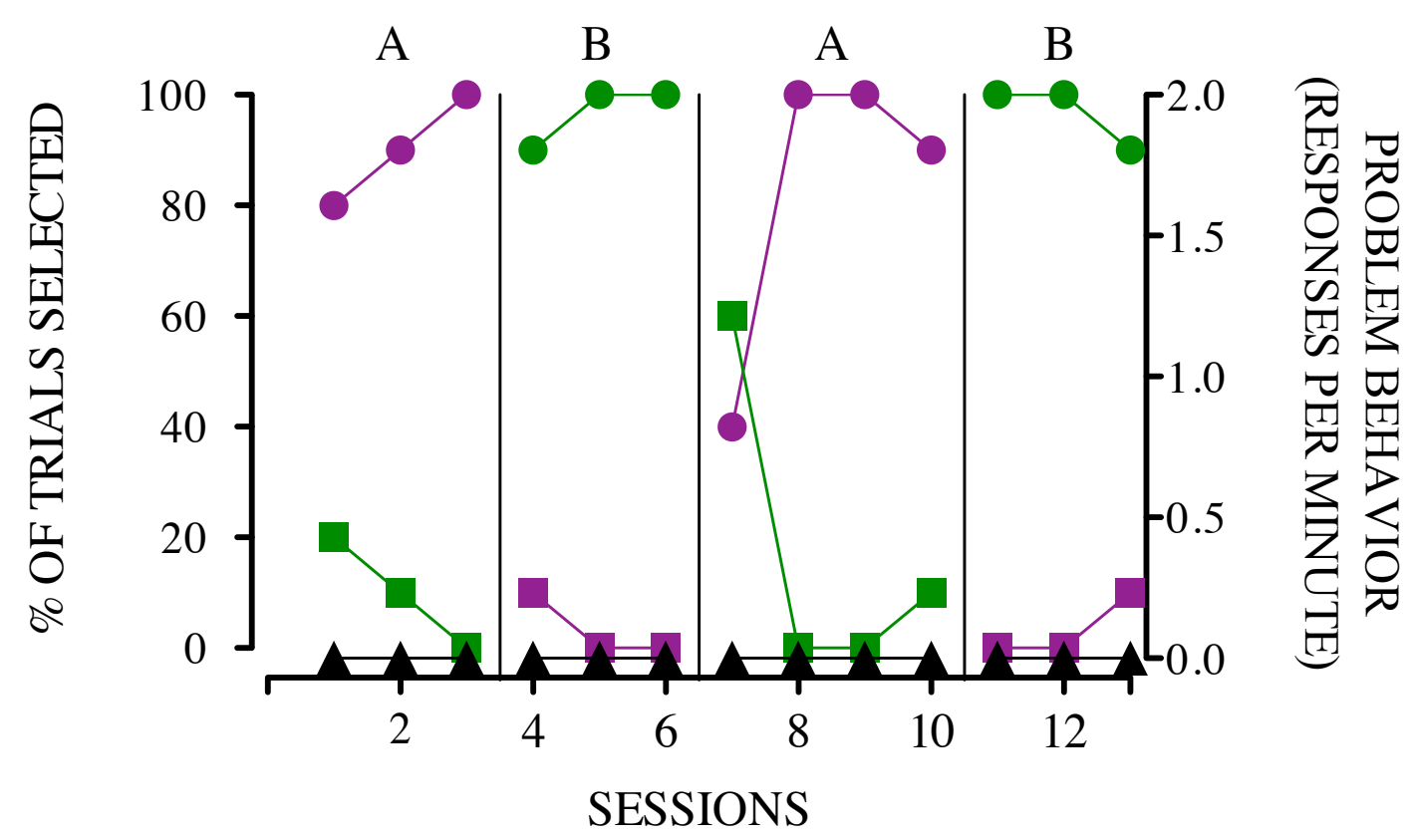

Figure 7. Rufus' quality sensitivity assessment. Circles denote high-quality selections and squares denote low-quality selections; these data paths are oriented to the left y-axis. Triangles denote problem behavior and are oriented to the right y-axis. Color of data path denotes the colors of the switches during the sessions. 


\section{Magnitude Sensitivity Assessment}

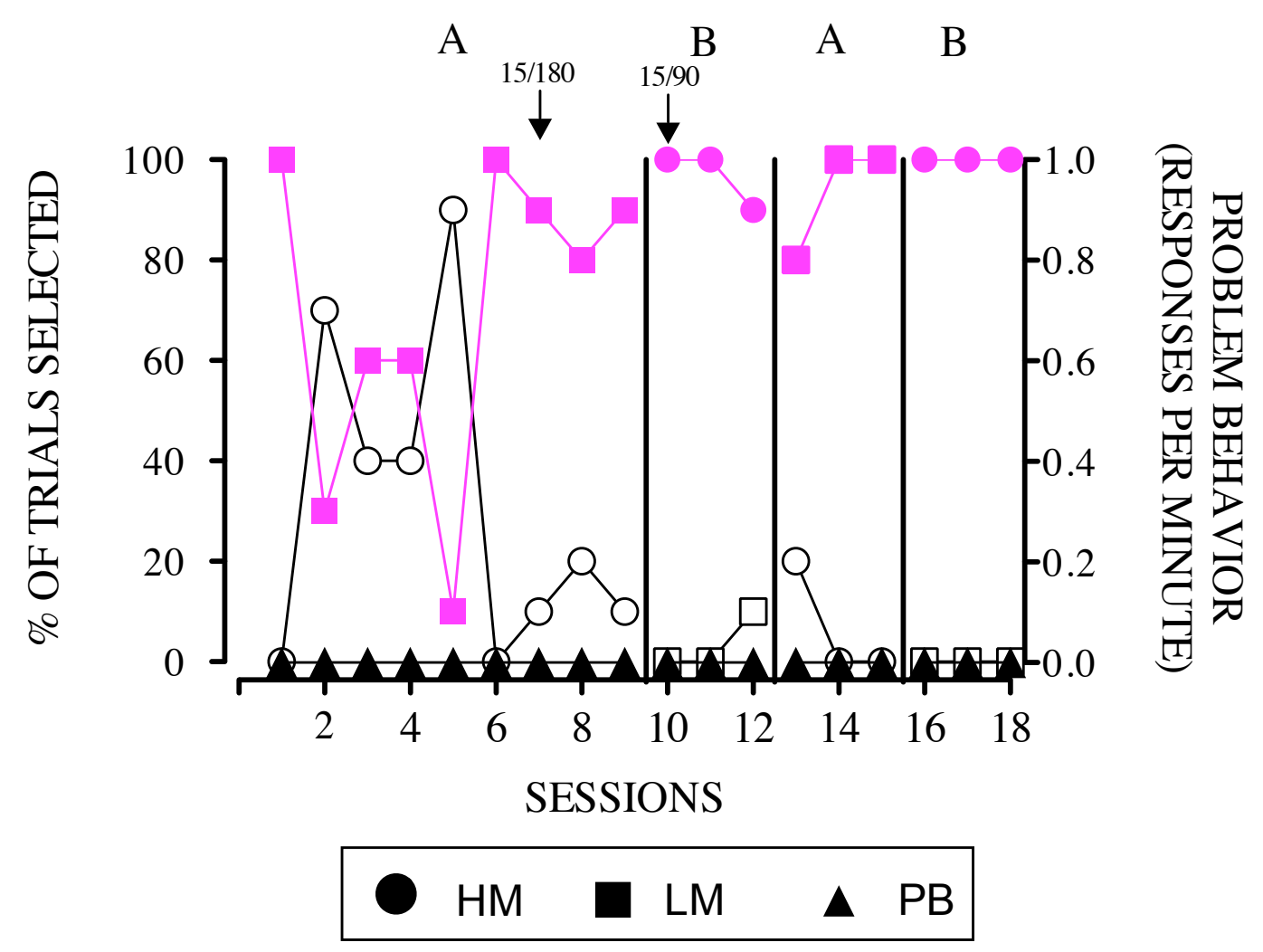

Figure 8. Rufus' magnitude sensitivity assessment. Circles denote high-magnitude selections and squares denote low-magnitude selections; these data paths are oriented to the left y-axis. Triangles denote problem behavior and are oriented to the right y-axis. Color of data path denotes the colors of the switches during the sessions. The numbers at the top of the graph denote the changes in magnitude values, with the low magnitude value appearing first. 


\section{Immediacy Sensitivity Assessment}

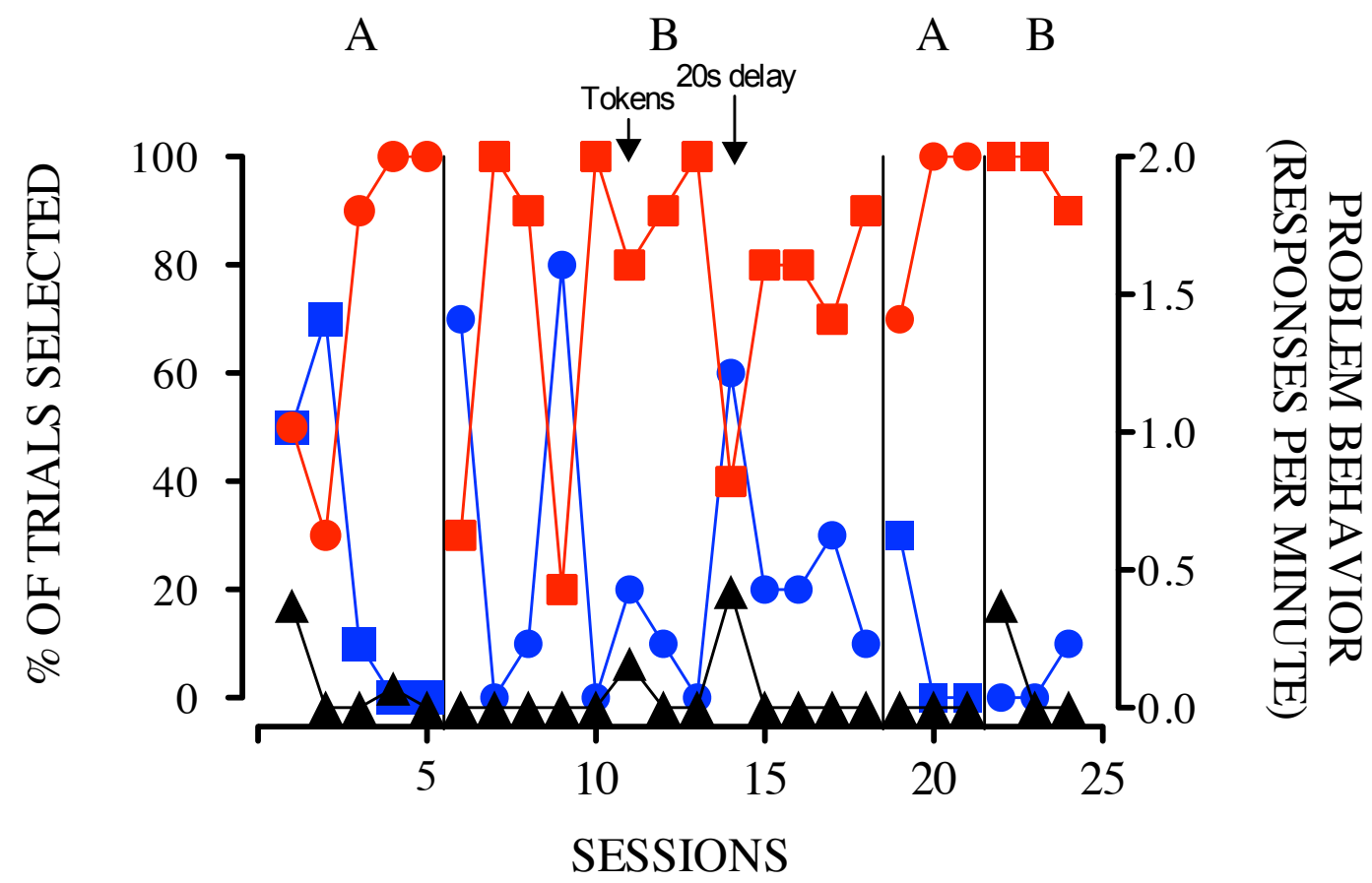

\section{- Imm Delayed $\boldsymbol{\Delta}$ PB}

Figure 9. Rufus' immediacy sensitivity assessment. Circles denote immediate selections and squares denote delayed selections; these data paths are oriented to the left y-axis. Triangles denote problem behavior and are oriented to the right y-axis. Color of data path denotes the colors of the switches during the sessions. The token economy was introduced in session 11 and the delay was increased to $20 \mathrm{~s}$ at session 14 . 


\section{Immediacy vs. Quality Tracking Test}

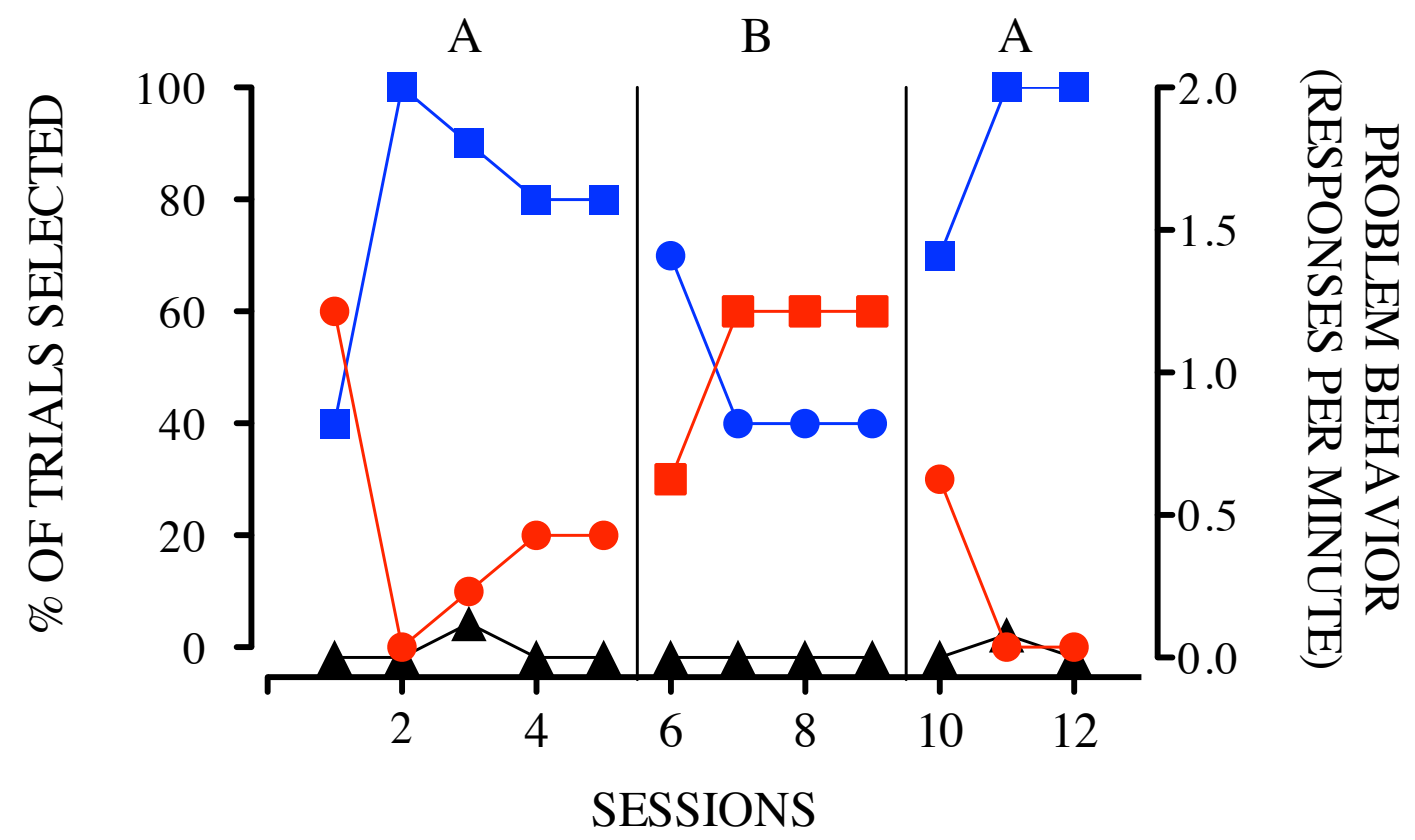

Figure 10. Rufus' immediacy versus quality tracking test. Circles denote the selection that produced low-quality items delivered immediately and squares denote the selection that produced high-quality items delivered after a 20 s delay; these data paths are oriented to the left y-axis. Triangles denote problem behavior and are oriented to the right y-axis. Color of data path denotes the colors of the switches during the sessions. 


\section{Quality Sensitivity Assessment}

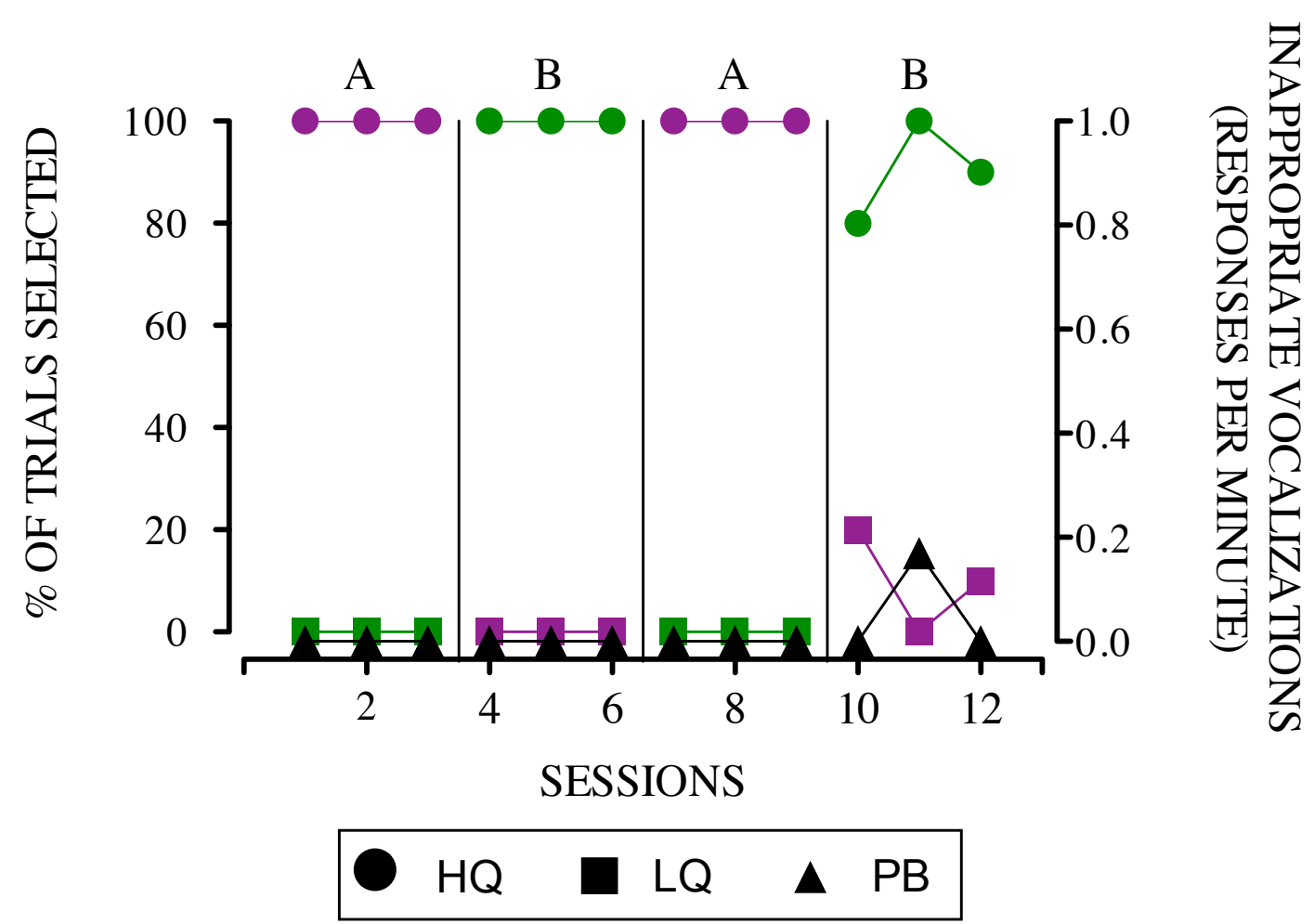

Figure 11. Sabrina's quality sensitivity assessment. Circles denote the selection that produced high-quality items and squares denote the selection that produced low-quality items; these data paths are oriented to the left y-axis. Triangles denote problem behavior and are oriented to the right $y$-axis. Color of data path denotes the colors of the switches during the sessions. 


\section{Magnitude Sensitivity Assessment}

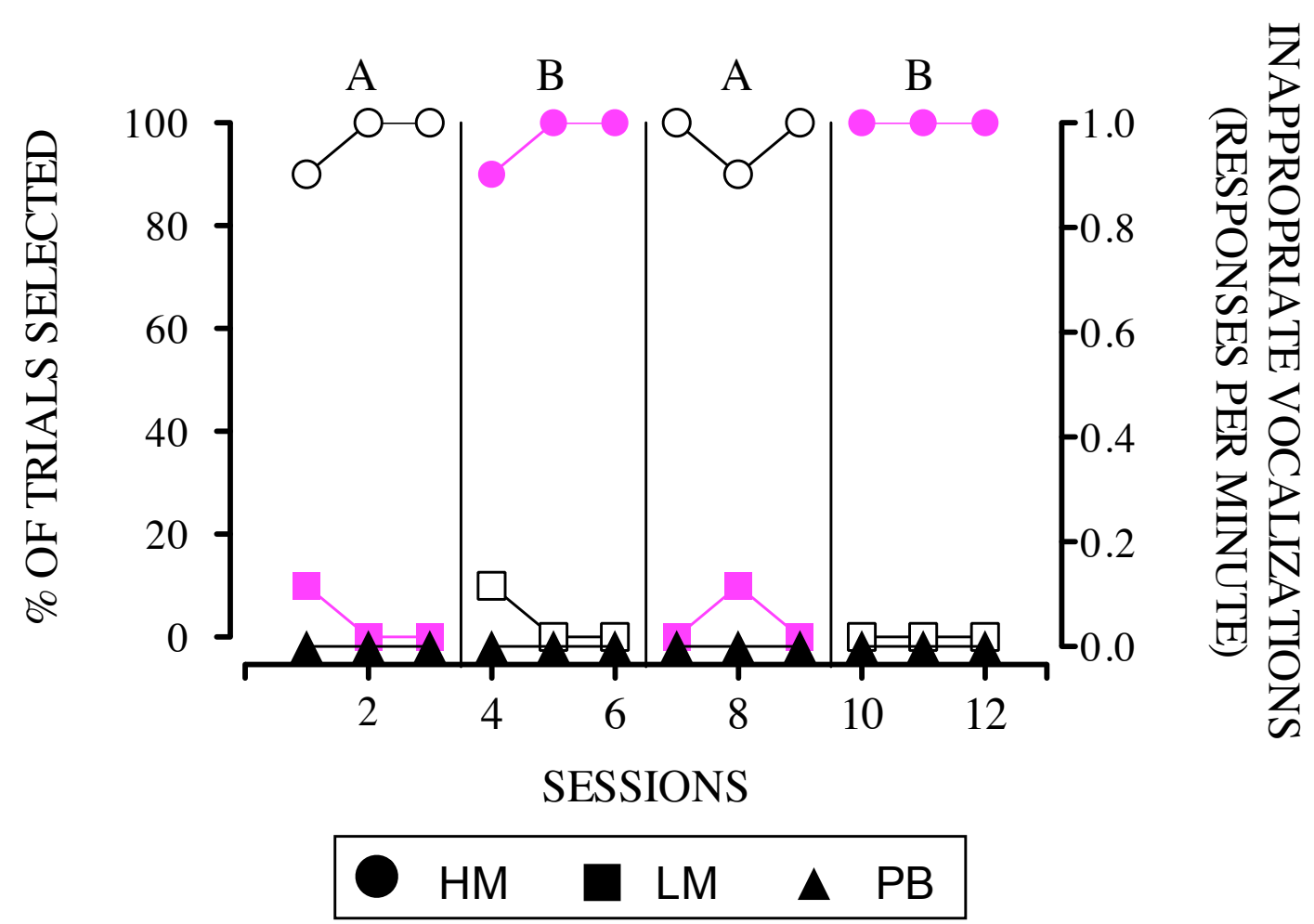

Figure 12. Sabrina's magnitude sensitivity assessment. Circles denote the selection that produced high-magnitude reinforcement and squares denote the selection that produced low-magnitude reinforcement; these data paths are oriented to the left y-axis. Triangles denote problem behavior and are oriented to the right y-axis. Color of data path denotes the colors of the switches during the sessions. 


\section{Immediacy Sensitivity Assessment}

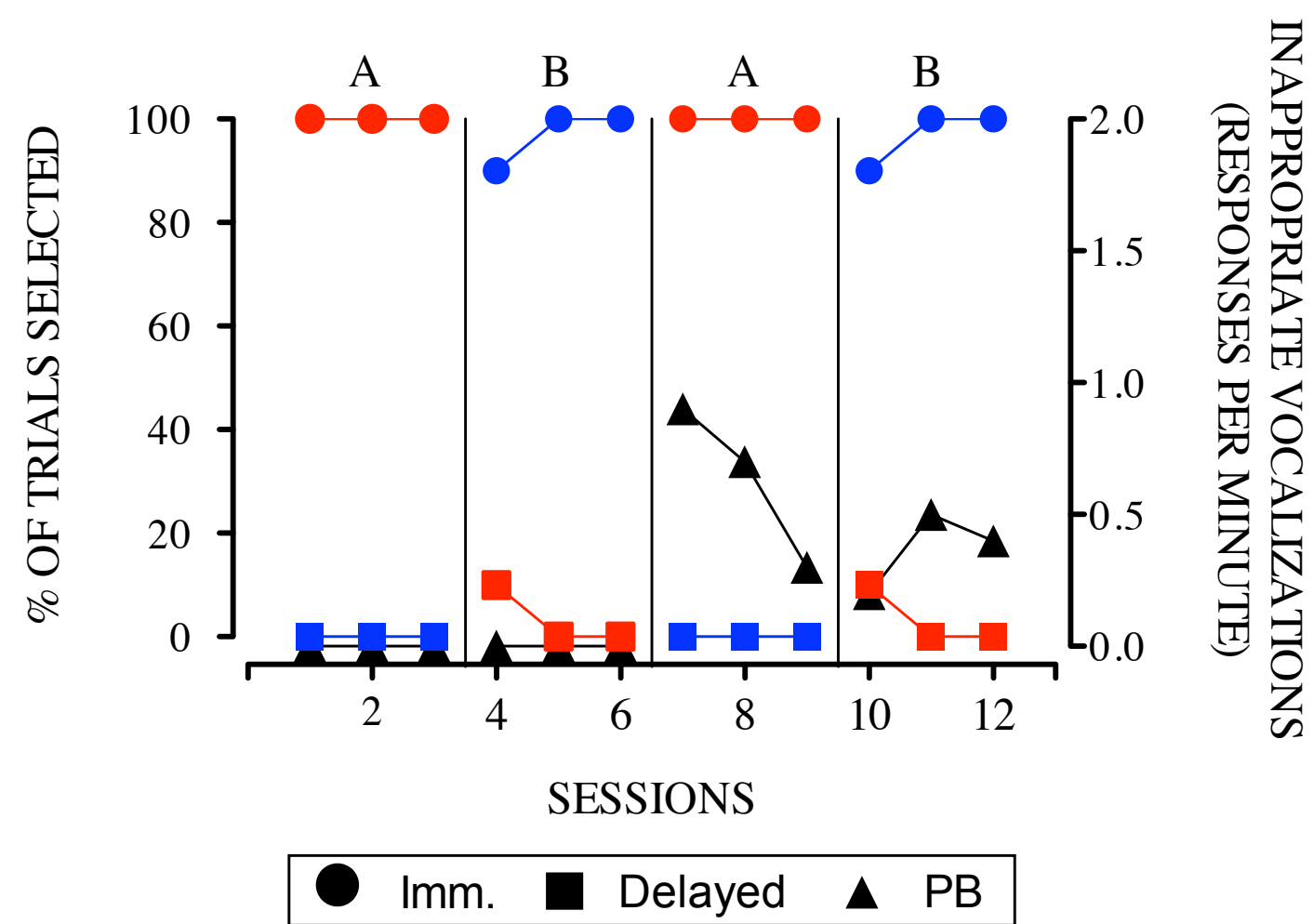

Figure 13. Sabrina's immediacy sensitivity assessment. Circles denote the selection that produced immediate reinforcement and squares denote the selection that produced delayed reinforcement; these data paths are oriented to the left y-axis. Triangles denote problem behavior and are oriented to the right y-axis. Color of data path denotes the colors of the switches during the sessions. 


\section{Magnitude vs. Immediacy Sensitivity Assessment}

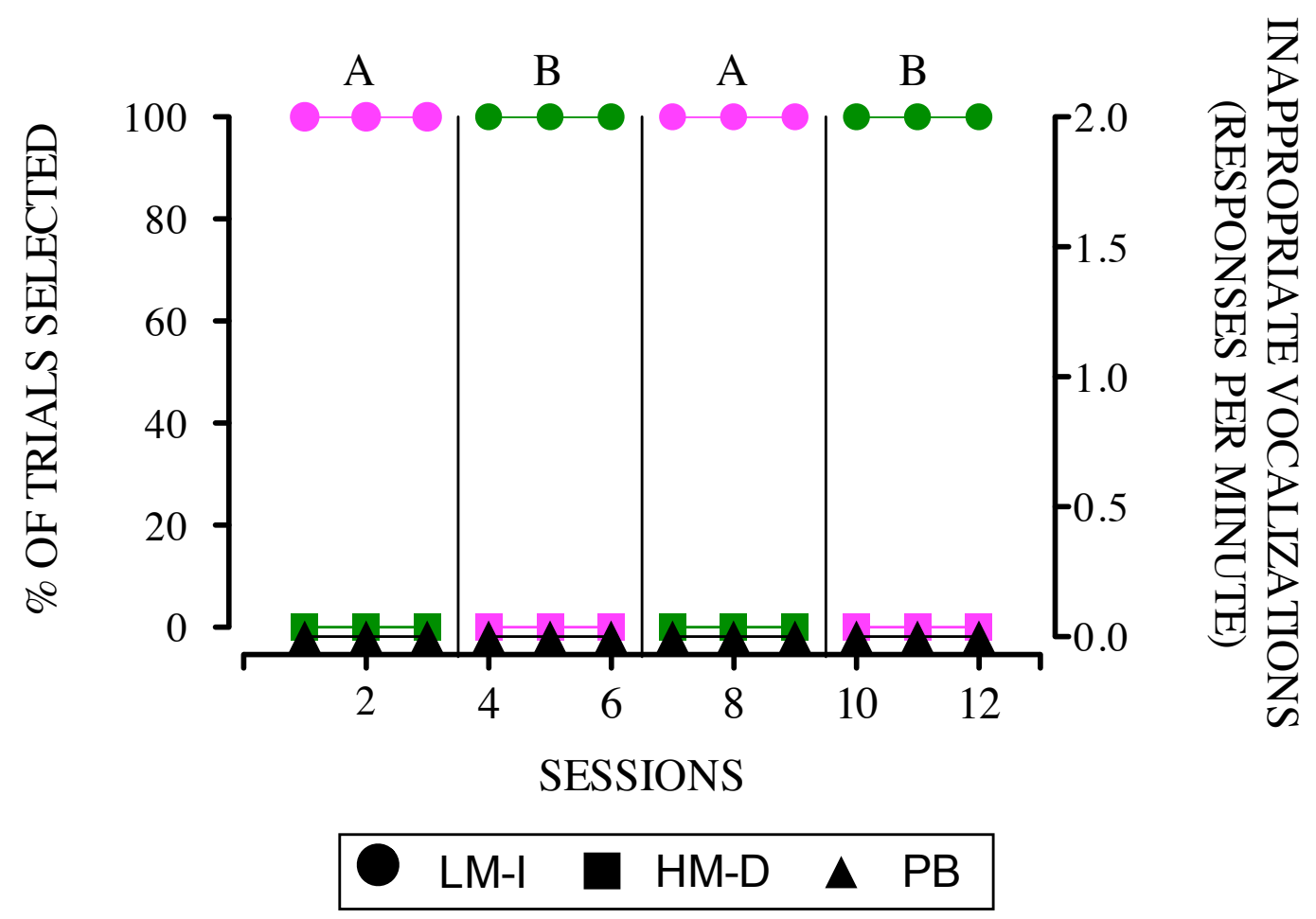

Figure 14. Sabrina's sensitivity comparison for magnitude and immediacy. Circles denote the selection that produced immediate low-magnitude reinforcement and squares denote the selection that produced delayed high-magnitude reinforcement; these data paths are oriented to the left y-axis. Triangles denote problem behavior and are oriented to the right $y$-axis. Color of data path denotes the colors of the switches during the sessions. 


\section{Immediacy vs. Quality Sensitivity Assessment}

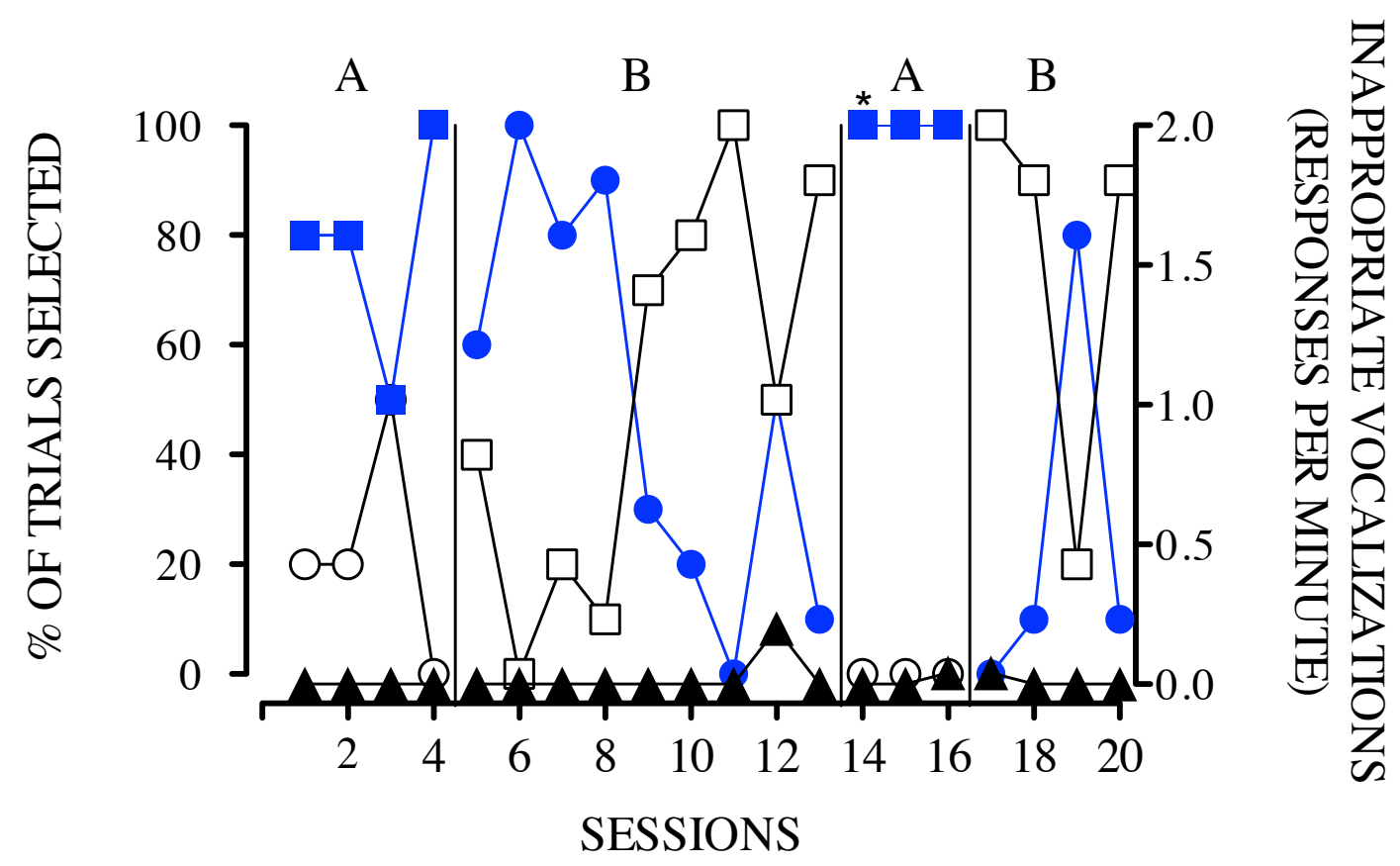

Figure 15. Sabrina's sensitivity comparison for immediacy and quality. Circles denote the selection that produced immediate low-quality reinforcement and squares denote the selection that produced delayed high-quality reinforcement; these data paths are oriented to the left y-axis. Triangles denote problem behavior and are oriented to the right $y$-axis. Color of data path denotes the colors of the switches during the sessions. The asterisk denotes when the token economy was introduced with Sabrina. 


\section{Magnitude vs. Quality Sensitivity Assessment}

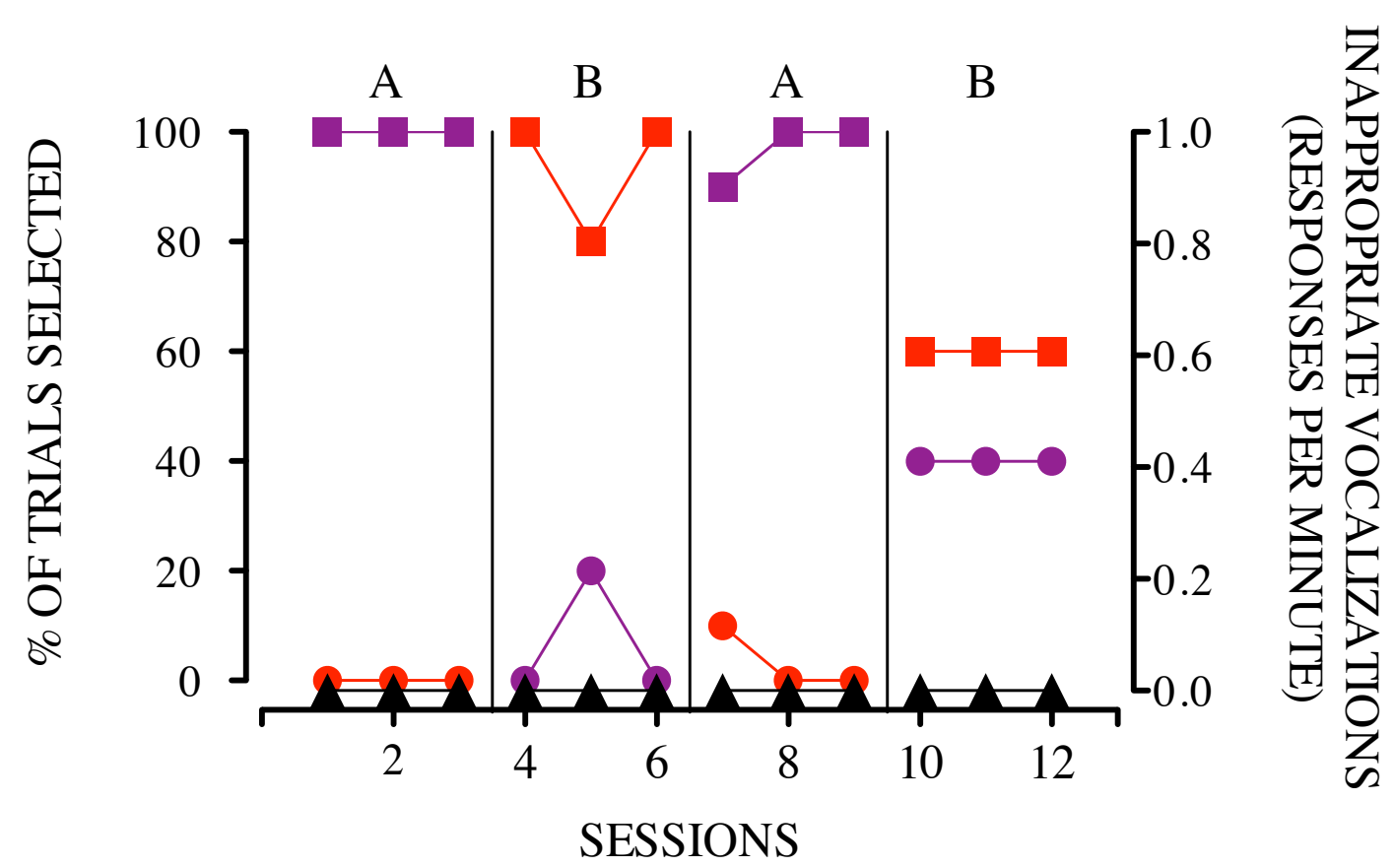

Figure 16. Sabrina's sensitivity comparison for magnitude and quality. Circles denote the selection that produced a high-magnitude of low-quality reinforcement and squares denote the selection that produced a low-magnitude of high-quality reinforcement; these data paths are oriented to the left y-axis. Triangles denote problem behavior and are oriented to the right $y$-axis. Color of data path denotes the colors of the switches during the sessions. 


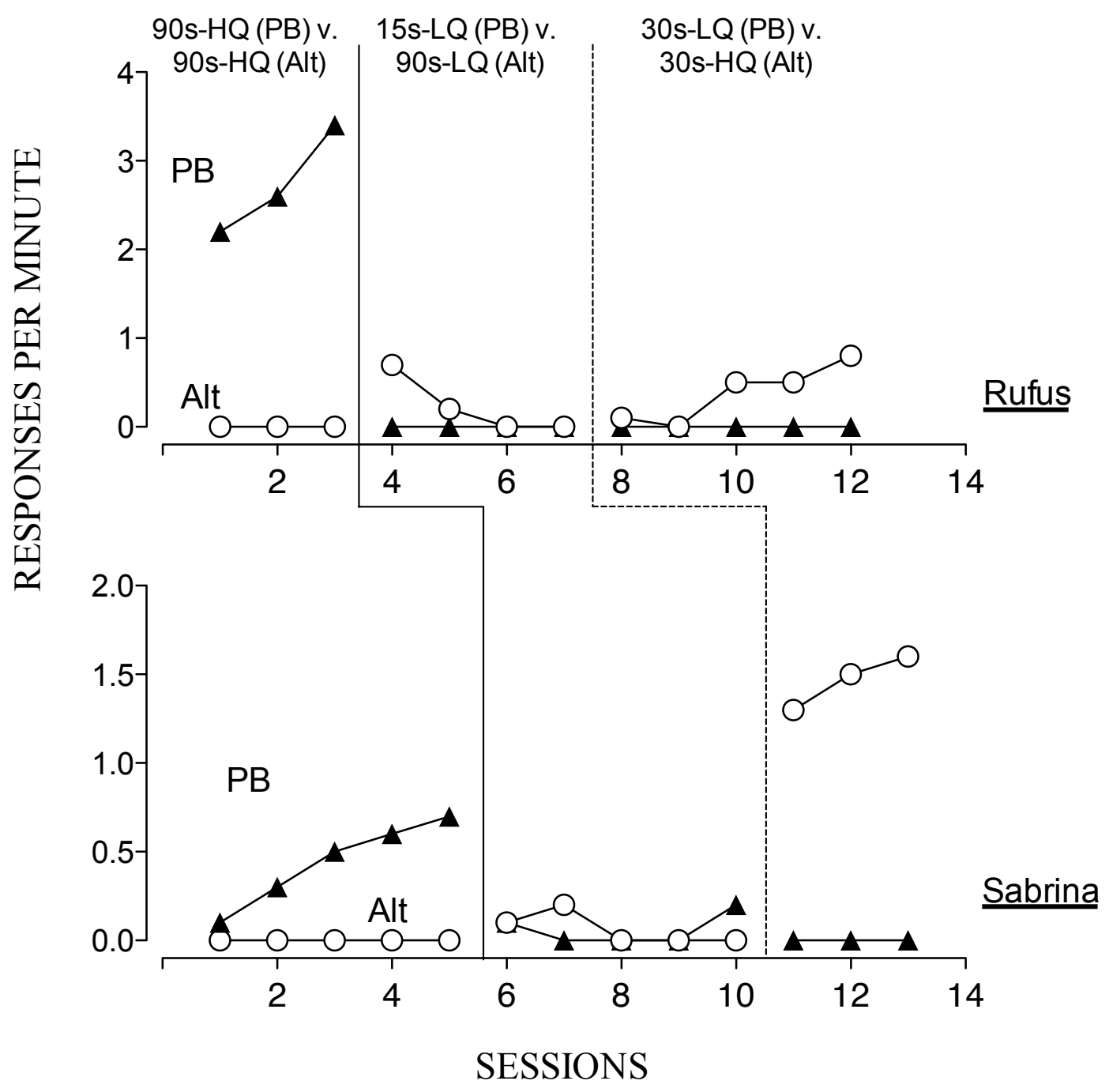

Figure 17. Intervention evaluation. Triangles denote problem behavior and open circles denote alternative behavior. 


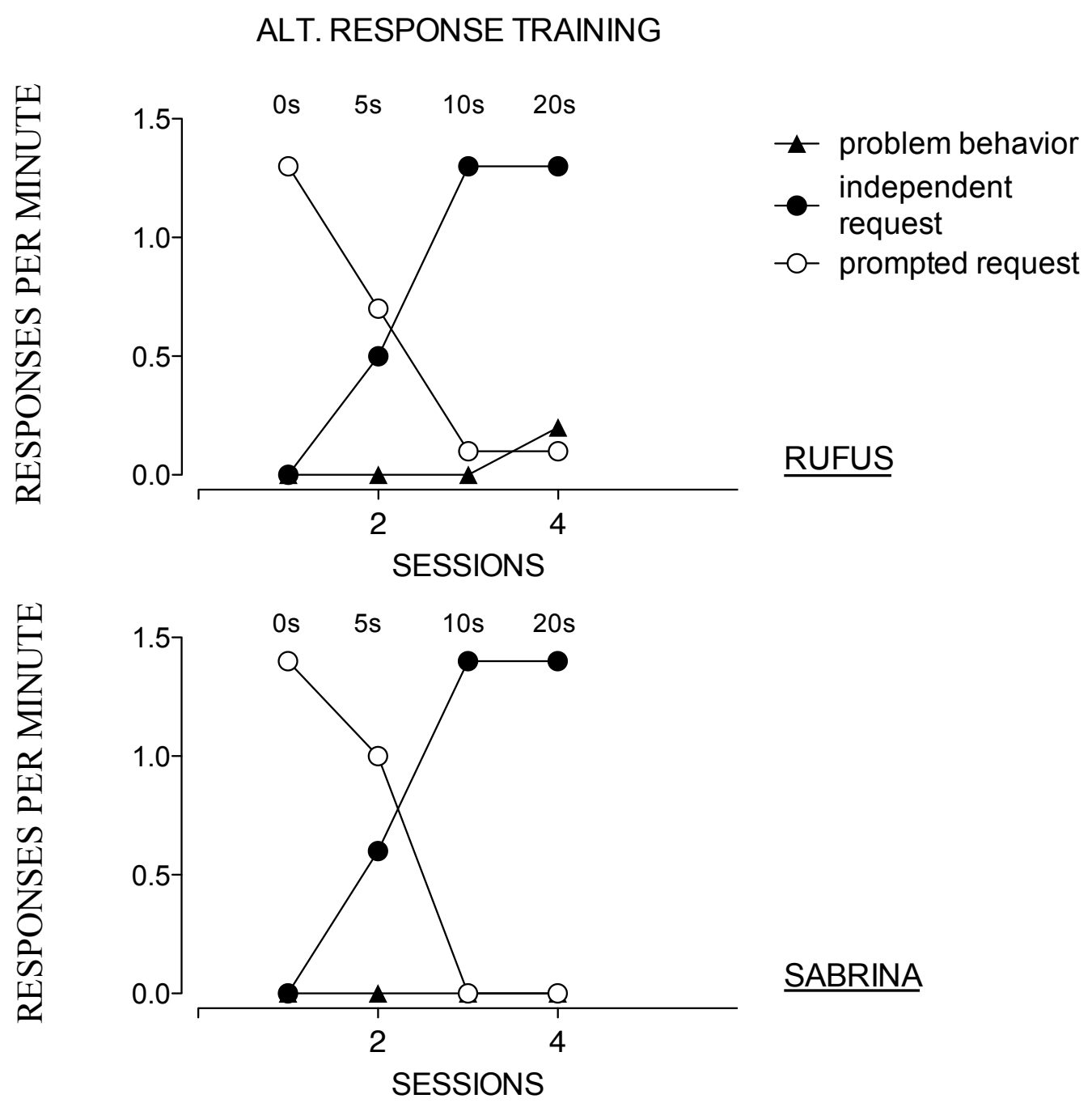

Figure 18. Alternative response-training data. The top panel is Rufus' data and the lower panel is Sabrina's. Triangles represent problem behavior; closed circles represent independent requests, and open circles represent prompted requests. The numbers at the top of the graphs denote the delay to prompts. 


\section{CURRICULUM VITAE}

\section{SORAYA SHANUN KUNNAVATANA}

shanun@kunnavatana.com

\section{EDUCATION}

2014 Ph.D., Utah State University - Logan, UT

Major: Disabilities Disciplines (Applied Behavior Analysis specialization)

Dissertation title: Manipulating parameters of reinforcement to reduce problem behavior without extinction

Advisors: Dr. Sarah E. Bloom, BCBA-D and Dr. Timothy A. Slocum

2011 M.A., University of the Pacific-Stockton, CA

Major: Psychology (Behavior Analysis specialization)

Thesis title: A rapid treatment analysis for noncompliance in young children

Advisor: Dr. Matthew P. Normand, BCBA-D

2003

B.A., University of California, Davis - Davis, CA

Major: Sociology

\section{PROFESSIONAL CERTIFICATION}

Board Certified Behavior Analyst, 2012-present Certificant 1-12-10045

\section{HONORS AND AWARDS}

Gipson Graduate Memorial Scholarship, Psychology Department, University of the Pacific (2009)

\section{MEMBERSHIP IN PROFESSIONAL SOCIETIES}

Association for Professional Behavior Analysts, Student Member (2013-present)

Utah Association for Behavior Analysis, Student Member (2011-present)

California Association for Behavior Analysis, Student Member (2008-2012)

Association for Behavior Analysis International, Student Member (2008-present)

Berkshire Association for Behavior Analysis, Student Member (2009-2010)

California Association for Behavior Analysis, Professional Member (2004-2007) 


\section{EDITORIAL ACTIVITIES AND PROFESSIONAL SERVICE}

Guest Review

2013

Education and Treatment of Children

RESEARCH

\section{PEER-REVIEWED PUBLICATIONS - PUBLISHED AND IN PRESS}

Snyder, K., Slocum, T. A., \& Kunnavatana, S. S. (in press). Variety is the spice of life: Promoting variability in individuals with autism spectrum disorder. Focus on Autism and Other Developmental Disabilities

Lambert, J. M., Bloom, S. E., Clay, C. J., Kunnavatana, S. S., \& Collins, S. D. (in press). Training residential staff and supervisors to conduct traditional functional analyses. Research in Developmental Disabilities

Kunnavatana, S. S., Bloom, S. E., Samaha, A. L., Lignugaris/Kraft, B., Dayton, E., \& Harris, S. K. (2013). Using a modified pyramidal training model to teach special education teachers to conduct trial-based functional analyses. Teacher Education and Special Education, 36, 267-285.

Kunnavatana, S. S., Bloom, S. E., Samaha, A. L., \& Dayton, E. (2013). Training teachers to conduct trial-based functional analyses. Behavior Modification, 37, 707-722.

Lambert, J. M., Bloom, S. E., Kunnavatana, S. S., Collins, S. D., \& Clay, C. J. (2013). Training residential staff and supervisors to conduct trial-based functional analyses. Journal of Applied Behavior Analysis, 46, 296-300.

\section{PEER-REVIEWED PUBLICATIONS - MANUSCRIPTS UNDER REVIEW}

Boyle, M. A., Samaha, A. L., Bloom, S. E., Kunnavatana, S. S., \& Dayton, E. (under review). Use of social reinforcers in children with autism: A data-based review. Research in Developmental Disabilities

\section{MANUSCRIPTS IN PREPARATION}

Lambert, J. M., Bloom, S. E., Dayton, E., Kunnavatana, S. S., \& Samaha, A. L. (in preparation) The effects of noncontingent reinforcement on the persistence/resurgence of behavior: Applications of behavioral momentum theory.

Lambert, J. M., Bloom, S. E., Kunnavatana, S. S., Boyle, M. A., \& Samaha, A. L. (in preparation). Evaluating correspondence between mand assessments and functional analyses of problem behavior. 
Samaha, A. L., Ludeman, K., Bloom, S. E., \& Kunnavatana, S. S. (in preparation). Evaluation criteria for trial-based functional analyses: A signal detection approach.

Dayton, E., Bloom, S. E., Samaha, A. L., Kunnavatana, S. S., \& Peal, A. M. (in preparation). Latency as the dependent variable in trial-based functional analyses.

\section{EXTERNAL RESEARCH AWARDS - IN PREPARATION}

\section{Student Researcher}

Principal Investigator: Dr. Sarah E. Bloom

"Trial-Based Functional Analysis and Treatment of Problem Behavior"

Institute of Education Sciences

Submission Target: October 5, 2013

\section{EXTERNAL RESEARCH AWARDS - NOT FUNDED}

\section{Student Researcher}

Faculty sponsor: Dr. Sarah E. Bloom

"An Evaluation of the Relationship Between Treatment Preference and Treatment Integrity"

The Wing Institute Graduate Research Funding in Evidence-based Education

Submitted: June 14, 2011

\section{ADDRESSES \& PRESENTATIONS (INVITED)}

Bloom, S. E., Samaha, A. L., Kunnavatana, S. S., Lambert, J. M., \& Clay, C. J. Approaches to Functional Behavior Assessment including trial-based FA. Invited training presentation at the Utah Personnel Development Center, December 2011

Bloom, S. E., Samaha, A. L., Kunnavatana, S. S., Lambert, J. M., \& Dayton, E. Teacher-conducted trial-based functional analysis: A two part professional development presentation, Cache County School District, October 2010

\section{CONFERENCE PRESENTATIONS}

Samaha, A. L., Bloom, S. E., Ludeman, K., Kunnavatana, S. S. (2013, September). Evaluation of criteria for interpreting trial-based functional analyses: A signal detection approach. In A. Betz, Chair, Evaluation of Interobserver Agreement and Visual Interpretation of Graphic Data. Symposium presented at the $33^{\text {rd }}$ annual meeting of the Florida Association for Behavior Analysts, Daytona, FL. 
Kunnavatana, S. S., Ludeman, K., Samaha, A. L., \& Bloom, S. E. (2013, May). Evaluation of criteria for interpreting trial-based functional analyses: A signal detection approach. In N. Call, Chair, Recent Innovations for Increasing the Precision and Social Validity of Functional Analysis Methodology. Symposium presented at the $39^{\text {th }}$ annual convention of the Association of Behavior Analysis International, Minneapolis, MN.

Samaha, A. L., Ludeman, K., Bloom, S. E., Kunnavatana, S. S. (2013, March). Evaluation of criteria for interpreting trial-based functional analyses: $A$ signal detection approach. In S. Bloom, Chair, Trial-Based Functional Analysis: Refinements and Extensions. Symposium presented at the 3rd annual convention of the Association of Professional Behavior Analysts, Las Vegas, NV.

Kunnavatana, S. S., Bloom, S. E., Samaha, A. L., \& Dayton, E. (2013, March). Training educators to conduct trial-based functional analyses. In S. Bloom, Chair, TrialBased Functional Analysis: Refinements and Extensions. Symposium presented at the 3rd annual convention of the Association of Professional Behavior Analysts, Las Vegas, NV.

Lambert, J. M., Bloom, S. E., Kunnavatana, S. S., Collins, S. D., \& Clay, C. J. (2012, June). Transitioning to functional analyses: An organization-wide training. In $\mathrm{S}$. Bloom, Chair, Applying Behavior Analysis to Educational and Human Service Settings. Symposium presented at the $3^{\text {rd }}$ annual meeting of the Utah Association for Behavior Analysis and Utah Conference on Effective Practices for Teachers and Human Service Professionals: Interventions Across the Lifespan, Logan, UT.

Lambert, J. M., Bloom, S. E., Dayton, E., Kunnavatana, S. S., \& Samaha, A. L. (2012, June). The effects of noncontingent reinforcement on the persistence/resurgence of behavior: Applications of behavioral momentum theory. In S. Bloom, Chair, Applying Behavior Analysis to Educational and Human Service Settings. Symposium presented at the $3^{\text {rd }}$ annual meeting of the Utah Association for Behavior Analysis and Utah Conference on Effective Practices for Teachers and Human Service Professionals: Interventions Across the Lifespan, Logan, UT.

Bloom, S. E., \& Kunnavatana, S. S. (2012, June). Functional behavior assessment: Ethical approaches. Talk presented at the $3^{\text {rd }}$ annual meeting of the Utah Association for Behavior Analysis and Utah Conference on Effective Practices for Teachers and Human Service Professionals: Interventions Across the Lifespan, Logan, UT.

Bloom, S. E., Kunnavatana, S. S., Samaha, A. L., Clay, C. J. (2012, June). Trial-based FA: What it is and how to do it. Talk presented at the $3^{\text {rd }}$ annual meeting of the Utah Association for Behavior Analysis and Utah Conference on Effective Practices for Teachers and Human Service Professionals: Interventions Across the Lifespan, Logan, UT. 
Kunnavatana, S. S., Bloom, S. E., Samaha, A. L., \& Dayton, E. (2012, May). Training educators to conduct trial-based functional analyses. In M. Kelley, Chair, Improving the Efficiency and Efficacy of Staff and Parent Training of Assessment and Treatment Procedures With Children Diagnosed with Autism and Other Developmental Disabilities. Symposium presented at the $38^{\text {th }}$ annual meeting of the Association for Behavior Analysis International, Seattle, WA.

Lambert, J. M., Bloom, S. E., Kunnavatana, S. S., Collins, S. D., \& Clay, C. J. (2012, May). Transitioning to functional analyses: An organization-wide training. In S. Collins, Chair, Staff Training in Community Residential Settings. Symposium presented at $38^{\text {th }}$ annual meeting of the Association for Behavior Analysis International, Seattle, WA.

Lambert, J. M., Bloom, S. E., Dayton, E., Kunnavatana, S. S., \& Samaha, A. L. (2012, May). The effects of noncontingent reinforcement on the persistence/resurgence of behavior: Applications of behavioral momentum theory. In S. Bloom, Chair, Evaluations of Interventions for Problem Behavior Using Contingent and Noncontingent Reinforcement. Symposium presented at $38^{\text {th }}$ annual meeting of the Association for Behavior Analysis International, Seattle, WA.

Bloom, S. E. \& Kunnavatana, S. S., Samaha, A. L., \& Clay, C. J. (2012, February). Trial-based functional analysis: What it is and how to do it. Workshop presented at $30^{\text {th }}$ Annual Western Regional Conference on Behavior Analysis, Garden Grove, CA.

Lambert, J. M., Bloom, S. E., Dayton, E., Kunnavatana, S. S., \& Samaha, A. L. (2012, February). The effects of noncontingent reinforcement on the persistence/resurgence of behavior: Applications of behavioral momentum theory. In T. Higbee, Chair, The Effects of Antecedent and Consequence Manipulations on Response Variability. Symposium presented at $30^{\text {th }}$ Annual Western Regional Conference on Behavior Analysis, Garden Grove, CA.

Kunnavatana, S. S. (2011, June). Restrictive procedures, punishment, and the right to effective interventions: Clinical implications and ethical considerations. Talk presented at the $2^{\text {nd }}$ annual meeting of the Utah Association for Behavior Analysis and Utah Conference on Effective Practices for Teachers and Human Service Professionals: Interventions Across the Lifespan, Logan, UT.

Kunnavatana, S. S., Bloom, S. E., Samaha, A. L. \& Dayton, E. (2011, June). Training educators to conduct trial-based functional analyses. In S. Bloom, Chair, Current Research on Trial-Based Functional Analysis. Symposium presented at the $2^{\text {nd }}$ annual meeting of the Utah Association for Behavior Analysis and Utah Conference on Effective Practices for Teachers and Human Service Professionals: Interventions Across the Lifespan, Logan, UT. 
Dayton, E., Bloom, S. E., Samaha, A. L., Kunnavatana, S. S., \& Peal, A. M. (2011, June). Latency as the dependent variable in trial-based functional analyses. In S. Bloom, Chair, Current Research on Trial-Based Functional Analysis. Symposium presented at the $2^{\text {nd }}$ annual meeting of the Utah Association for Behavior Analysis and Utah Conference on Effective Practices for Teachers and Human Service Professionals: Interventions Across the Lifespan, Logan, UT.

Dayton, E., Bloom, S. E., Samaha, A. L., Kunnavatana, S. S., \& Peal, A. M. (2011, May). Latency as the dependent variable in trial-based functional analyses. In. A. Samaha, Chair, Factors Influencing Selection of Assessment and Treatment Development and Refinement of Assessment and Treatment Approaches for Individuals with Intellectual and Developmental Disabilities. Symposium presented at 37th annual meeting of the Association for Behavior Analysis International, Denver, CO.

Boyle, M. A., Samaha, A. L., Bloom, S. E., Rodewald, A., Kunnavatana, S. S. \& Dayton, E. (2011, May). Recent publication trends in the assessment and treatment of individuals with autism and other intellectual and developmental disabilities. In. A. Samaha, Chair, Factors Influencing Selection of Assessment and Treatment Development and Refinement of Assessment and Treatment Approaches for Individuals with Intellectual and Developmental Disabilities. Symposium presented at 37th annual meeting of the Association for Behavior Analysis International, Denver, CO.

Kunnavatana, S. S. \& Normand, M. P. (2010, May). A rapid treatment analysis for noncompliance in young children. In A. Karsten, Chair, Assessing and Treating Noncompliance of Young Children. Symposium presented at the $36^{\text {th }}$ annual meeting of the Association of Behavior Analysis International, San Antonio, TX

Kunnavatana, S. S. \& Normand, M. P. (2010, February). A rapid treatment analysis for noncompliance in young children. In S. Bloom, Chair, Approaches to Treatment of Problem Behavior Maintained by Negative Reinforcement. Symposium presented at the $28^{\text {th }}$ annual meeting of the California Association for Behavior Analysis, Irvine, CA.

\section{POSTER PRESENTATIONS}

Kunnavatana, S. S., Bloom, S. E., Samaha, A. L., Harris, S. K., \& Dayton, E. (2012, November). Addressing problem behavior in classrooms: Training educators to conduct trial-based functional analyses. Interactive Paper Session presented at the $35^{\text {th }}$ Annual Teacher Education Division Conference, Grand Rapids, MI.

Kunnavatana, S. S., Bloom, S. E., \& Samaha, A. L. (2012, June). An evaluation of the relationship between treatment preference and treatment integrity. Poster 
presented at the $3^{\text {rd }}$ annual meeting of the Utah Association for Behavior Analysis and Utah Conference on Effective Practices for Teachers and Human Service Professionals: Interventions Across the Lifespan, Logan, UT.

Steiner, C., Kunnavatana, S. S., Jensen, S., Miller, B., \& Quan, P. (2010, April). Measuring change in parent behavior via role-plays: A validation study. Poster presented at the $90^{\text {th }}$ Annual Meeting of the Western Psychological Association, Cancun, Mexico.

Kunnavatana, S. S., Normand, M. P., Larson, T., \& Jensen, S. (2010, February). Assessing the effectiveness of a parent training model though direct measurement of parent behavior change. Poster presented at the $28^{\text {th }}$ annual meeting of the California Association for Behavior Analysis, Irvine, CA.

Kunnavatana, S. S. \& Normand, M. P. (2009, October). A rapid treatment analysis for noncompliance in young children. Poster presented at the $30^{\text {th }}$ annual meeting of the Berkshire Association for Behavior Analysis and Therapy, Amherst, MA.

Kunnavatana, S. S., Normand, M. P., Larson, T., \& Jensen, S. (2009, October). Assessing the effectiveness of a parent-training model through direct measurement of parent behavior change. Poster presented at the $30^{\text {th }}$ annual meeting of the Berkshire Association for Behavior Analysis and Therapy, Amherst, MA.

Hustyi, K. M. \& Kunnavatana, S. S. (2008 March). A comparison of the free-operant and MSWO preference assessments. Poster presented at the $27^{\text {th }}$ annual meeting of the California Association for Behavior Analysis, Burlingame, CA.

\section{TEACHING}

\section{UNIVERSITY COURSES}

Fall 2013/Spring 2014: Guest Lecturer, Psychology Department, Utah State University PSYC 3500-Research Methods

Topic: Introduction to single-subject research design

Spring 2013: Co-Instructor, Department of Special Education and Rehabilitation, Utah State University

SPED 5050-Applied Behavior Analysis 2: Applications

Spring 2012: Teaching Assistant, Department of Special Education and Rehabilitation, Utah State University SPED 5050-Applied Behavior Analysis 2: Applications 
Spring 2011: Guest Lecturer, Department of Special Education and Rehabilitation, Utah State University EDUC 6730-Educational Applications of Behavior Analysis

Topic: Ethics and the use of punishment

Spring 2010: Teaching Assistant, Psychology Department, University of the Pacific PSYC 031 - Introduction to Psychology

Fall 2009: Teaching Assistant, Psychology Department, University of the Pacific PSYC 107/207-Psychology of Learning

Fall 2008: Teaching Assistant, Psychology Department, University of the Pacific PSYC 053-Behavior Change Practicum

\section{SERVICE}

\section{SUPERVISION OF MASTERS STUDENTS SEEKING BCBA CERTIFICATION}

Audrey Hoffmann

Cicely Nickerson

Bistra Bogoev

Rachelle Peterson

Hayley Halverson

\section{PROFESSIONAL SERVICE, OUTSIDE OF THE UNIVERSITY}

Research and Clinical Director, Severe Behavior Clinic, Utah State University (August, 2013-present)

Human Rights Committee Member, North Eastern Services, Logan, UT (August, 2013present)

BCBA Certification supervision for individuals not associated with Utah State University to facilitate the development of behavioral services throughout the state of Utah (August, 2013-present)

Student Representative, Utah Association of Behavior Analysis (2011-2013)

\section{PROFESSIONAL SERVICE, WITHIN THE UNIVERSITY}

Graduate Student Representative, Psychology Department, University of the Pacific (2008-2009)

\section{CLINICAL EXPERIENCE}

Graduate Research Assistant (2010-present)

Severe Behavior Clinic, Utah State University, Logan, UT

Supervisors: Dr. Sarah E. Bloom, BCBA-D and Dr. Andrew Samaha, BCBA-D 
Autism Educator/Consultant (2009-2010)

Square One, Sacramento, CA

Supervisors: Cynthia Long, M.A., BCBA, Any Jacobs-Schroeder, B.A., BCABA, and Laurie McKinnie, M.A.

Behavioral Intern: Stockton Unified School District (2007-2010)

Behavioral Intern: Aspire Public Schools (2008-2009)

University of the Pacific, Stockton, CA

Supervisors: Holly White, M.A., BCBA and Dr. Matthew Normand, BCBA-D

Program Coordinator: Martin Gipson Socialization Center (2007-2009)

Community Re-Entry Program, University of the Pacific, Stockton, CA

Supervisor: Todd Fabian, M.A., BCBA

Behavioral Supervisor (2005-2007)

Behavioral Consultant (2004-2005)

Autism Tutor/Instructional Aide (2001-2004)

Advance Kids, Sacramento, CA

Supervisor: Michelle Wenell, M.A., BC 